UCRL-ID-113521

\title{
Interim Report on Verification and Benchmark Testing of the NUFT Computer Code
}

\author{
October 1993
}

Kenrick H. Lee Adarsh Kulshrestha*

John J. Nitao

*Weiss Associates, Inc., Emeryville, California

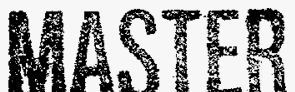




\begin{abstract}
This interim report presents results of work completed in the ongoing verification and benchmark testing of the NUFT (Nonisothermal Unsaturated-saturated Flow and Transport) computer code. NUFT is a suite of multiphase, multicomponent models for numerical solution of thermal and isothermal flow and transport in porous media, with application to subsurface contaminant transport problems. The code simulates the coupled transport of heat, fluids, and chemical components, including volatile organic compounds. Grid systems may be cartesian or cylindrical, with one-, two-, or fully three-dimensional configurations possible. In this initial phase of testing, the NUFT code was used to solve seven one-dimensional unsaturated flow and heat transfer problems. Three verification and four benchmarking problems were solved. In the verification testing, excellent agreement was observed between NUFT results and the analytical or quasianalytical solutions. In the benchmark testing, results of code intercomparison were very satisfactory. From these testing results, it is concluded that the NUFT code is ready for application to field and laboratory problems similar to those addressed here. Multidimensional problems, including those dealing with chemical transport, will be addressed in a subsequent report.
\end{abstract}




\section{DISCLAIMER}

This report was prepared as an account of work sponsored by an agency of the United States Government. Neither the United States Government nor any agency thereof, nor any of their employees, make any warranty, express or implied, or assumes any legal liability or responsibility for the accuracy, completeness, or usefulness of any information, apparatus, product, or process disclosed, or represents that its use would not infringe privately owned rights. Reference herein to any specific commercial product, process, or service by trade name, trademark, manufacturer, or otherwise does not necessarily constitute or imply its endorsement, recommendation, or favoring by the United States Government or any agency thereof. The views and opinions of authors expressed herein do not necessarily state or reflect those of the United States Government or any agency thereof. 


\section{DISCLAIMER}

Portions of this document may be illegible in electronic image products. Images are produced from the best available original document. 


\section{Contents}

1. Introduction 1

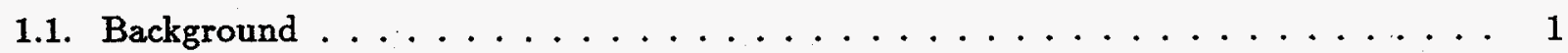

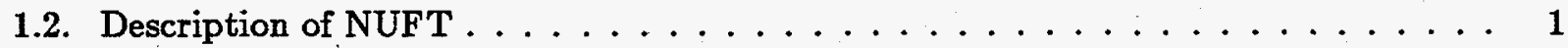

1.3. Verification and Benchmark Testing . . . . . . . . . . . . . . 2

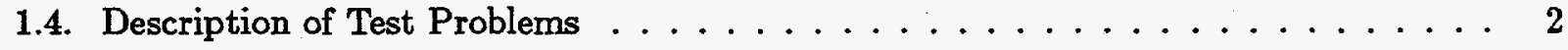

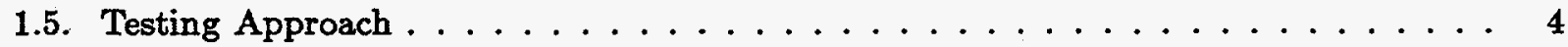

2. Isothermal Test Cases $\quad 4$

2.1. VI-1. Philip's Solution for a Vertical Column . . . . . . . . . . . . . . 4

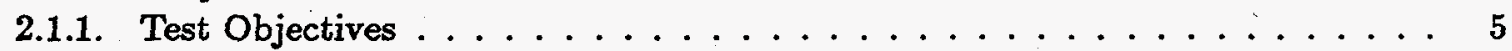

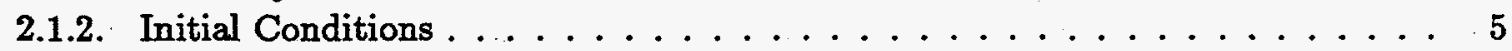

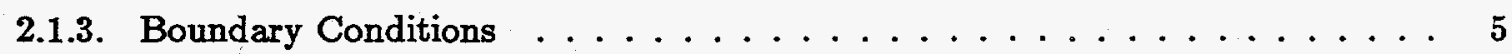

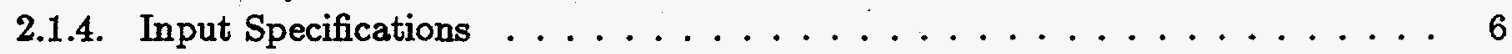

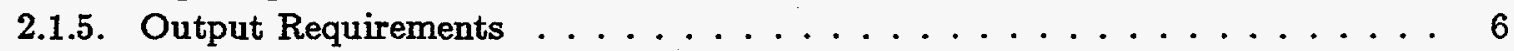

2.1.6. Results ............................. 7

2.2. BI-1. Vertical Flow in a Laboratory Soil Column with Ponding . . . . . . . . . 7

2.2.1. Problem Definition . . . . . . . . . . . . . . . . 7

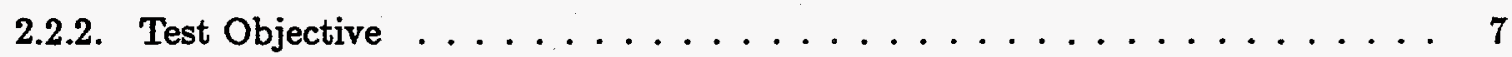

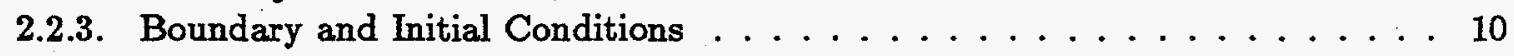

2.2.4. Input Specifications . . . . . . . . . . . . . . . . 10

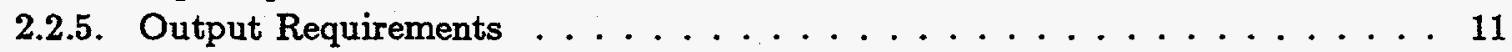

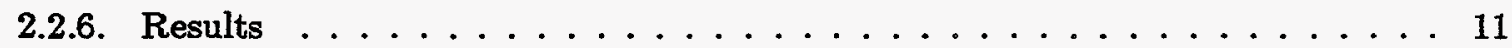

2.3. BI-2. Infiltration in a Stratified Vadose Zone . . . . . . . . . . . . . 11

2.3.1. Problem Definition . . . . . . . . . . . . . . . . . 11

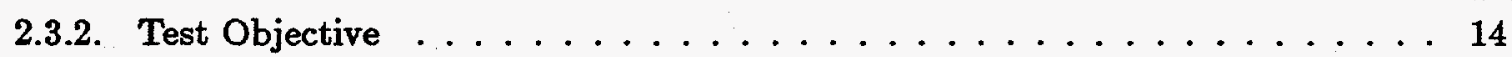

2.3.3. Input Specifications . . . . . . . . . . . . . . . . 14

2.3.4. Output Requirements ..................... 15

2.3.5. Results ........................... 15

2.4. BI-3. Partially Saturated Flow in Basalt . . . . . . . . . . . . 15

2.4.1. Problem Definition . . . . . . . . . . . . . . . . 15

2.4.2. Test Objectives . . . . . . . . . . . . . . . . 17

2.4.3. Initial Conditions . . . . . . . . . . . . . . . 17

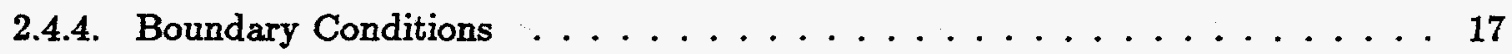

2.4.5. Input Specifications . . . . . . . . . . . . . . 17

2.4.6. Output Requirements . . . . . . . . . . . . . . . . 19

2.4.7. Results ......................... 19 
3. Nonisothermal Test Cases 22

3.1. VT-1. Heat Conduction with Sinusoidal Boundary Condition . . . . . . . . . 22

3.1.1. Problem Definition . . . . . . . . . . . . . . . . 22

3.1.2. Governing Equations . . . . . . . . . . . . . . . . . . 22

3.1.3. Test Objectives ......................... . . 24

3.1.4. Boundary and Initial Conditions . . . . . . . . . . . . . . 24

3.1.5. Analytical Solution . . . . . . . . . . . . . . . . . 24

3.1.6. Input Specifications . . . . . . . . . . . . . . . 24

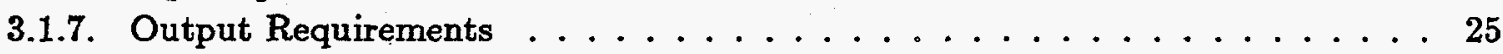

3.1.8. Results . . . . . . . . . . . . . . . . . . 25

3.2. VT-2. Heat Conduction with Constant Heat Flux . . . . . . . . . . 27

3.2.1. Problem Definition . . . . . . . . . . . . . . . . . 27

3.2.2. Governing Equations . . . . . . . . . . . . . . . . . 27

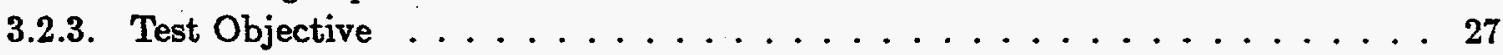

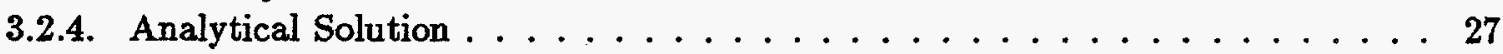

3.2.5. Input Specifications . . . . . . . . . . . . . . . 28

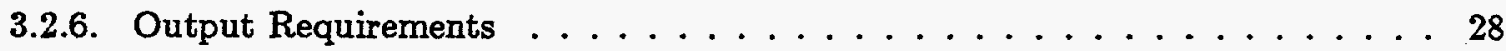

3.2.7. Results .......................... 28

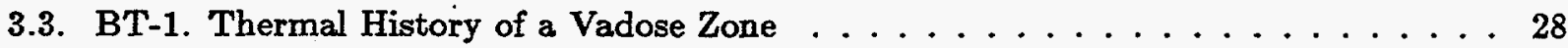

3.3.1. Problem Definition . . . . . . . . . . . . . . . . 28

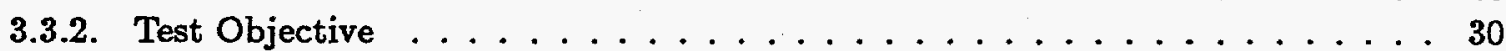

3.3.3. Initial Conditions . . . . . . . . . . . . . . . 30

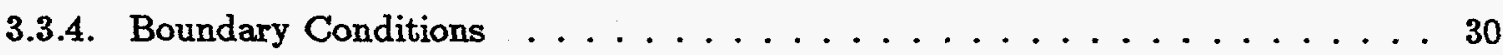

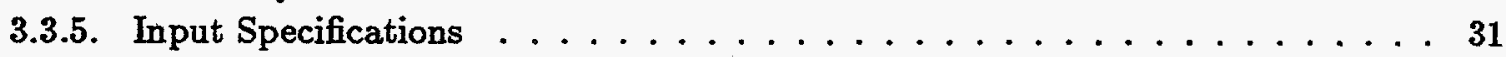

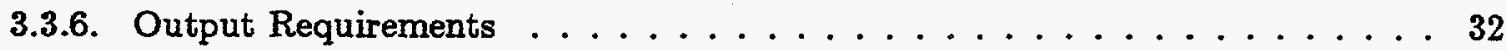

3.3.7. Results ....................... 32

4. Conclusions $\quad 32$

5. References $\quad 34$

6. Acknowledgments $\quad 35$

Appendix A: Input Data Files $\quad 36$

1.1. Problem VI-1: Philip's Solution for a Vertical Column. . . . . . . . . . . . 36

1.2. Problem BI-1: Vertical Flow in a Laboratory Soil Column with Ponding. . . . . . . . 38

1.3. Problem BI-2: Infiltration in a Stratified Vadose Zone. . . . . . . . . . . . . . 41

1.4. Problem BI-2: Infiltration in a Stratified Vadose Zone, Run 2. . . . . . . . . . . 46

1.5. Problem BI-3: Partially Saturated Flow in Basalt. . . . . . . . . . . . . . . 49

1.6. Problem VT-1: Heat Conduction with Sinusoidal Boundary Condition. . . . . . . 55

1.7. Problem VT-1: Heat Conduction with Sinusoidal Boundary Condition, Run 2. . . . 60

1.8. Problem VT-2: Heat Conduction with Constant Heat Flux. . . . . . . . . . . 65

1.9. Problem BT-1: Thermal History of a Vadose Zone . . . . . . . . . . . . . . 70 


\section{List of Figures}

1. Comparison of moisture content profiles from NUFT and INFIL after $2 \mathrm{hr}$, for test case VI-1. . . . . . . . . . . . . . . . . . .

2. Comparison of moisture content profiles from NUFT and INFIL after $4 \mathrm{hr}$, for test case VI-1. . . . . . . . . . . . . . . . . . . . . 8

3. Schematic of laboratory soil column with $0.75 \mathrm{~cm}$ of ponded water. . . . . . . 10

4. Problem BI-1: Comparison of moisture content profiles at 15, 30, and 90 min with ponding height of $0.75 \mathrm{~cm} \ldots \ldots \ldots \ldots \ldots \ldots \ldots$

5. Cross section through stratified vadose zone (Baca and Magnuson, 1990). . . . . . 13

6. Problem BI-2: Comparison of moisture content profiles from NUFT and UNSAT-H,

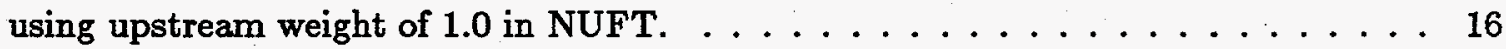

7. Cross section through layered basalt (Baca and Magnuson, 1990). . . . . . . . 18

8. Problem BI-3: Initial steady-state moisture content profiles from NUFT and UNSAT-

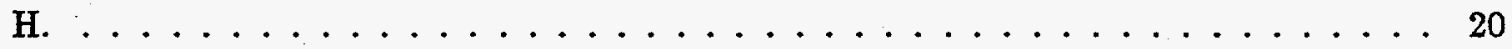

9. Problem BI-3: Moisture content profiles from NUFT and UNSAT-H immediately after flooding (time $=5$ days) $\ldots \ldots \ldots \ldots \ldots \ldots \ldots \ldots$

10. Problem BI-3: Moisture content profiles from NUFT and UNSAT-H 105 days after

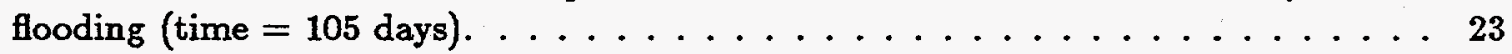

11. Heat conduction with sinusoidal boundary condition (VT-1): comparison of temperature profiles from NUFT and the analytical solution. . . . . . . . . . . 26

12. Problem VT-2: Comparison of temperature profiles from NUFT and analytical solution. . . . . . . . . . . . . . . . . . . . . 29

13. Simplified cross section for RWMC vadose zone (Baca and Magnuson, 1990). . . . 31

14. Problem BT-1: Comparison of temperature histories from NUFT and UNSAT-H. . . 33

\section{List of Tables}

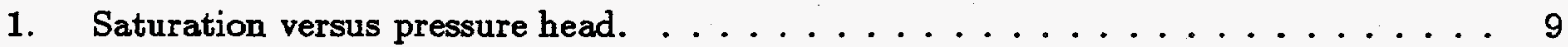

2. Relative hydraulic conductivity function. . . . . . . . . . . . . . 9

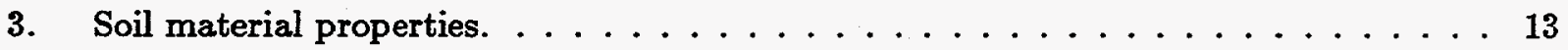

4. Soil parameter values for $S_{w}(\psi)$ and $K_{r w}(\psi) \ldots \ldots \ldots \ldots \ldots \ldots$

5. Material properties and van Genuchten parameters. . . . . . . . . . . . . 19

6. Thermal properties of soil and rock materials. . . . . . . . . . . . . . 32 


\section{Introduction}

This interim report presents results of work completed in the ongoing verification and benchmark testing of the NUFT (Nonisothermal Unsaturated-saturated Flow and Transport) computer code. NUFT (Nitao, 1993a) is a multiphase, multicomponent model for numerical solution of isothermal and thermal flow and transport through porous media. The code was developed primarily for application to the Livermore Site at Lawrence Livermore National Laboratory (LLNL), where the soil and ground water are contaminated with volatile organic compounds (VOCs), tritiated water, petroleum hydrocarbons, and, possibly, heavy metals. The primary goal of this verification and benchmarking effort is to determine code readiness for application to field and laboratory flow and transport problems. A secondary goal is to present NUFT code users with a number of solved example problems of varying levels of complexity.

In this initial phase of testing, seven one-dimensional fluid flow and thermal energy transport problems are solved. Multidimensional problems, including those dealing with chemical transport, will be addressed in a subsequent report. The basis, approach, and results for the initial code testing phase are described in this report.

\subsection{Background}

LLNL is a research and development facility owned by the U.S. Department of Energy (DOE) and operated by the University of California. LLNL was added to the Superfund National Priorities List (NPL) in 1987 on the basis of high VOC concentrations discovered in the ground water. Site characterization and general remediation strategies are described by Thorpe et al., (1990).

Recognizing the potential for contaminated areas in the vadose zone to act as a continued source of contaminants to the ground water, LLNL initiated a vadose zone investigation program (VZIP) in 1991 (Iovenitti et al., 1992). The principal objectives of the program are to identify potential source areas in the vadose zone, prioritize these areas, and select and design the most effective remediation schemes. The VZIP is a fully integrated evaluation system comprised of numerical and analytical modeling, field studies, and laboratory measurements. As part of the modeling effort, conceptual and mathematical models of multiphase flow and contaminant transport in the vadose zone were formulated by Bear and Nitao (1993). NUFT is the numerical model developed to perform vadose zone flow and transport simulations in support of the VZIP.

\subsection{Description of NUFT}

The NUFT code is actually a suite of multiphase, multicomponent models for numerical solution of nonisothermal flow and transport in porous media, with application to subsurface contaminant transport problems (Nitao, 1993a). The code simulates the coupled transport of heat, fluids, and chemical components, including VOCs. A two-phase, two-component, isothermal module with a passive gas phase solves problems with variable water saturation and with a single contaminant dissolved in the water and adsorbed onto the solid surfaces (Nitao, 1993b). A second module solves multicomponent, multiphase, isothermal, and nonisothermal problems (Nitao, 1993c). Grid 
systems may be cartesian or cylindrical, with one-, two-, or fully three-dimensional configurations possible.

The code simulates flow of three fluid phases, where all three phases may be mobile. There are two liquid phases: (1) an aqueous phase, which is predominantly the component water but may contain other dissolved components; and (2) a nonaqueous phase liquid (NAPL), which is usually made up of hydrocarbon or organic components, some of which may be volatile. The third phase is the gas phase containing dry air (treated as a pseudocomponent), water vapor, and vapors of VOCs. Each phase may contain a variable number of components, with component phase changes and partitioning between the phases permitted. For strongly nonisothermal applications, such as steam injection, the gas phase may contain high mass fractions of steam.

It is assumed that solid surfaces are always coated by at least a thin film of water, so that the solid phase interfaces only with the aqueous phase and, therefore, only solid-aqueous phase adsorption of components is possible. Adsorption may follow a linear or nonlinear isotherm.

\subsection{Verification and Benchmark Testing}

The primary objective of this verification and benchmarking exercise is to examine the readiness of NUFT for general application to field and laboratory problems. It is essential that a numerical code be adequately tested before it can be considered as an effective predictive tool.

The term "verification" is used here to imply checking of the governing equations of the mathematical model to ensure that they have been properly programmed, and that the numerical solution algorithm works as intended. Code verification was performed by making direct comparisons between NUFT simulation results and known analytical or semianalytical solutions of appropriate problems. Analytical and semianalytical solutions are available for only a limited range of problems of interest, often with highly simplifying assumptions. Therefore, verification does not necessarily imply a fully debugged code, but does suggest that the code's main program and its frequently used subroutines are functioning adequately.

In order to test the code's performance on real or hypothetical field and laboratory problems for which analytical solutions are not available, results from the tested code are directly compared with results of well-established codes that have been previously tested. Benchmarking is used here to imply this kind of code-to-code comparison using test problems that are more realistic and of practical interest. If the simulation results in such a code intercomparison do not deviate significantly from each other, a relative or comparative validity is established (van der Heijde et al., 1988). Through benchmarking, the credibility of a well-established code can be transferred to another code. The codes used for intercomparison with NUFT are well established and have been independently tested.

\subsection{Description of Test Problems}

The test problems selected here were obtained from a report on the verification and benchmark testing of the UNSAT-H computer code (Baca and Magnuson, 1990). Because UNSAT-H is a one-dimensional unsaturated flow and heat transport code, these initial test problems are all onedimensional single-phase water flow and heat transport problems. 
Two of the test problems solved by UNSAT-H were omitted from this first phase of testing. The first problem was Philip's solution for horizontal water flow in an unsaturated soil column. This problem is not included because the code features that would be tested are also tested in some of the other problems solved. The second test problem omitted dealt with coupled heat and fluid flow in a field test plot. While this problem was solved by UNSAT-H considering only single-phase flow, it is really a two-phase flow problem. There is significant vaporization and recondensation of water as the temperature fluctuates, resulting in some water transport in the gas phase. Since this gas phase water transport is handled by NUFT and not by UNSAT-H, it is inappropriate to compare the solutions from the two codes. In a later series of tests, NUFT will be benchmarked against multiphase, nonisothermal codes using problems involving coupled fluid flow and heat transport.

The test problems are classified as isothermal and thermal. The seven problems solved comprise four isothermal and three thermal problems. A brief description of each of them follows.

1. VI-1. Philip's Solution for a Vertical Column. This first isothermal test case is a verification problem addressing vertical unsaturated flow in a laboratory soil column. It requires simulation of the rapid movement of a wetting front driven by gravity and capillary forces. The quasianalytical solution (Philip, 1957) was obtained using the INFIL computer code (El-Kadi, 1987). This test is a direct check of the computational accuracy of the code in the solution of Richards equation.

2. BI-1. Vertical Flow in a Laboratory Soil Column with Ponding. This is a benchmark problem addressing vertical flow in a relatively dry laboratory soil column under ponded conditions. The problem is similar to VI-1, except a constant ponding height is maintained at the upper boundary. This problem tests the capability of the code to handle strong nonlinearities and high pressure gradients. The NUFT simulation results are compared with the results from three other codes: UNSAT-H, FLASH, and TOUGH.

3. BI-2. Infiltration in a Stratified Vadose Zone. This benchmark problem addresses infiltration in a thick, relatively dry, multilayered vadose zone located in a semiarid environment, and was originally solved by Huyakorn et al. (1984). The simulation deals with moisture movement through dessicated soils of highly variable hydrologic properties. It is assumed that the system is initially at steady state, receiving recharge at a constant rate. The recharge rate is then drastically reduced, and the response of the system, as it adjusts to the new recharge rate and eventually approaches a new steady-state, is simulated. This type of problem is usually difficult to solve numerically, and provides a good test of the code's numerical solution technique. NUFT is benchmarked against UNSAT-H.

4. BI-3. Partially Saturated Flow in Basalt. This problem requires simulation of unsaturated flow through a layered field site. The site considered is the vadose zone beneath the Radioactive Waste Management Complex of the Idaho National Engineering Laboratory (INEL). The geology consists of surficial sediments underlain by flows of vesicular and massive basalt (Baca and Magnuson, 1990). This test case will evaluate the code's performance in simulating flow at an actual field site using data obtained from laboratory and field measurements. NUFT is benchmarked against UNSAT- $\mathrm{H}$.

5. VT-1. Heat Conduction with Sinusoidal Boundary Conditions. This nonisothermal problem presents a direct test of the code's ability to solve the energy equation for purely conductive heat transfer with a time-varying temperature boundary condition. The system is a homogeneous soil 
column at a uniform initial temperature and a sinusoidal boundary temperature. Fluid flow is turned off to prevent convective heat transfer. The problem simulates the temperature distribution actually observed in soil, including diurnal temperature fluctuations. Simulation results from NUFT are compared with the closed form analytical solution.

6. VT-2. Heat Conduction with Constant Heat Flux. This problem tests the code's ability to solve the energy equation for purely conductive heat transfer with a constant heat flux boundary condition. As with VT-1, the system is a homogeneous soil column at a uniform initial temperature, with fluid flow turned off to prevent convection. NUFT results are compared with the closed form analytical solution.

7. BT-1. Thermal History of a Vadose Zone. This verification problem is based on field studies of soil temperatures at INEL (Baca and Magnuson, 1990). The objective is to simulate the soil temperature history. The geology consists of surficial sediments and basalts. The system is simplified to two soil layers, each with homogeneous thermal properties. The surface boundary condition reflects seasonal temperature changes. The simulation results from NUFT are compared to results from UNSAT-H.

\subsection{Testing Approach}

To meet the objectives of this code testing effort, it must be verified that the NUFT code accurately represents the mathematical framework of the vadose zone flow and transport model, as described by Bear and Nitao (1993). This is done by verification and benchmark testing, which serve to check the accuracy of the computational algorithm for solving the governing equations, and to ensure that the computer code is fully operational. However, no widely accepted quantitative measures of code performance are currently available for application in code evaluation. Quantitative measures of goodness-of-fit, such as maximum deviation, average deviation, and spreading in deviation, do not adequately describe the performance of the code.

It was therefore decided to base this test evaluation on visual inspection of graphical representation of the test variables. Instead of presenting just a few fit parameters, this approach will present more details of the code's ability to follow complex graphs, clearly showing areas of agreement and areas of significant offset.

\section{Isothermal Test Cases}

\subsection{VI-1. Philip's Solution for a Vertical Column}

In this test problem, we simulate one-dimensional transient fluid flow in a homogeneous soil column of uniform initial saturation. Transient fluid flow occurs in response to gravity and capillary forces due to a full saturation boundary condition imposed at the top end of the column.

Vertical movement of moisture, from the top end into the soil column, is represented by the nonlinear, parabolic Richards equation:

$$
C(\psi) \frac{\partial \psi}{\partial t}=\frac{\partial}{\partial z}\left[K(\psi)\left(\frac{\partial \psi}{\partial z}-1\right)\right]
$$


where $\psi$ is the pressure head (negative in unsaturated soils), $t$ is the time variable, $z$ is the depth from the top end of the column, and $K(\psi)$ is the unsaturated hydraulic conductivity. $C(\psi)$, the specific moisture capacity, relates the volumetric water content $(\theta)$ to the pressure head $(\psi)$ :

$$
C(\psi)=\frac{\partial \theta}{\partial \psi}
$$

Philip (1957) presented a quasianalytical series solution to the one-dimensional form of Richards equation. El-Kadi (1987) developed INFIL, a computer code that solves Richards equation, based on Philip's solution. We compare NUFT results against output generated by INFIL.

\subsubsection{Test Objectives}

In this test problem, we use NUFT module us $1 p$ to simulate transient moisture flow as presented by Richards equation. The objective is to compare the NUFT solution to the quasianalytical solution under the following conditions:

- The soil column is vertically oriented.

- Initially, the soil column has uniform moisture content.

- The top end of the soil column is held at full saturation.

- The soil column is at constant, uniform temperature.

\subsubsection{Initial Conditions}

Initial conditions for the flow model are specified in data unit state of the NUFT input file (Appendix A1.1). The soil column has a uniform pressure head of $601.8 \mathrm{~cm}$; which corresponds to a liquid saturation (Sl) of 0.4808 . For partially saturated elements, the pressure head is set to zero. However, the code uses the moisture characteristics curve to compute an initial pressure head corresponding to the initial saturation.

\subsubsection{Boundary Conditions}

Boundary conditions are specified in data unit bctab of the NUFT input file. The total simulation time is $4 \mathrm{hr}$. The topmost element (S \# 1:1:1) of the vertical soil column is held at $100 \%$ saturation $(\mathrm{SI}=1.0)$ and zero pressure head. (NOTE: For a partially saturated element, the pressure head is computed from the saturation, and can be set to zero in the input file.) This saturation boundary condition results in differential capillary forces across the column. Water flow is driven by a combination of capillary and gravity forces. 


\subsubsection{Input Specifications}

Mesh generation parameters are specified in data unit genmsh of the NUFT input file (Appendix A1.1). The soil column is $15 \mathrm{~cm}$ long, which for modeling purposes is discretized using a grid spacing of $0.075 \mathrm{~cm}$. The topmost grid block is subdivided into two blocks of thickness $0.01 \mathrm{~cm}$ (node 1) and $0.065 \mathrm{~cm}$ (node 2). The total number of nodes is 201 .

Soil hydraulic properties are specified in data unit rocktab. The soil is Yolo Light Clay. We use the following Haverkamp (1977) functions for the moisture retention and unsaturated hydraulic conductivity curves:

$$
\begin{array}{rlrl}
\theta(\psi) & =\frac{\alpha\left(\theta_{s}-\theta_{r}\right)}{\alpha+\left(\ln \left|\frac{\psi}{\psi_{0}}\right|\right)^{\beta}}+\theta_{r} & & \text { if }|\psi| \geq \psi_{0} \\
\theta & =\theta_{s} & \text { if }|\psi|<\psi_{0}
\end{array}
$$

and:

$$
K(\psi)=K_{3} \frac{A}{\left(A+\left|\frac{\psi}{\psi_{0}}\right|^{B}\right)}
$$

where

$\theta_{s}=$ Saturated volumetric moisture content $(=0.495)$,

$\theta_{r}=$ Residual volumetric moisture content $(=0.124)$, and

$K_{s}=$ Saturated hydraulic conductivity $(=1.24 \mathrm{E}-07 \mathrm{~m} / \mathrm{s})$.

$\psi_{0}=$ Pressure head unit conversion factor $(=0.01 \mathrm{~m} / \mathrm{cm})$.

The pressure head unit conversion factor, $\psi_{0}$, is added to the original Haverkamp functions so that different pressure head units can be used, while retaining the characteristic curve parameters derived for pressure heads expressed in $\mathrm{cm}$.

A saturated volumetric moisture content $\left(\theta_{s}\right)$ of 0.495 corresponds to a maximum saturation Smax of 1.0 in NUFT input. Likewise, $\theta_{r}$ of 0.124 corresponds to a residual saturation $\operatorname{Sr}\left(=\theta_{r} / \theta_{s}\right)$ of 0.2505. $\alpha, \beta, A$, and $B$ are Haverkamp characteristic curve parameters for Yolo Light Clay, and have the following values:

$\alpha=739.0$

$\beta=4.0$

$A=124.6$

$B=1.77$.

\subsubsection{Output Requirements}

Output requirements are specified in data unit output. To estimate the transient flow of moisture, we obtain moisture content profiles at $t=2 \mathrm{hr}$ and $4 \mathrm{hr}$. The simulation results are graphically compared to the quasianalytical solution from INFIL. 


\subsubsection{Results}

Figures 1 and 2 present graphical comparisons of moisture content profiles predicted by NUFT and INFIL, after $2 \mathrm{hr}$ and $4 \mathrm{hr}$, respectively.

The two codes (NUFT and INFIL) compare well in predicting the movement of the wetting front, but NUFT predicts a slightly higher moisture content compared to INFIL. After $2 \mathrm{hr}$ (Fig. 1), the total depth of penetration of the wetting front is $7.6 \mathrm{~cm}$. NUFT predicts a slightly higher moisture content for the top $4 \mathrm{~cm}$. The results are in excellent agreement between the depths of $4 \mathrm{~cm}$ and $5.8 \mathrm{~cm}$. For depths greater than $5.8 \mathrm{~cm}$ (and less than $7.6 \mathrm{~cm}$ ), NUFT again predicts a higher moisture content than INFIL, but the difference is even smaller than for the top $4 \mathrm{~cm}$. After $4 \mathrm{hr}$ (Fig. 2), the total depth of penetration of the wetting front is $10.8 \mathrm{~cm}$. NUFT predicts a slightly higher moisture content along the wetting front.

The difference in NUFT and INFIL predictions may result from truncation errors in the finitedifference solution, or from approximations in the quasianalytical solution as implemented in the INFIL code. The UNSAT-H code results display similar differences when compared to INFIL, as seen in Figure 6 of Baca and Magnuson (1990). UNSAT-H predicts higher moisture contents than INFIL, for the depths and times discussed above.

\subsection{BI-1. Vertical Flow in a Laboratory Soil Column with Ponding}

\subsubsection{Problem Definition}

This isothermal problem considers the vertical flow of water into a relatively dry soil column under ponded conditions. The data are obtained from laboratory experiments presented by Skaggs et al. (1970). The focus of their work was to determine the unsaturated hydraulic conductivity function of unsaturated soils. This test case was also solved by Davis and Neuman (1983) using the UNSAT2 code.

A schematic representation of the soil column is shown in Figure 3. The depth of the column is $50 \mathrm{~cm}$ and the height of ponded water, $0.75 \mathrm{~cm}$. The soil is a dry sand mix material with an initial water content of 0.045 . The sand is assumed to be homogeneous and isotropic with a saturated hydraulic conductivity of $7.22 \times 10^{-6} \mathrm{~m} / \mathrm{s}$. The soil moisture retention and relative hydraulic conductivity functions, obtained from Davis and Neuman (1983), are shown in Tables 1 and 2 , respectively.

\subsubsection{Test Objective}

The objective of this test case was to test the ability of the NUFT code to solve the variably saturated flow equations for one-dimensional vertical flow under ponded conditions. Ponding above a fairly dry soil causes development of a sharp wetting front, which propagates down the column. The problem tests the ability of NUFT to track the movement of such a wetting front. The results from NUFT are compared to published results from the following three codes: UNSAT-H and FLASH (Baca and Magnuson, 1990), and TOUGH (Pruess, 1987). 


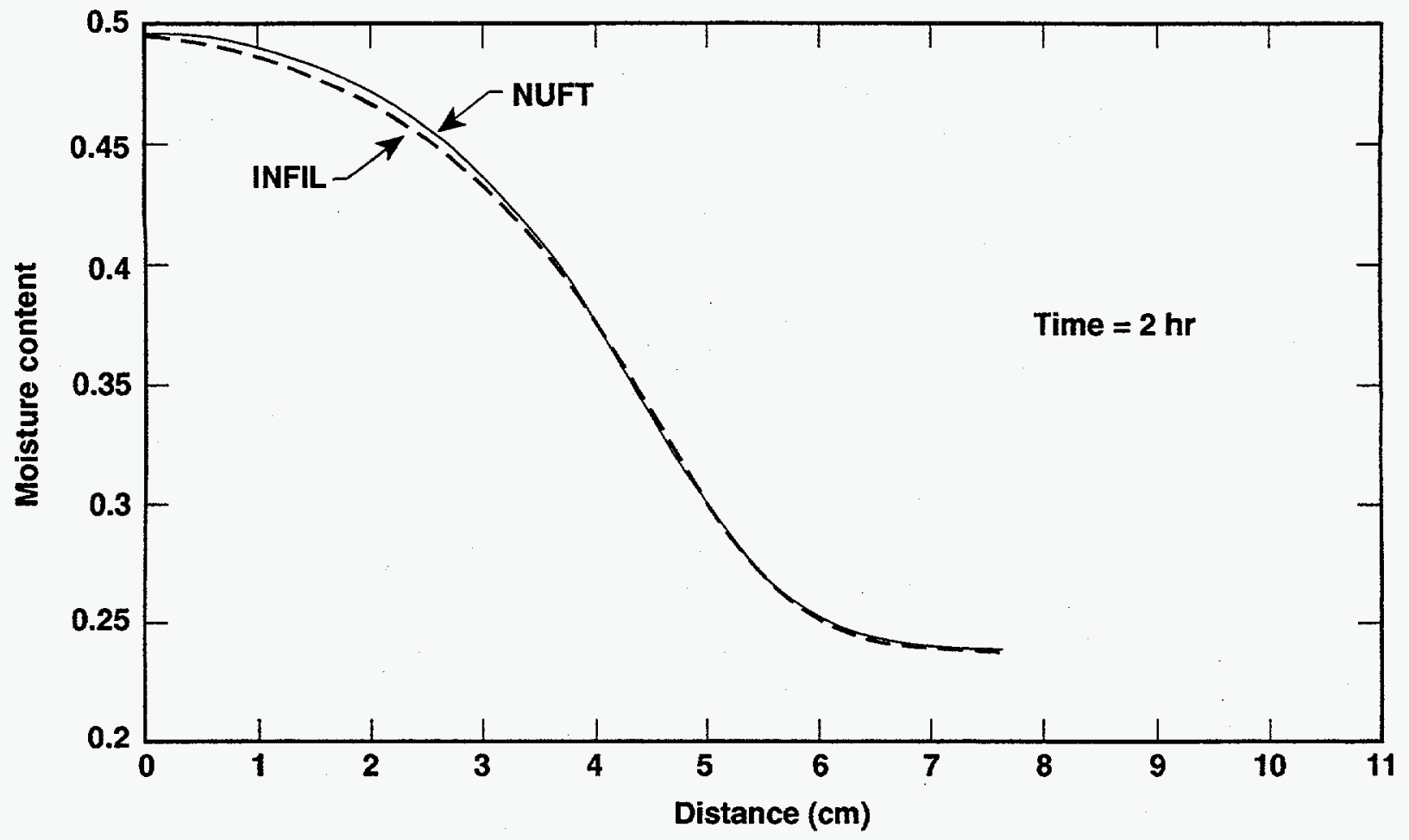

Figure 1. Comparison of moisture content profiles from NUFT and INFIL, after 2 hr, for test case VI-1.

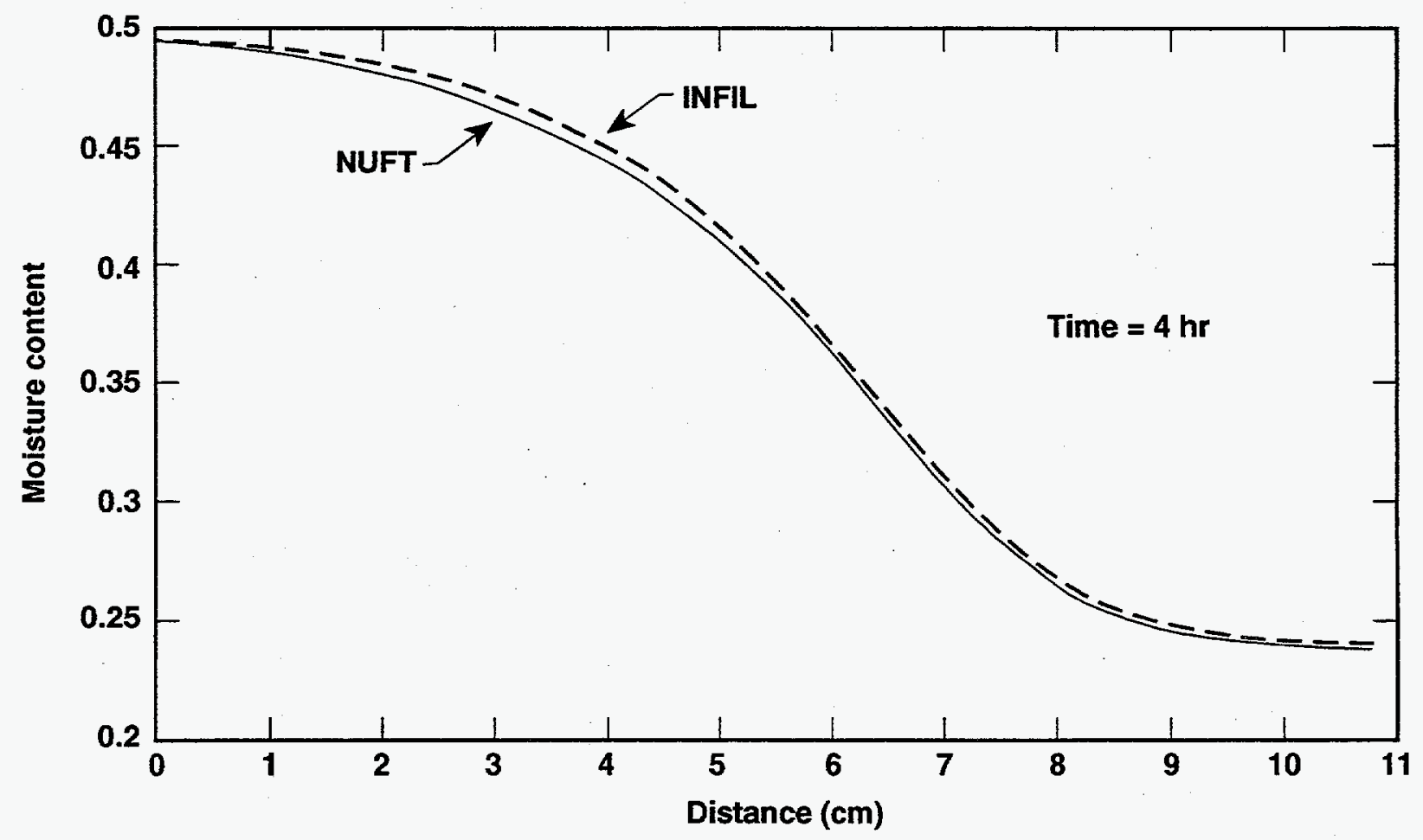

ERD-LSR-93-0086

Figure 2. Comparison of moisture content profiles from NUFT and INFIL, after 4 hr, for test case VI-1. 
Table 1. Saturation versus pressure head.

\begin{tabular}{cc}
\hline \hline $\begin{array}{c}\text { Saturation } \\
\mathrm{S}\left(\mathrm{m}^{3} / \mathrm{m}^{3}\right)\end{array}$ & $\begin{array}{c}\text { Negative pressure } \\
\text { head } \psi(\mathrm{m})\end{array}$ \\
\hline 0.080 & 2.00 \\
0.177 & 1.00 \\
0.243 & 0.80 \\
0.331 & 0.60 \\
0.509 & 0.40 \\
0.757 & 0.20 \\
0.874 & 0.10 \\
1.000 & 0.00 \\
\hline
\end{tabular}

Table 2. Relative hydraulic conductivity function.

\begin{tabular}{cc}
\hline \hline $\begin{array}{c}\text { Saturation } \\
\mathrm{S}\left(\mathrm{m}^{3} / \mathrm{m}^{3}\right)\end{array}$ & $\begin{array}{c}\text { Relative hydraulic } \\
\text { conductivity } K(\psi) / K_{s}\end{array}$ \\
\hline 0.080 & $1.00 \times 10^{-6}$ \\
0.177 & $1.00 \times 10^{-4}$ \\
0.286 & $1.00 \times 10^{-3}$ \\
0.429 & $1.00 \times 10^{-2}$ \\
0.500 & $3.00 \times 10^{-2}$ \\
0.571 & $8.20 \times 10^{-2}$ \\
0.643 & $2.25 \times 10^{-1}$ \\
0.714 & $5.50 \times 10^{-1}$ \\
0.786 & $8.86 \times 10^{-1}$ \\
0.821 & $9.63 \times 10^{-1}$ \\
0.857 & $9.92 \times 10^{-1}$ \\
0.874 & $9.97 \times 10^{-1}$ \\
1.000 & 1.00 \\
\hline \hline
\end{tabular}




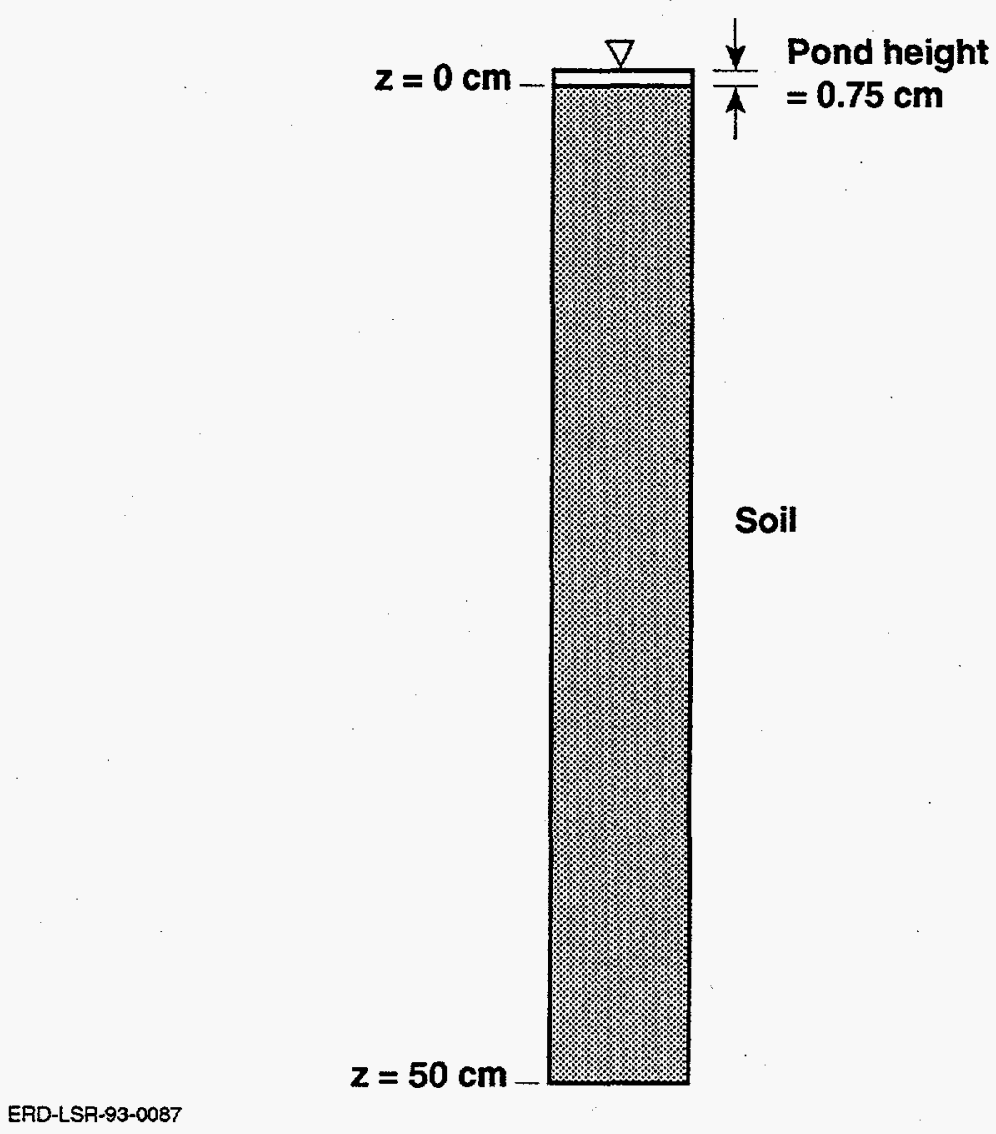

Figure 3. Schematic of laboratory soil column with $0.75 \mathrm{~cm}$ of ponded water.

\subsubsection{Boundary and Initial Conditions}

The upper boundary condition is a pressure head of $0.75 \mathrm{~cm}$ and full saturation. The lower boundary pressure is fixed at zero, permitting free drainage. The initial saturation is 0.129 throughout the column. This initial saturation corresponds to a water content of 0.045 .

\subsubsection{Input Specifications}

The problem is run using the us1p module of NUFT. The input file is shown in Appendix A1.2. A vertical, one-dimensional rectangular mesh is used. The column is discretized into 123 blocks, each $0.5 \mathrm{~cm}$ long, with the exception of the upper boundary block which is $1.0 \times 10^{-6} \mathrm{~cm}$ long. The $\mathrm{x}-\mathrm{y}$ dimensions of the blocks are arbitrarily selected at 0.75 by $0.75 \mathrm{~cm}$. Relevant hydrologic properties of the soil are input in the rocktab data unit of the input file. The soil-water characteristics (Table 1) and relative hydraulic conductivity function (Table 2) are input in tabular form here.

Boundary conditions are set in the bctab data unit. For the ponded upper boundary condition, the surface node is set at full saturation and at a pressure head of $7.5 \times 10^{-3} \mathrm{~m}$ to represent the depth of ponded water at the soil surface. The lower boundary saturation is set at the initial value of 0.129 to allow free drainage. The initial saturation is 0.129 for all nodes, with the exception of the surface node, which is at full saturation.

The simulation time is $90 \mathrm{~min}$. 


\subsubsection{Output Requirements}

Water content profiles from NUFT are computed for comparison with profiles from the benchmark codes. The profiles are compared at 15, 30, and $90 \mathrm{~min}$. The results are compared graphically.

\subsubsection{Results}

In Figure 4, water content profiles from NUFT are compared with the profiles generated by UNSATH, FLASH, and TOUGH. Data from UNSAT-H (Baca and Magnuson, 1990) were obtained through personal communication with the authors, while the data from TOUGH and FLASH were digitized from a plot in the UNSAT-H test report (Baca and Magnuson, 1990, Fig. 8, p. 26).

Figure 4 shows good agreement between NUFT, UNSAT-H, and FLASH, while TOUGH computed a slightly faster movement of the wetting front. The higher wetting front speed shown by TOUGH might have resulted from the use of full upstream weighting in calculating the interfacial hydraulic conductivities. For calculation of the interfacial hydraulic conductivivities using NUFT, we use a weighted average approximation with a weighting parameter of 0.5 . The slight differences between NUFT, UNSAT-H, and FLASH results are probably due to differences in the interpolation schemes used to fit the moisture characteristics and unsaturated hydraulic conductivity data. However, the results from the four codes are in fairly good agreement.

\subsection{BI-2. Infiltration in a Stratified Vadose Zone}

\subsubsection{Problem Definition}

This benchmark problem addresses infiltration in a multilayered soil system in a semiarid environment. The problem was originally solved by Huyakorn et al. (1984). A schematic of the lithology is shown in Figure 5. The conceptual, one-dimensional flow model is a 700-m-thick, stratified vadose zone. The system receives recharge through precipitation from the surface. The transient response of the flow system is studied by imposing a large change in the specified surface fiux to simulate a drastic change in recharge rate. The problem is highly nonlinear and difficult to solve numerically.

We assume that the system was initially at steady state while receiving a surface recharge of $5.0736 \times 10^{-9} \mathrm{~m} / \mathrm{sec}(16 \mathrm{~cm} / \mathrm{yr})$. This recharge rate was subsequently reduced to $1.903 \times 10^{-10}$ $\mathrm{m} / \mathrm{sec}(0.6 \mathrm{~cm} / \mathrm{yr})$, and the response of the system was simulated. The new rate was maintained for $40 \mathrm{yr}$.

Soil material properties and layer thicknesses for the four layers, obtained from Huyakorn et al. (1984), are shown in Table 3.

The soil-water characteristics and relative hydraulic conductivity function are based on experimental data obtained from Elzeftawy and Cartwright (1983). The data were fitted to equations of the form:

$$
S_{e}=\frac{1}{\left[1+\left(\alpha\left|\psi-\psi_{a}\right|\right)^{\beta}\right]^{\gamma}}
$$




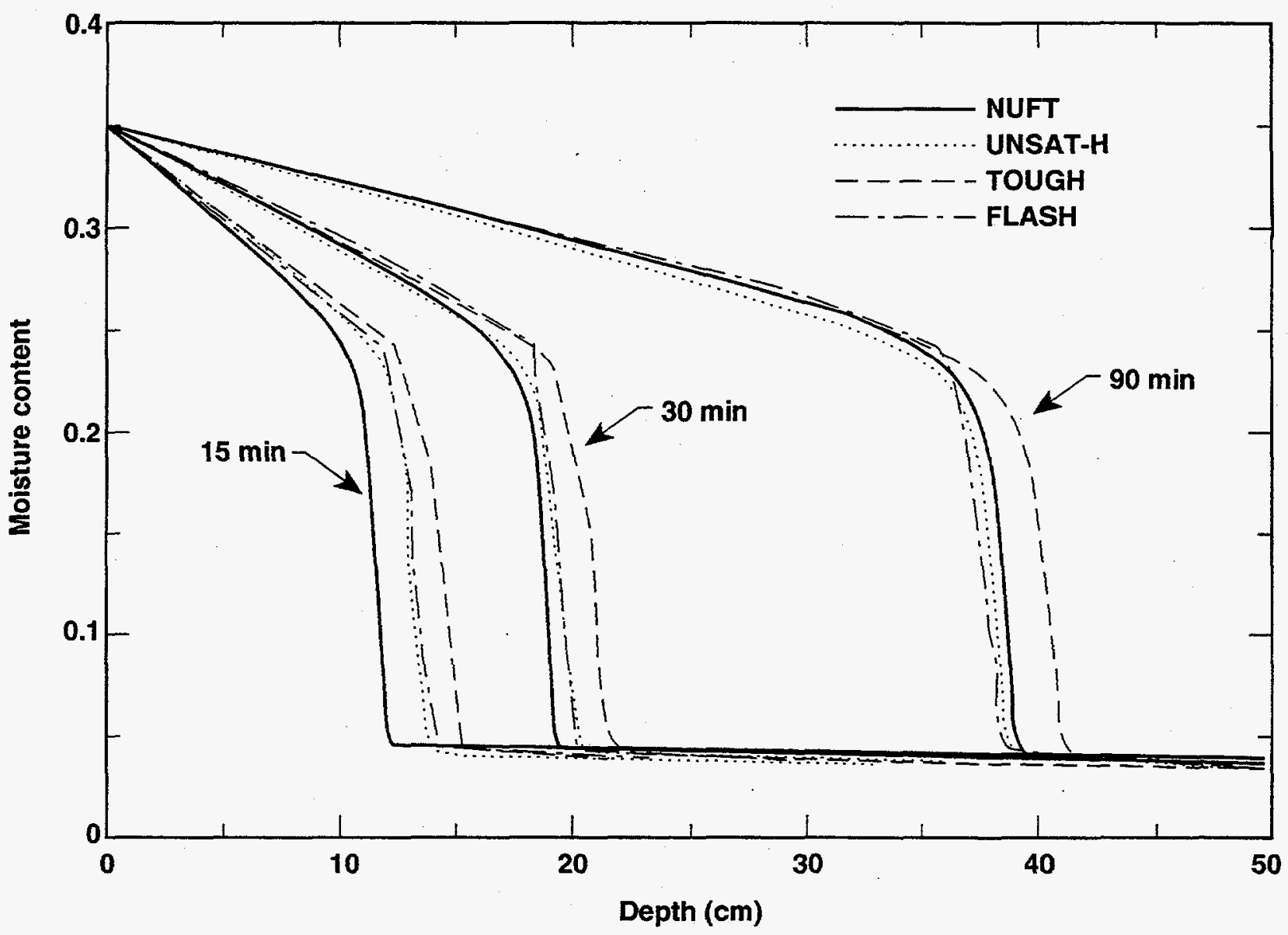

ERD-LSR-93-0088

Figure 4. Problem Bl-1: Comparison of moisture content profiles at 15, 30 , and 90 min with ponding height of $0.75 \mathrm{~cm}$. 


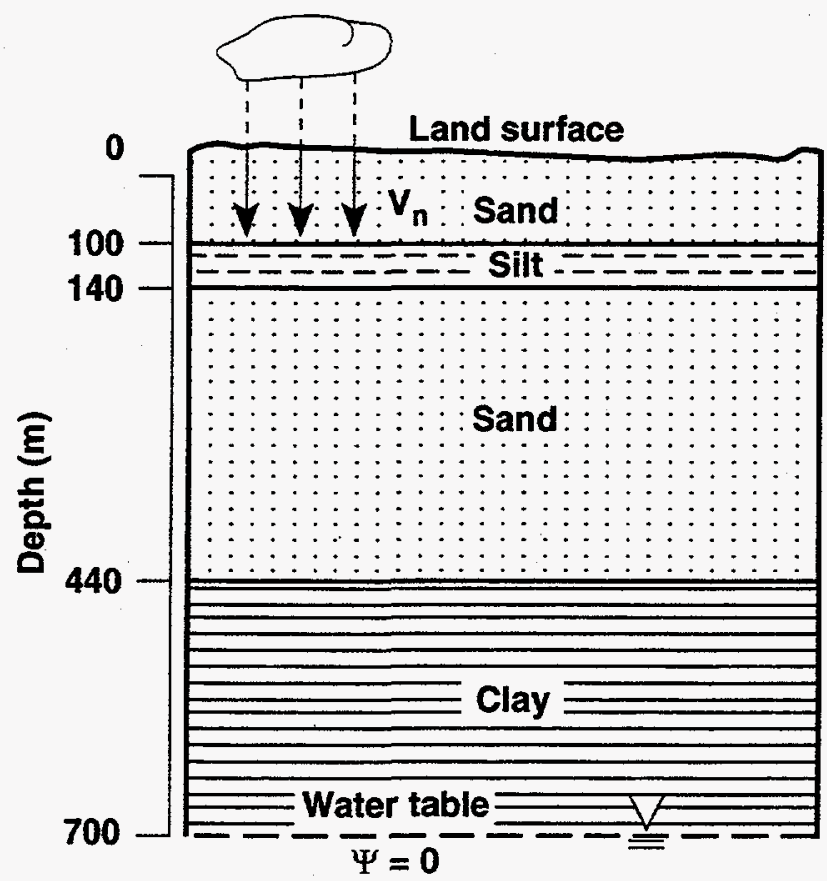

ERD-LSR-93-0089

Figure 5. Cross section through stratified vadose zone (Baca and Magnuson, 1990).

Table 3. Soil material properties.

\begin{tabular}{lcccc}
\hline \hline & $\begin{array}{c}\text { Saturated } \\
\text { hydraulic } \\
\text { Soil } \\
\text { conductivity } \\
(\mathrm{m} / \mathrm{sec})\end{array}$ & $\begin{array}{c}\text { Layer } \\
\text { thickness } \\
(\mathrm{m})\end{array}$ & $\begin{array}{c}\text { Porosity } \\
\left(\mathrm{m}^{3} / \mathrm{m}^{3}\right)\end{array}$ & $\begin{array}{c}\text { Residual } \\
\text { saturation } \\
\left(\mathrm{m}^{3} / \mathrm{m}^{3}\right)\end{array}$ \\
\hline Sand & $1.06 \times 10^{-4}$ & 100 & 0.36 & 0.03 \\
Silt & $4.02 \times 10^{-5}$ & 40 & 0.62 & 0.12 \\
Sand & $1.06 \times 10^{-4}$ & 300 & 0.36 & 0.03 \\
Clay & $2.85 \times 10^{-6}$ & 260 & 0.58 & 0.26 \\
\hline
\end{tabular}


Table 4. Soil parameter values for $S_{w}(\psi)$ and $K_{r w}(\psi)$.

\begin{tabular}{lccccc}
\hline \hline $\begin{array}{l}\text { Material } \\
\text { type }\end{array}$ & $\begin{array}{c}\alpha \\
\left(m^{-1}\right)\end{array}$ & $\beta$ & $\gamma$ & $\mathrm{a}$ & $\mathrm{b}$ \\
\hline Sand & 1.42 & 2.620 & 0.197 & -5. & 1.000 \\
Silt & $8.17 \times 10^{-2}$ & 0.903 & 1.830 & 0. & 5.566 \\
Clay & $8.63 \times 10^{-3}$ & 0.627 & 2.830 & 0. & 9.300 \\
\hline \hline
\end{tabular}

and:

$$
\log _{10} K_{r w}=\left[a S_{e}{ }^{2}+(b-2 a) S_{e}+a-b\right]
$$

where $S_{e}$ is the effective water saturation, defined as $S_{e}=\left(S_{w}-S_{w r}\right) /\left(1-S_{w r}\right)$. The other variables are defined as:

$$
\begin{aligned}
& \psi=\text { pressure head. } \\
& \psi_{a}=\text { air entry pressure head. } \\
& S_{w}=\text { water saturation. } \\
& S_{w r}=\text { residual water saturation. } \\
& K_{r w}=\text { relative hydraulic conductivity. }
\end{aligned}
$$

The fit parameters $\alpha, \beta, \gamma, \mathrm{a}$, and $\mathrm{b}$ are given in Table 4 .

\subsubsection{Test Objective}

The objective of this test case was to examine the capability of the NUFT code to solve the problem of vertical flow through unsaturated, layered geologic media of highly variable hydrologic properties, under relatively dry conditions. This type of problem is computationally difficult because of the drastic changes in hydrologic properties of the soil.

\subsubsection{Input Specifications}

The problem was solved using the us1p module of NUFT. The problem was executed in two phases. An initial run was made to compute the steady-state conditions based on a recharge rate of $5.0736 \times 10^{-9} \mathrm{~m} / \mathrm{sec}$. The problem was allowed to run long enough to establish a steady-state water content profile. The output from this first run was then used as the initial conditions for a restart run with a reduced recharge rate of $1.903 \times 10^{-10} \mathrm{~m} / \mathrm{sec}$.

The input file for the first run is shown in Appendix A1.3. The NUFT code accepts water characteristic data in the form of Eq. (2.5), and relative hydraulic conductivity data in the form of Eq. (2.6). Soil material properties from Table 3 and parameter values from Table 4 were included in the rocktab data unit of the input file. The $700-\mathrm{m}$-thick vadose zone was discretized into a one-dimensional rectangular mesh composed of 124 elements. The element thickness varied from 
a minimum of $1.0 \times 10^{-5} \mathrm{~m}$ at the upper and lower boundaries to a maximum of $10 \mathrm{~m}$ within the problem domain. The finer mesh sizes were used close to the layer boundaries. The upper boundary condition, a constant source of $5.0736 \times 10^{-9} \mathrm{~m} / \mathrm{sec}$, is entered in the data unit srctab as a volumetric rate of $1.9026 \times 10^{-10} \mathrm{~m}^{3} / \mathrm{sec}$ into the upper element. The lower boundary is set at zero pressure head and full saturation to simulate a water table condition. The initial conditions were set arbitrarily since they will have no effect on the eventual steady-state conditions.

This first run was allowed to continue to steady-state, and a restart file was generated for use in the second run, at the reduced infiltration rate. The input data file for the second run is shown in Appendix A1.4. The first run was made for a simulation time of $2,000 \mathrm{yr}$, and the restart run for an additional $40 \mathrm{yr}$.

\subsubsection{Output Requirements}

Water content profiles are plotted after $8 \mathrm{yr}$ and $40 \mathrm{yr}$ of infiltration at the reduced rate of $1.903 \times$ $10^{-10} \mathrm{~m} / \mathrm{sec}$. These results are compared graphically with the results from the UNSAT-H computer code (Baca and Magnuson, 1990). Very good agreement was obtained by Baca and Magnuson (1990) when UNSAT-H was benchmarked against FLASH and TRACR3D using this problem.

\subsubsection{Results}

Figure 6 shows a graphical comparison of water content profiles from NUFT and UNSAT-H. The profiles are compared at $8 \mathrm{yr}$ and $40 \mathrm{yr}$. Very good agreement is observed between profiles from the two codes. The water content values in the sand layers are almost identical. In the silt and clay layers, the differences are slightly greater, but the maximum moisture content difference is only about 0.01 .

The results from this benchmarking analysis show that the performance of NUFT, in simulating one-dimensional unsaturated flow through highly stratified soils, is very satisfactory when compared to the UNSAT-H code. Since UNSAT-H was satisfactorily benchmarked against FLASH and TRACER3D, it implies that NUFT would also benchmark satisfactorily against these other two codes.

\subsection{BI-3. Partially Saturated Flow in Basalt}

\subsubsection{Problem Definition}

In this benchmark test problem, we simulate transient moisture infiltration into an unsaturated, heterogeneous basalt. The flow is one-dimensional and vertical. The temperature is held uniform and constant throughout the flow domain, and does not influence moisture movement. The model uses field data on soil stratigraphy underlying the Radioactive Waste Management Complex (RWMC) at the Idaho National Engineering Laboratory (INEL), and soil property measurements from test cores collected at the RWMC site.

In the first stage, water continuously infiltrates through the upper surface of the soil at a very low infiltration rate $\left(Q_{i}\right)$, until the soil equilibrates to a steady-state moisture profile. The simulation time for this first phase was $500 \mathrm{yr}$. The steady-state profile is then used as the initial 


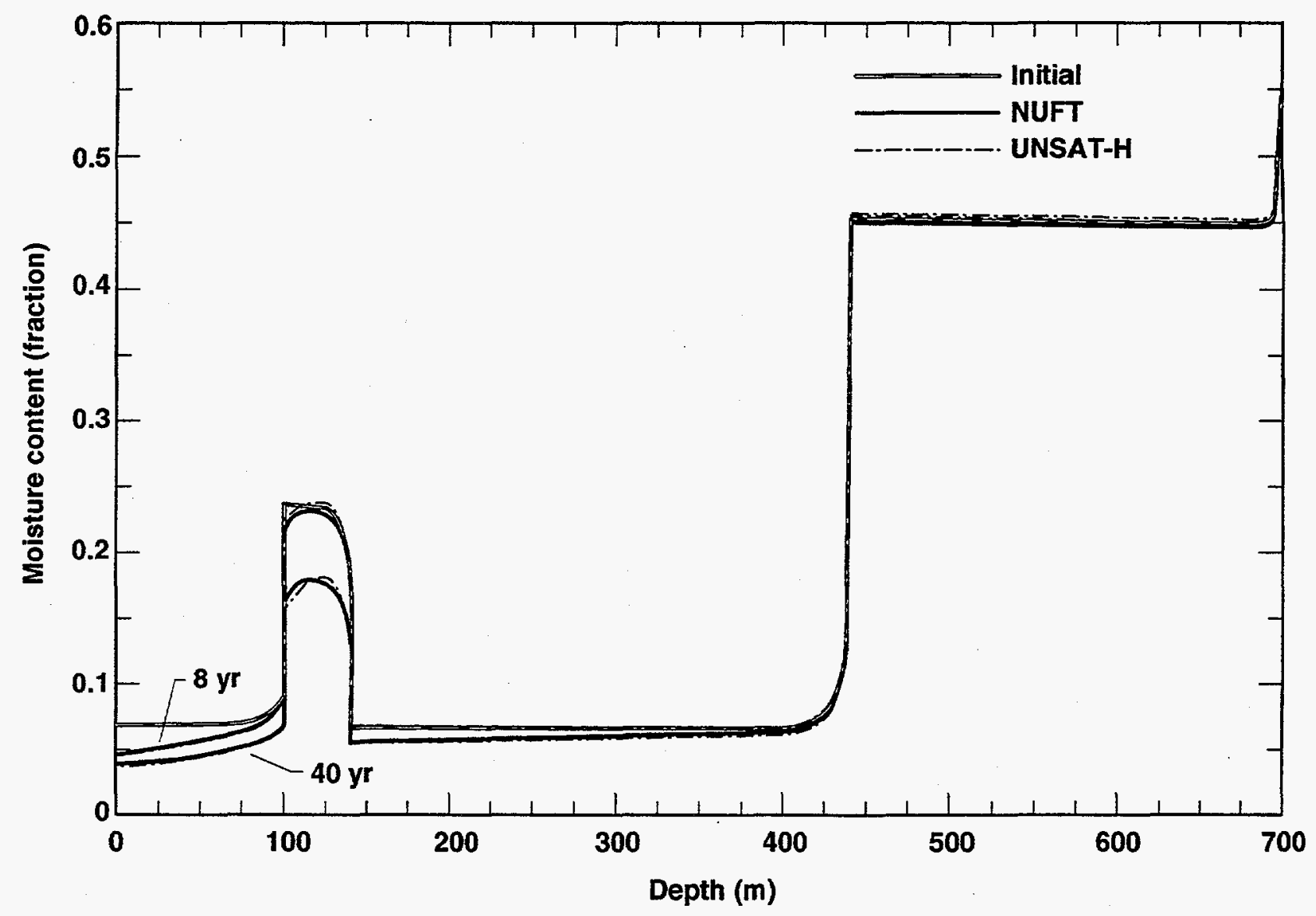

ERD-LSR-93-0090

Figure 6. Problem BI-2: Comparison of moisture content profiles from NUFT and UNSAT-H, using upstream weight of 1.0 in NUFT. Moisture content profile shown at initial time, $8 \mathrm{yr}$, and $40 \mathrm{yr}$. 
condition for the second phase, in which infiltration is instantaneously increased (stepped up) to a much higher rate, $\left(Q_{f}\right)$, held constant for some time, then stepped down back to $Q_{i}$. The simulation time for this second phase was 150 days. This scenario simulates a flash flooding event. The model predicts the redistribution of soil moisture in response to the flood.

\subsubsection{Test Objectives}

The main aim is to test NUFT's ability to simulate a realistic field situation, using field data on site stratigraphy and laboratory measurements of soil properties from test cores collected at the site. The stratigraphy chosen for this test problem exhibits sharp changes in soil properties across abrupt and well-defined interfaces. Step changes (three orders of magnitude) are imposed on the infiltration rate. Thus, the contrasting site stratigraphy and abruptly varying infiltration rate increase the computational difficulty and check the numerical stability of the model.

\subsubsection{Initial Conditions}

Initial conditions for the flow model (module us1p) are specified in data unit state of the NUFT input file (Appendix A1.5). The different soil types in the stratigraphy are each given an initial liquid saturation (Sl) slightly greater than the residual saturation (Sr). For example, vesicular basalt (vbas) has a residual saturation of 0.175 (from data unit rocktab), and is set at an initial liquid saturation of 0.18 . The pressure head $(\mathrm{H})$ is computed from the liquid saturation, based on the retention curve, and may be set to zero in the input file.

\subsubsection{Boundary Conditions}

Boundary conditions are specified in data unit bctab of the NUFT input file. The liquid saturation at the bottom end of the soil column (element $b \# 1: 1: 197$ ) is fixed at the initial value of 0.18 , allowing free drainage.

The infiltration flux at the top end of the column (element t\#1:1:1) varies with time. The flux is specified by supplying the total volumetric flow rate of liquid across the surface as input to data unit srctab of the NUFT input file. A constant initial infiltration rate $\left(Q_{i}=4.98 \mathrm{E}-09\right.$ $\mathrm{m}^{3} / \mathrm{sec}$ ), equivalent to $5 \mathrm{~cm} / \mathrm{yr}$, is applied to the top of the simulated soil column for $500 \mathrm{yr}$. At the end of $500 \mathrm{yr}$, soil moisture is in equilibrium with the applied liquid flux, and a steady-state initial moisture (and pressure) profile is established. The infiltration flux is then instantaneously stepped-up to $3155.76 \mathrm{~cm} / \mathrm{yr}\left(Q_{f}=3.14 \times 10^{-06} \mathrm{~m}^{3} / \mathrm{sec}\right)$, and maintained at that level for 5 days to simulate a flooding event. Following the 5 days of flooding, the infiltration flux is reduced to the initial steady-state value $\left(Q_{i}\right)$ of $5 \mathrm{~cm} / \mathrm{yr}$, and the additional soil moisture from flooding is allowed to redistribute in the soil column.

\subsubsection{Input Specifications}

The input file used for NUFT computations (Appendix A1.5) contains all of the input specifications described herein. The modeled column consists of eight layers of four different material types as 


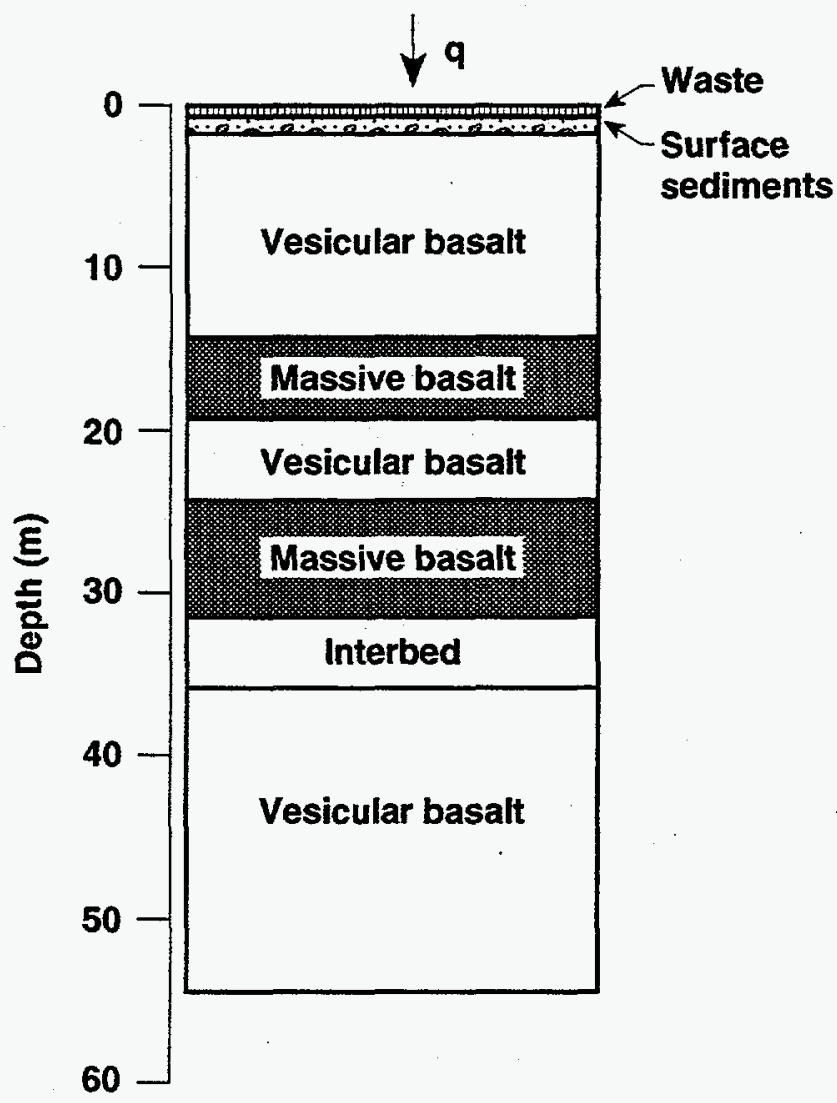

ERD-LSR-93-0091

Figure 7. Cross section through layered basalt (Baca and Magnuson, 1990).

shown in Figure 7. The four material types are waste, surface sediments, vesicular basalt, and massive basalt. The materials exist as discrete horizontal layers in the vertical soil column:

$\begin{array}{ll}\text { Soil type } & \text { Depth }(\mathrm{m}) \\ & \\ \text { Waste } & 2.5-3.5 \\ \text { Sediments } & 3.5-4.5 \\ \text { Vesicular basalt } & 4.5-17.3 \\ \text { Massive basalt } & \mathbf{1 7 . 3 - 2 2 . 0} \\ \text { Vesicular basalt } & \mathbf{2 2 . 0 - 2 6 . 3} \\ \text { Massive basalt } & 26.3-34.0 \\ \text { Sediments } & \mathbf{3 4 . 0}-38.0 \\ \text { Vesicular basalt } & \mathbf{3 8 . 0}-55.0\end{array}$

The properties of these four materials are listed in Table 5 and are specified in data unit rocktab of the NUFT input file (Appendix A1.5). We ignore the presence of entrapped air, and set the maximum liquid saturation (Smax) to 1.0. In this test problem, the saturation varies spatially and temporally. Changes in saturation are related to changes in the pressure head and unsaturated hydraulic conductivity by the van Genuchten characteristic curve formulation. The 
Table 5. Material properties and van Genuchten parameters.

\begin{tabular}{lccrcc}
\hline \hline Material & $\theta_{s}$ & $\theta_{r}$ & $\alpha(1 / \mathrm{m})$ & $\mathrm{n}$ & $K_{s}(\mathrm{~m} / \mathrm{sec})$ \\
\hline Waste & 0.350 & 0.0 & 5.5100 & 2.430 & $1.00 \times 10^{-3}$ \\
Sediments & 0.280 & 0.1000 & 0.0918 & 1.788 & $3.00 \times 10^{-6}$ \\
V. Basalt & 0.244 & 0.0427 & 40.2560 & 1.346 & $4.35 \times 10^{-5}$ \\
M. Basalt & 0.120 & 0.0123 & 7.3990 & 1.696 & $5.46 \times 10^{-4}$ \\
\hline \hline
\end{tabular}

hydraulic properties of waste were arbitrarily chosen to be similar to those of a well-drained soil. The hydraulic properties of sediments were based on measurements on test cores, and those of basalt were based on mercury injection measurements.

Mesh generation parameters are specified in the data unit genmsh of the NUFT input file (Appendix A1.5). We specify a one-dimensional cylindrical column with a radius of $1 \mathrm{~m}$. A nonuniform grid size was imposed on the problem domain. The grid consisted of 197 grid blocks. The smallest grid block had a thickness of $0.01 \mathrm{~m}$ (boundary or material interface grid blocks), and the largest grid block had a thickness of $2.5 \mathrm{~m}$ (interior of thick soil layers). Grid block dimensions are specified in data unit genmsh of the NUFT input file.

\subsubsection{Output Requirements}

To estimate the initial steady-state moisture profile, we obtained the moisture content profile at $t$ $=500 \mathrm{yr}$. We obtained two additional moisture profiles: one immediately after the flooding event $(500 \mathrm{yr}+5$ days), and the other 100 days after the end of flooding ( $500 \mathrm{yr}+105$ days). The simulation results were graphically compared to the output produced by UNSAT-H.

\subsubsection{Results}

Figure 8 presents a graphical comparison of the steady-state moisture profile predictions of NUFT and UNSAT-H. In general, the two predicted profiles match very well. At the interface of the waste and sediment stratigraphic units $(z=3.5 \mathrm{~m})$, NUFT predicts a slightly higher moisture content than UNSAT-H. Just above the interface of the massive and vesicular basalt units $(\mathrm{z}=22.0 \mathrm{~m})$, UNSAT-H predicts a slightly higher moisture content. In the sediments $(\mathrm{z}=34.0 \mathrm{~m}$ to $\mathrm{z}=38.0$ m), UNSAT-H predicts a slightly higher moisture content.

Figure 9 compares moisture content profiles (from NUFT and UNSAT-H) immediately after the flash flooding event. The profile represents transient moisture redistribution. Within rock type vesicular basalt (vbas) and at a depth of $8.9 \mathrm{~m}$, UNSAT-H predicts a very sharp drop in moisture content from 0.210 down to 0.123 , whereas NUFT predicts a more gradual drop across the same values of moisture content. The disparity is probably due to differences in numerical schemes employed in the codes. An upstream weight of 1.0 (the default value) was used in NUFT. Just above the interface of the massive and vesicular basalt stratigraphic units $(\mathrm{z}=22.0 \mathrm{~m})$, NUFT predicts a slightly lower moisture content. Just before the interface of the stratigraphic units massive basalt (mbas) and the sediments (sedi) $(\mathrm{z}=3.4 \mathrm{~m})$, NUFT predicts a slightly higher 


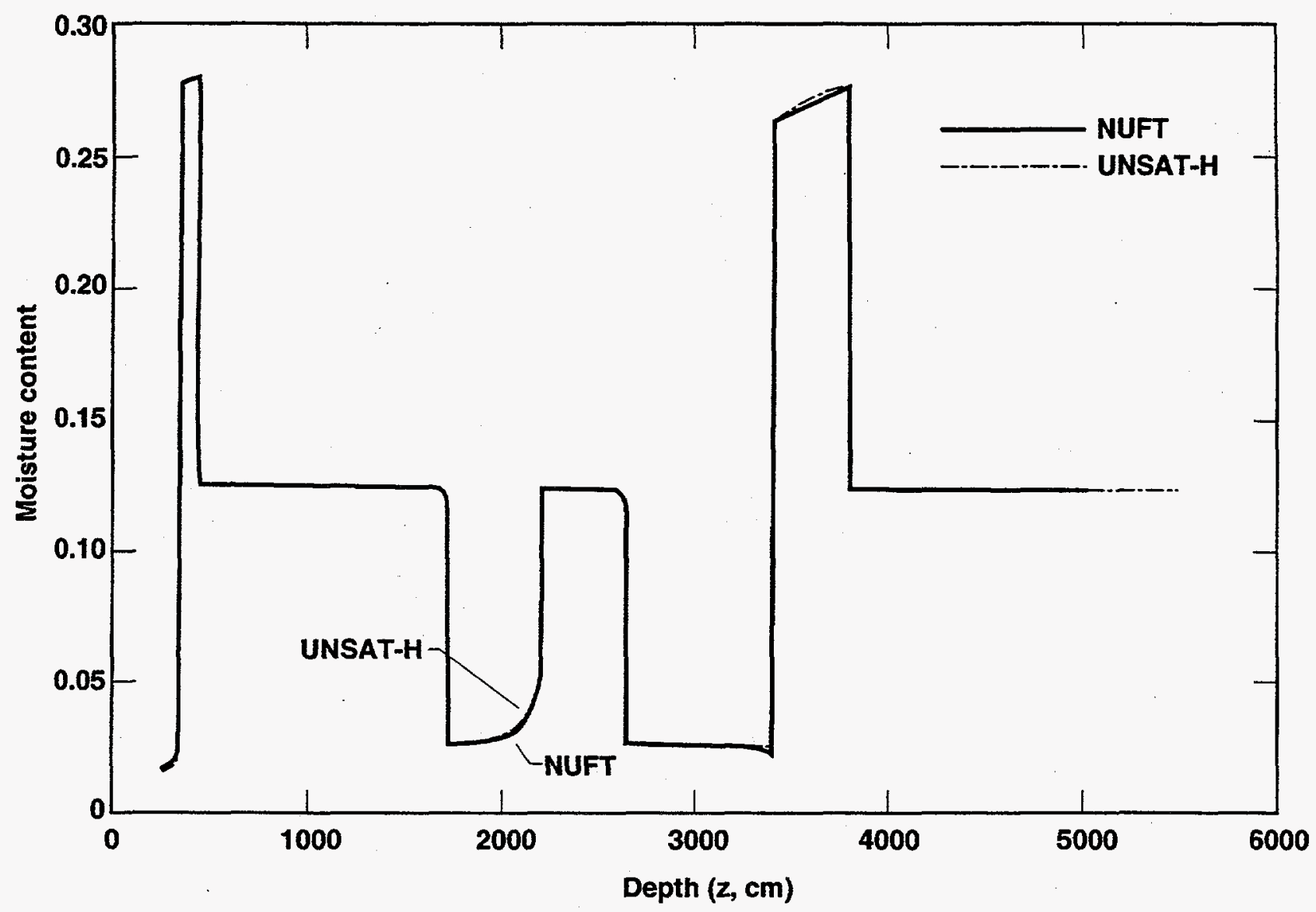

ERD-LSR-93-0092

Figure 8. Problem BI-3: Initial steady-state moisture content profiles from NUFT and UNSAT-H. 


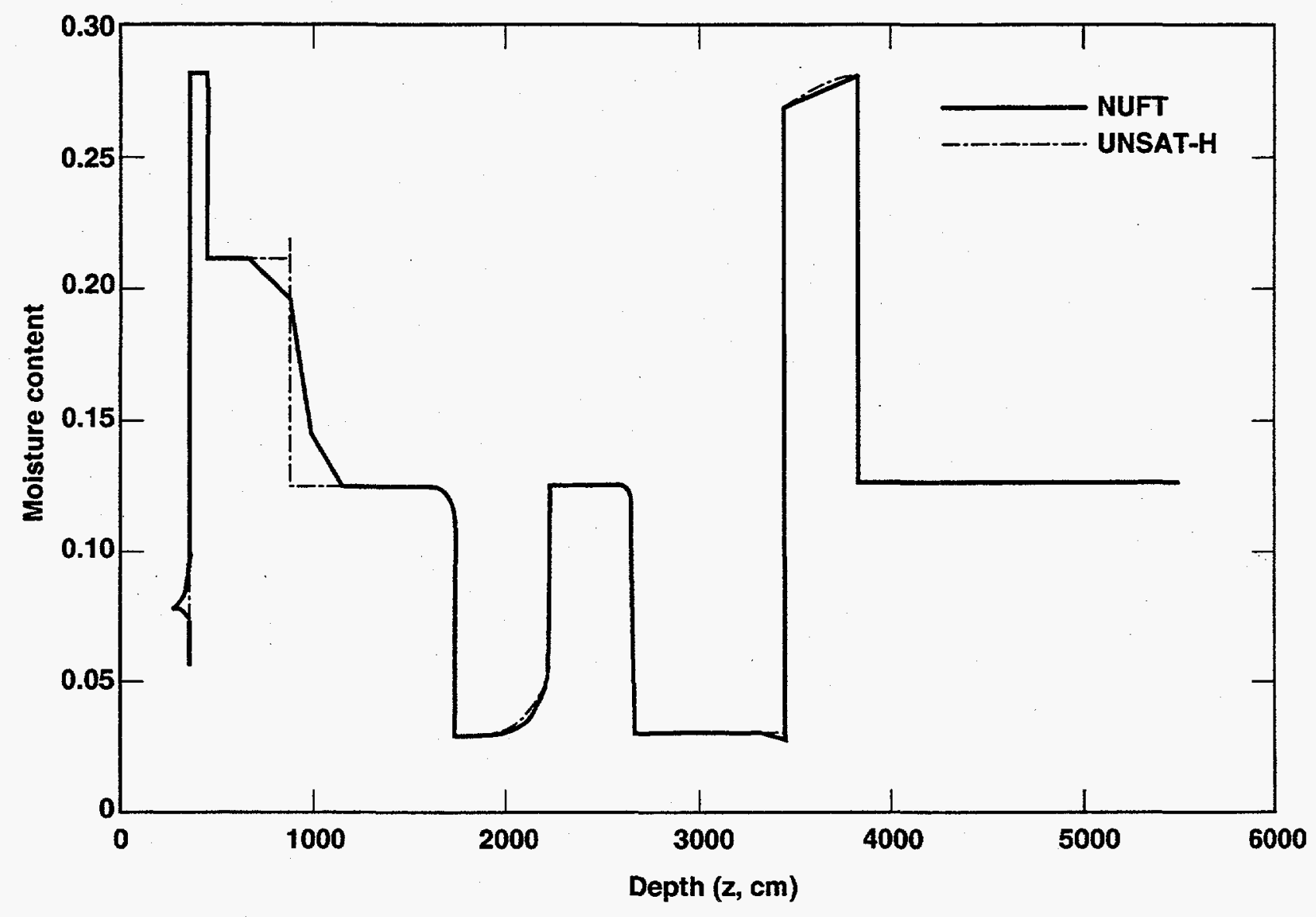

ERD-LSR-93-0093

Figure 9. Problem BI-3: Moisture content profiles from NUFT and UNSAT-H immediatly after flooding (time $=5$ days). 
moisture content than UNSAT-H. Within the sediment unit $(z=3.4 \mathrm{~m}$ to $\mathrm{z}=3.8 \mathrm{~m})$, UNSAT-H predicts a slightly higher moisture content than NUFT.

Figure 10 compares transient moisture profiles 105 days after the beginning of the flash flooding event. For the vesicular basalt unit $(z=4.5 \mathrm{~m}$ to $z=17.3 \mathrm{~m})$, NUFT predicts a slightly higher moisture content than UNSAT-H. Just above the interface $(z=26.3 \mathrm{~m})$ of the vesicular and massive basalt units, UNSAT-H predicts a sharp drop in moisture content, whereas NUFT predicts a gradual decrease (smeared front); just past the interface, NUFT predicts a significantly lower moisture content than UNSAT-H, which may be representative of the predicted moisture content just above the interface. In the sediment unit which starts at a depth of $34.0 \mathrm{~m}$, UNSAT-H predicts a slightly higher value for the moisture content.

In summary, we notice good general agreement between the profiles predicted by NUFT and UNSAT-H, with differences mostly at stratigraphic interfaces. The disparities are probably due to differences in numerical schemes employed by the two codes.

UNSAT-H uses harmonic averaging of relative conductivities, which may seriously underpredict and slow the propagation of the wetting front if the downstream node has a low saturation. In an extreme case when the downstream node is at residual saturation, wetting front propagation would be stopped altogether.

Currently, in NUFT, the relative permeability between elements has an upstream-downstream weighting factor. A flux-corrected method by Smolarkiewicz is also available. However, the saturated conductivity is harmonically averaged. It would seem to be more appropriate to perform a Smolarkiewicz weighting on the product of saturated conductivity and relative permeability. This may explain the difference between NUFT and UNSAT-H in predicting the wetting front propagation.

\section{Nonisothermal Test Cases}

\subsection{VT-1. Heat Conduction with Sinusoidal Boundary Condition}

\subsubsection{Problem Definition}

The system simulated here is a homogeneous soil column with simple one-dimensional heat conduction. No fluid flow is allowed in the column, so that heat convection is eliminated and the only active heat transfer mechanism is conduction. The column is initially at uniform temperature, before a sinusoidal temperature boundary condition is applied at one end.

\subsubsection{Governing Equations}

The governing equation describing heat transfer in the column is the one-dimensional heat conduction equation:

$$
\frac{\partial T}{\partial t}=\kappa \frac{\partial^{2} T}{\partial z^{2}}
$$




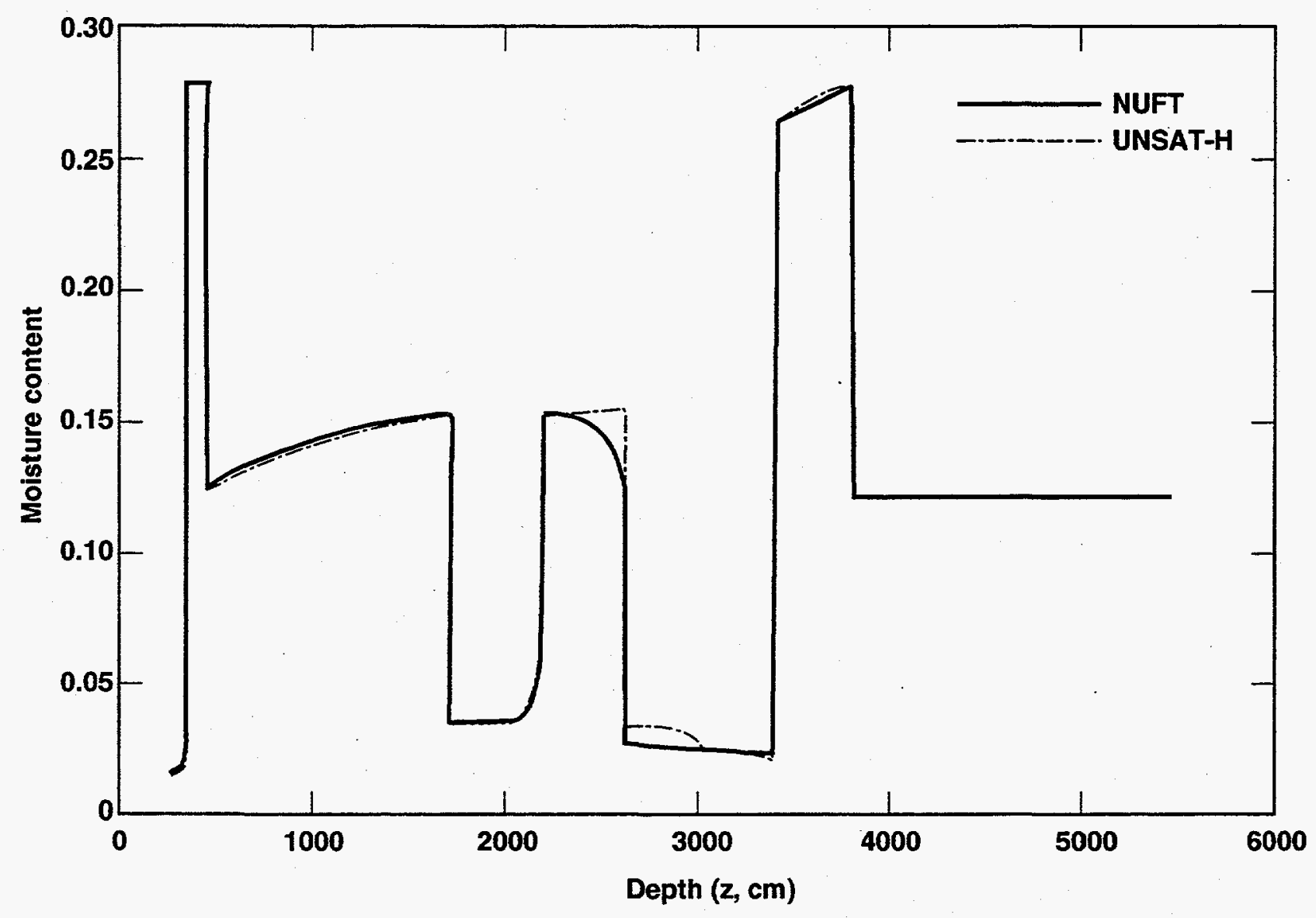

ERD-LSR-93-0094

Figure 10. Problem BI-3: Moisture content profiles from NUFT and UNSAT-H 105 days after flooding (time $=105$ days). 
where $\mathrm{T}$ is the temperature, and $\kappa$ is the thermal diffusivity. The thermal diffusivity is defined as:

$$
\kappa=\frac{K_{T}}{\rho C}
$$

where $\rho$ is the bulk density, $\mathrm{C}$ the specific heat, and $K_{T}$ the thermal conductivity of the bulk medium.

\subsubsection{Test Objectives}

The objective of this verification test case was to test the ability of the NUFT code to solve the one-dimensional heat conduction equation, with the following conditions:

- Time-varying temperature boundary condition.

- Constant initial temperature.

- Constant thermal properties.

- No fluid flow.

\subsubsection{Boundary and Initial Conditions}

The upper boundary temperature is sinusoidal, with a mean value of $14.8^{\circ} \mathrm{C}\left(288^{\circ} \mathrm{K}\right)$, an amplitude of $3^{\circ} \mathrm{C}$, and a period of $24 \mathrm{hr}$. The lower boundary of the soil column is held at $14.8^{\circ} \mathrm{C}$. The initial temperature is uniform at $14.8^{\circ} \mathrm{C}$. The length of column modeled is $18 \mathrm{~cm}$. Because this problem is simulating the effects of diurnal temperature fluctuations, the phase of the sine curve is shifted to obtain a peak surface temperature after $13 \mathrm{hr}$, which is equivalent to a time of 1:00 p.m.

\subsubsection{Analytical Solution}

The analytical solution to Eq. (3.7), for a semi-infinite column with a sinusoidal temperature boundary condition and a uniform temperature initial condition, is obtained from Kirkham and Powers (1972, p. 471) as:

$$
T(z, t)=T_{\alpha}+\alpha \exp \left[-\left(\frac{\omega}{2 \kappa}\right)^{1 / 2} z\right] \sin \left[\omega t-\left(\frac{\omega}{2 \kappa}\right)^{1 / 2} z-\frac{7 \pi}{12}\right]
$$

where $T_{\alpha}$ is the mean temperature, $\alpha$ is the amplitude of the sine wave, and $\omega=2 \pi / P$ where $P$ is the time period, equal to $24 \mathrm{hr}$ here. The last term in the analytical solution shifts the phase of the boundary temperature, forcing the maximum temperature to occur at $13 \mathrm{hr}$. This solution holds for a finite length column at times that are sufficiently short to prevent the temperature disturbance from approaching the lower boundary. 


\subsubsection{Input Specifications}

This problem is run using the usnt module of NUFT. Fluid flow is turned off by using a constant relative permeability of zero for both the aqueous and gaseous phases. The initial input file is shown in Appendix A1.6. With the fluids immobile, no convection occurs, making conduction the only active heat transfer mechanism. In addition, the porosity of the medium is set to the very low value of $0.1 \%$, which ensures that heat transport is dominated by the thermal properties of the solid, which are completely user-specified. The thermal conductivity is made independent of fluid saturation by specifying the same value for the solid matrix, water-saturated soil, and gas-saturated soil. The result is a constant bulk thermal diffusivity for the soil. The initial water saturation was arbitrarily selected as $25 \%$. The main input parameters required to solve this problem are as follows:

- $T_{\alpha}=14.8^{\circ} \mathrm{C}$

- $\alpha=3^{\circ} \mathrm{C}$

- $K_{T}=2.634 \times 10^{-3} \mathrm{~W} / \mathrm{m} / \mathrm{C}$

- $\rho \mathrm{C}=1.1705 \times 10^{6} \mathrm{~J} / \mathrm{m}^{3} / \mathrm{C}$

A rectangular grid comprising 74 nodes was used. Block dimension in the z-direction was $0.25 \mathrm{~cm}$, except for the upper and lower boundary nodes, which were each $1.0 \times 10^{-3} \mathrm{~cm}$ long. The sinusoidal upper boundary temperatures were input at 0.2 -hr intervals. The lower boundary temperature was fixed at the initial value of $14.8^{\circ} \mathrm{C}$.

To obtain the true initial temperature profile for such diurnal surface temperature fluctuations, the problem was run for several days from a uniform initial temperature of $14.8^{\circ} \mathrm{C}$, until the temperature profile converged to the true initial state. The initial run is made for 19 days, and the new profile is used as the initial profile for a restart run. The input file for the restart run is shown in Appendix A1.7. The restart run was made for an additional simulation time of 16 days.

\subsubsection{Output Requirements}

Temperature profiles were computed at four different times for comparison with the analytical solution which was programmed. The times selected are 4, 8, 12, and $16 \mathrm{hr}$. A graphical comparison is made between the numerical and analytical solutions.

\subsubsection{Results}

Figure 11 compares temperature profiles from NUFT and the analytical solution, for the upper $8 \mathrm{~cm}$ of soil column. Temperatures are compared at $4,8,12$, and $16 \mathrm{hr}$. It is seen that the simulation results match the analytical solution excellently. It can therefore be concluded that NUFT accurately solves the one-dimensional heat conduction equation for a uniform temperature initial condition and a time-varying temperature boundary condition. 


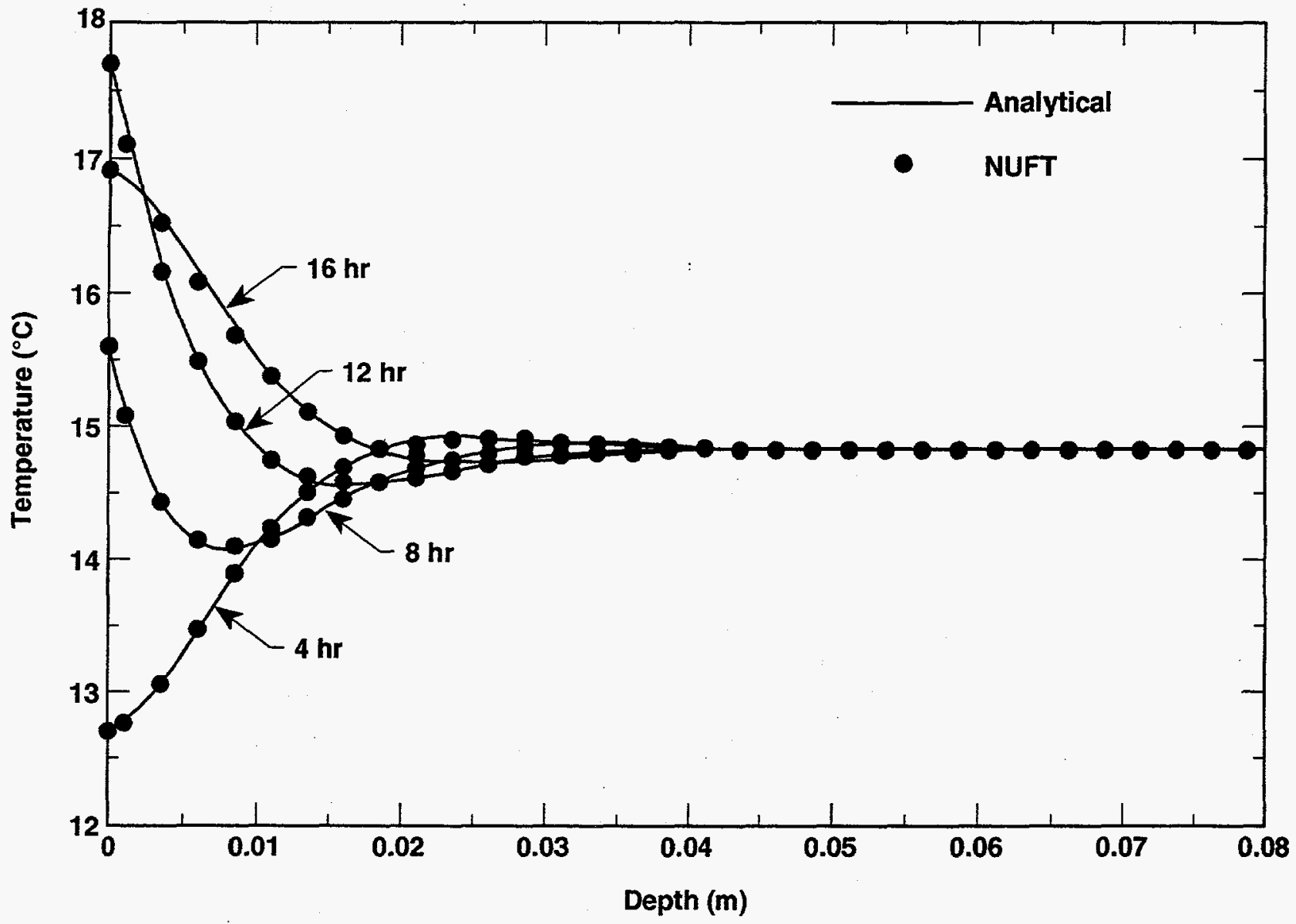

ERD-LSR-93-0095

Figure 11. Heat conduction with sinusoidal boundary condition (VT-1): comparison of temperature profiles from NUFT and the analytical solution. 


\subsection{VT-2. Heat Conduction with Constant Heat Flux}

\subsubsection{Problem Definition}

The system simulated here is, as in test case VT-1, a homogeneous soil column with simple onedimensional heat conduction. However, the upper boundary condition is now a constant heat flux instead of a sinusoidal temperature. This boundary condition is meant to simulate the case where the atmosphere acts as a source of thermal energy to the soil, and transient heat flow occurs in response to a constant heat flux at the surface. Again, no fluid flow is allowed in the column, so that heat convection is effectively turned off, making conduction the only active heat transfer mechanism. A uniform initial temperature is specified for the column. The lower boundary temperature is fixed at the initial value. The height of the column is $1 \mathrm{~m}$.

\subsubsection{Governing Equations}

The governing equation describing heat transfer in the column is the one-dimensional heat conduction equation:

$$
\frac{\partial T}{\partial t}=\kappa \frac{\partial^{2} T}{\partial z^{2}}
$$

where $\mathrm{T}$ is the temperature, and $\kappa$ is the thermal diffusivity. The thermal diffusivity is defined as:

$$
\kappa=\frac{K_{T}}{\rho C}
$$

where $\rho$ is the bulk density, $\mathrm{C}$ the specific heat, and $K_{T}$ the thermal conductivity of the bulk medium.

\subsubsection{Test Objective}

The objective of this thermal verification test case was to test the ability of the NUFT code to solve the one-dimensional heat conduction equation, with the following conditions:

- Constant heat flux boundary condition.

- Uniform initial temperature.

- Constant thermal properties.

- No fluid flow.

\subsubsection{Analytical Solution}

The analytical solution to Eq. (3.9), with a constant upper boundary flux, uniform initial temperature, and a fixed lower boundary temperature equal to the initial temperature, is given by Arpaci (1966, p. 277-279) as:

$$
\frac{T(z, t)-T_{i}}{q L / K_{T}}=\frac{\kappa t}{L^{2}}+\frac{1}{2}\left(\frac{z}{L}\right)^{2}-\frac{1}{6}-2 \sum_{n=1}^{\infty} \frac{(-1)^{n}}{\left(\lambda_{n} L\right)^{2}} \exp \left\{-\kappa \lambda_{n}^{2} t\right\} \cos \left\{\lambda_{n} z\right\}
$$


where $T_{i}$ is the initial temperature, $q$ is the specified heat flux, $\mathrm{L}$ is the length of the column, and $\lambda_{n}=n \pi / L$, where $\mathrm{n}$ is the index for terms in the series.

\subsubsection{Input Specifications}

The problem is run using the usnt module of NUFT with fluid flow turned off by using a constant relative permeability of zero for both the liquid and gas phases. The input file is shown in Appendix A1.8. With the fluid immobile, no convection occurs, making conduction the only active heat transfer mechanism. In addition, the porosity of the medium is set to the very low value of $0.1 \%$, which ensures that heat transport is dominated by the thermal properties of the solid, which are completely user-specified. The thermal conductivity is made independent of fluid saturation by specifying the same value for the solid matrix, water-saturated soil, and gas-saturated soil. The result is a constant bulk thermal diffusivity for the soil. The initial water saturation was arbitrarily selected as $25 \%$. The main input parameters required to solve this problem are as follows:

- $T_{i}=14.85^{\circ} \mathrm{C}$

- $K_{T}=0.840 \mathrm{~W} / \mathrm{m} / \mathrm{C}$

- $\rho \mathrm{C}=4.184 \times 10^{6} \mathrm{~J} / \mathrm{m}^{3} / \mathrm{C}$

- $q=1000.0 \mathrm{~W} / \mathrm{m}^{2}$

A rectangular grid comprising 102 nodes is used. Block dimension in the z-direction is $1.0 \mathrm{~cm}$, except for the upper and lower boundary nodes, which are each $1.0 \times 10^{-5} \mathrm{~cm}$ long.

\subsubsection{Output Requirements}

Temperature profiles were computed at $24 \mathrm{hr}$ and $48 \mathrm{hr}$ for comparison with the analytical solution, which was programmed. A graphical comparison is made between the numerical and analytical solutions.

\subsubsection{Results}

Figure 12 shows a graphical comparison of temperature profiles from NUFT and the analytical solution, at 24 and $48 \mathrm{hr}$. It is seen that the simulation results match the analytical solution excellently. The numerical and analytical solutions are virtually identical, for both the $24-\mathrm{hr}$ and 48-hr temperature profiles. It can therefore be concluded that the NUFT code accurately solves the one-dimensional heat conduction equation for a constant heat flux upper boundary condition and a uniform initial temperature.

\subsection{BT-1. Thermal History of a Vadose Zone}

\subsubsection{Problem Definition}

In this benchmark test problem, we simulate heat conduction in a one-dimensional, unsaturated, heterogeneous soil column. The model uses field data on soil stratigraphy underlying the Radioac- 


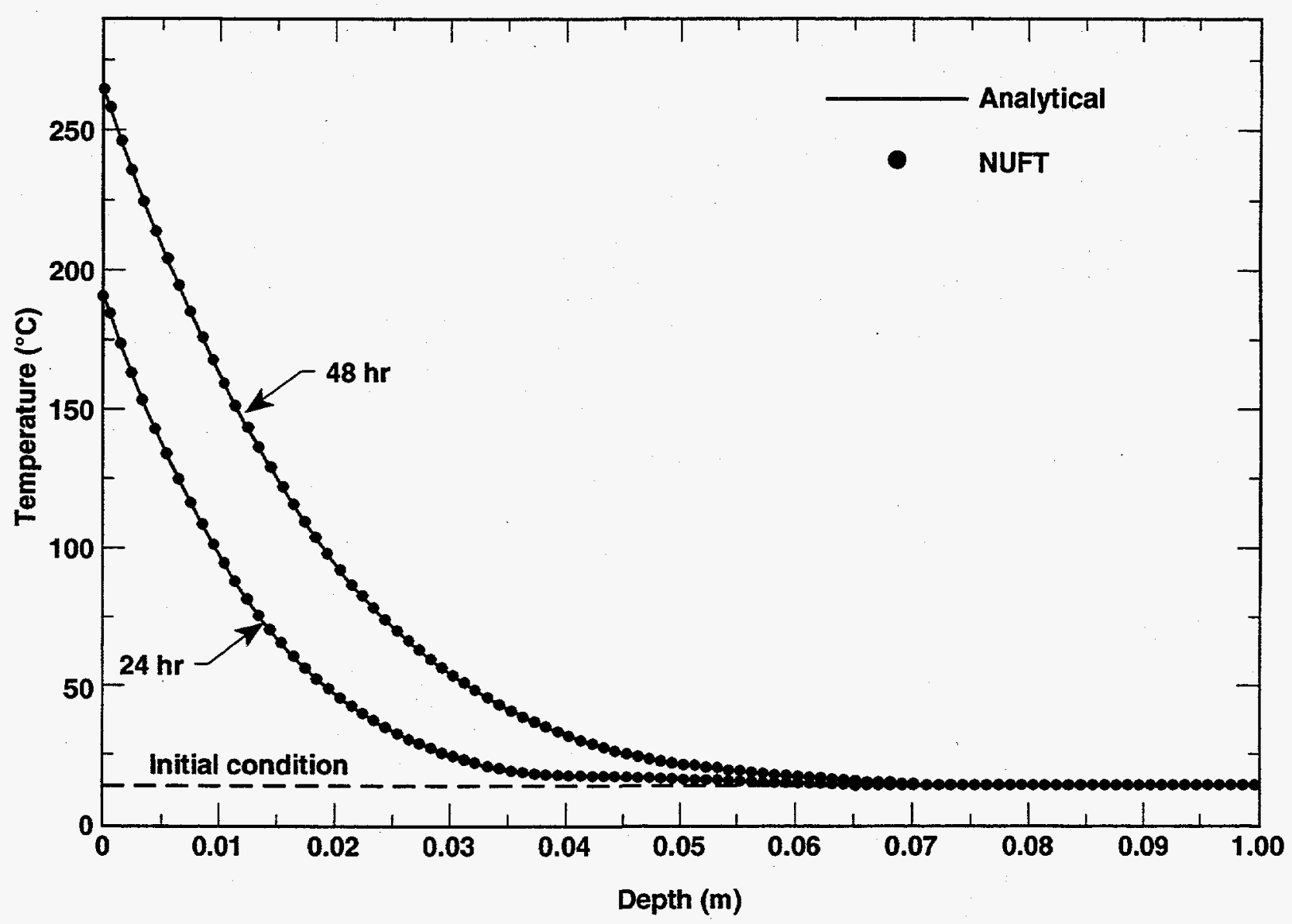

ERD-LSR-93-0096

Figure 12. Problem VT-2: Comparison of temperature profiles from NUFT and analytical solution. 
tive Waste Management Complex (RWMC) at the Idaho National Engineering Laboratory (INEL), and soil property measurements from test cores collected at the RWMC site. The model consists of two stratigraphic units, surface sediments and basalt.

In 1985-86, thermistors were used to monitor surface and down-hole temperatures at the RWMC site. A harmonic function (temperature as a function of time, $T(t)$ ) was fitted to the temperature profile generated from thermistor measurements, and used as thermal input to the model.

\subsubsection{Test Objective}

The objective of this benchmarking exercise was to test NUFT's ability to simulate the temperature history of surficial soils under the following conditions:

- There is no fluid flow in the column, and therefore no convective heat transport.

- Conduction is the only mechanism for heat transport.

- Each soil layer has homogeneous and constant thermal properties.

\subsubsection{Initial Conditions}

Initial conditions for the heat transport simulation (module usnt) are specified in data unit state of the NUFT input file (Appendix A1.9). The initial gas phase pressure is assumed to be barometric, with a value of $1.0 \times 10^{05} \mathrm{~Pa}$. The two rock types in the soil column are specified an initial saturation, arbitrarily chosen to be slightly less than full saturation. The entire soil column has a uniform initial temperature of $8.4^{\circ} \mathrm{C}$ (Note: As per NUFT input requirements, the temperature was offset by $40^{\circ} \mathrm{C}$ ).

\subsubsection{Boundary Conditions}

Boundary conditions are specified in data unit bctab of the NUFT input file. The temperature at the top surface of the soil column is temporally varied to follow the harmonic functional fit to field measured temperature values. The resulting surface temperature boundary condition is:

$$
\begin{aligned}
T_{s}=8.4 & -1.75 \sin \left(0.005734\left(t_{d}+1039.4\right)\right)+3.21 \sin \left(0.01147\left(t_{d}+6.9\right)\right) \\
& +17.2 \sin \left(0.0172\left(t_{d}-100.9\right)\right)-2.81 \sin \left(0.02294\left(t_{d}-61.2\right)\right) \\
& +3.62 \sin \left(0.02867\left(t_{d}-33.5\right)\right)+1.27 \sin \left(0.0344\left(t_{d}+62.8\right)\right)
\end{aligned}
$$

where $T_{s}$ is the time-dependent surface temperature, $t$ is the elapsed time, and $t_{d}=t-417$ days. The bottom boundary is maintained at a constant temperature of $8.4^{\circ} \mathrm{C}$ (Note: As per NUFT input requirements, the temperature was offset by $40^{\circ} \mathrm{C}$ ). 


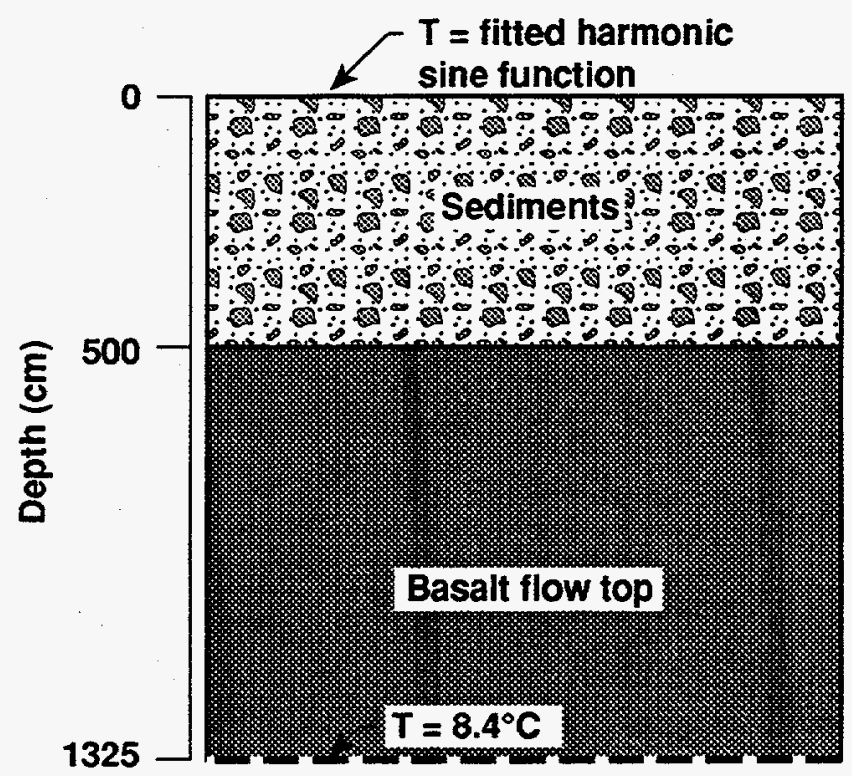

ERD-LSR-93-0097

Figure 13. Simplified cross section for RWMC vadose zone (Baca and Magnuson, 1990).

\subsubsection{Input Specifications}

The input file used for NUFT computations (Appendix A1.9) contains all of the input specifications described herein. The modeled column consists of two layers, each of a different material type, as shown in Figure 13. The material types are surface sediments and basalt.

The thermal properties of these materials are listed in Table 6, and are specified in data unit rocktab. The solid, liquid, and gas phases are assigned identical values for thermal conductivity (tcond-solid and tcond-sat), equal to the bulk thermal conductivity of the medium. The liquid and gas phases are assigned a relative permeability (kr.liquid and $\mathrm{kr}$.gas) of zero (0) to ensure that there is no fluid movement in the column. Further, due to the absence of fluid flow, the moisture profile and unsaturated hydraulic properties remain constant; therefore, we do not specify characteristic curve relations.

The materials exist as two discrete horizontal layers, as shown in Figure 13. Sediments occur from the surface down to a depth of $5.0 \mathrm{~m}$, and basalt from $5.0 \mathrm{~m}$ to $13.25 \mathrm{~m}$.

Grid discretization is specified in data unit genmsh of the NUFT input file. A nonuniform, finite-difference grid is imposed on the problem domain. The grid consists of 81 grid blocks. The smallest grid block has a thickness of $0.01 \mathrm{~m}$ (boundary or material interface grid blocks), and the largest grid block has a thickness of $0.5 \mathrm{~m}$ (interior of thick soil layers). 
Table 6. Thermal properties of soil and rock materials.

\begin{tabular}{ccccc}
\hline \hline Material & Porosity & $\begin{array}{c}\text { Specific } \\
\text { heat capacity } \\
(\mathrm{J} / \mathrm{Kg} / \mathrm{K})\end{array}$ & $\begin{array}{c}\text { Solid } \\
\text { density } \\
\left(\mathrm{Kg} / \mathrm{m}^{3}\right)\end{array}$ & $\begin{array}{c}\text { Thermal } \\
\text { conductivity } \\
(\mathrm{J} / \mathrm{m} / \mathrm{s} / \mathrm{K})\end{array}$ \\
\hline Sediments & 0.001 & 952.85 & $2,650.0$ & 1.0795 \\
Basalt & 0.001 & 803.01 & $2,650.0$ & 1.0795 \\
\hline \hline
\end{tabular}

\subsubsection{Output Requirements}

NUFT generated temperature histories at depths of $0.1,2.1$, and $4.0 \mathrm{~m}$ below the top of the soil column. History output is generated using the format specified in data unit output of the NUFT input file. NUFT output is compared to UNSAT-H results.

\subsubsection{Results}

This benchmark test case simulates heat conduction in real stratigraphy, and uses field data from a heterogeneous soil setting. The input is specified so as to shut off fluid movement so that conduction is the only active heat transfer mechanism.

Figure 14 presents a graphical comparison of temperature histories predicted by NUFT and UNSAT-H at depths of $0.1,2.1$, and $4.0 \mathrm{~m}$. Predictions from the two codes are in excellent agreement.

\section{Conclusions}

In this initial phase of verification and benchmark testing, the NUFT code was used to solve seven one-dimensional unsaturated flow and heat transfer problems. Three verification and four benchmarking problems were solved. Verification was performed by making direct comparisons between NUFT simulation results and known analytical or semianalytical solutions. Benchmark testing was done by comparing NUFT simulation results with the results from well established and previously tested codes, using field and laboratory problems for which analytical solutions are not available.

In the verification testing, excellent agreement was observed between NUFT results and the analytical solutions. In the benchmark testing, results of code intercomparison were very satisfactory.

From these testing results, it is concluded that the NUFT code is ready for application to the types of unsaturated flow and heat transport problems addressed here. Additional code testing is ongoing. Multidimensional problems, including chemical transport problems, will be addressed in a subsequent report. 


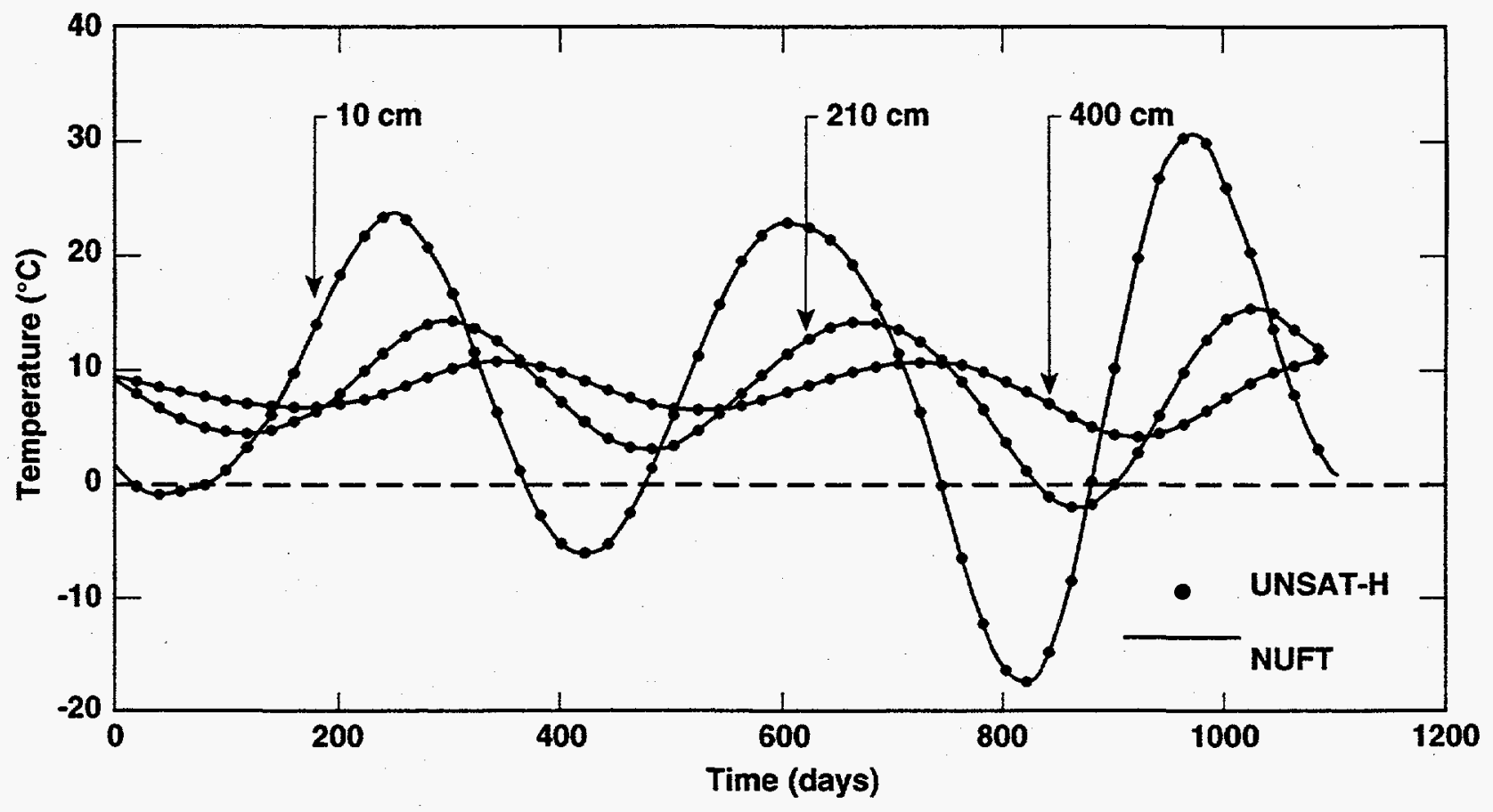

ERD-LSR-93-0098

Figure 14. Problem BT-1: Comparison of temperature histories from NUFT and UNSAT-H. 


\section{References}

Arpaci, V. S. (1966), Conduction Heat Transfer, Addison-Wesley, Reading, MA.

Baca, R. G., and S. O. Magnuson (1990), Independent Verification and Benchmark Testing of the UNSAT-H Computer Code, Version 2.0, EGG-BEG-8811, Idaho National Engineering Laboratory, Idaho Falls, ID.

Bear, J., and J. J.Nitao (1993), Inflitration and Contaminant Transport in the Vadose Zone (Nonisothermal), Part 1: Conceptual and Mathematical Models, Lawrence Livermore National Laboratory, Livermore, CA (UCRL-JC-111742 pt 1).

Davis, L. A., and S. P. Neuman (1983), Documentation and User's Guide: UNSAT2-Variably Saturated Flow Model, WWL/TM-1791-1, Water,Waste \& Land, Inc., Ft. Collins, CO.

El-Kadi, A. I. (1987), INFIL, International Groundwater Modeling Center, Holcomb Research Institute, IN.

Elzeftawy, A., and K. Cartwright (1983), Undisturbed Core Method for Determining and Evaluating the Hydraulic Conductivity of Unsaturated Sediments, Rep. UILU-WRC-83-0177, 49 pp., Ill. State Geol. Surv., Springfield.

Haverkamp, R., M. Vanclin, J. Touma, P. J. Wierenga, and G. Vachaud (1977), “A Comparison of Numerical Simulation Models for One-Dimensional Infiltration," Soil Sci. Soc. Am. J., 41, 285-294.

Huyakorn, P. S., S. D. Thomas, and B. M. Thompson (1984), "Techniques for Making Finite Elements Competitive in Modeling Flow in Variably Saturated Porous Media," Water Resources Research, 20(8), 1099-1115.

Iovenitti, J., J. J. Nitao, and D. J. Bishop (1992), Vadose Zone Investigations at the Lawrence Livermore National Laboratory Superfund Site: An Overview, Lawrence Livermore National Laboratory, Livermore, CA (UCRL-JC-110606).

Kirkham, D., and W. L. Powers (1972), Advanced Soil Physics, Wiley-Interscience, New York, NY.

Nitao, J. J. (1993a), Reference Manual for the NUFT Flow and Transport Code, Version 1.0, Lawrence Livermore National Laboratory, Livermore, CA (UCRL-ID-113518, in progress).

Nitao, J. J. (1993b), User's Manual for US1 Module of the NUFT Code, Version 1.0, Lawrence Livermore National Laboratory, Livermore, CA (UCRL-ID-113520, in progress).

Nitao, J. J. (1993c), User's Manual for USNT Module of the NUFT Code, Version 1.O, Lawrence 
Livermore National Laboratory, Livermore, CA (UCRL-ID-113519, in progress).

Philip, J. R.(1957), "Numerical Solution of Equations of the Diffusion Type with Diffusivity Concentration-Dependent: 2," Australian Journal of Physics, 10(2), $29-42$.

Pruess, K. (1987), Tough User's Guide, LBL-20700, NUREG/CR-4645, prepared for the U.S. Nuclear Regulatory Commission by Lawrence Berkeley Laboratory, Berkeley, CA.

Skaggs, R. W., E. J. Monke, and L. F. Huggins (1970), An Approximate Method for Determining the Hydraulic Conductivity Function of an Unsaturated Flow, Technical Report No. 11, Water Resources Research Center, Purdue University, Lafayette, IN.

Thorpe, R. K., W. F. Isherwood, M. D. Dresen, and C. P. Webster-Scholten, Eds. (1990), CERCLA Remedial Investigations Report for the LLNL Livermore Site, Lawrence Livermore National Laboratory, Livermore, CA (UCAR-10299).

van der Heijde, P. K. M., A. I. El-Kadi, and S. A. Williams (1988), Groundwater Modeling: An Overview and Status Report, EPA/600/2-89/028, Robert S. Kerr Environmental Research Laboratory, U.S. Environmental Protection Agency, Ada, OK.

\section{Acknowledgments}

We wish to express our gratitude to the management of Lawrence Livermore National Laboratory Site Restoration Program for giving us the opportunity to pursue this work. We also gratefully acknowledge the assistance of Howard Sherman, who edited this manuscript, and Kim Heyward, who helped with preparation of the figures. 


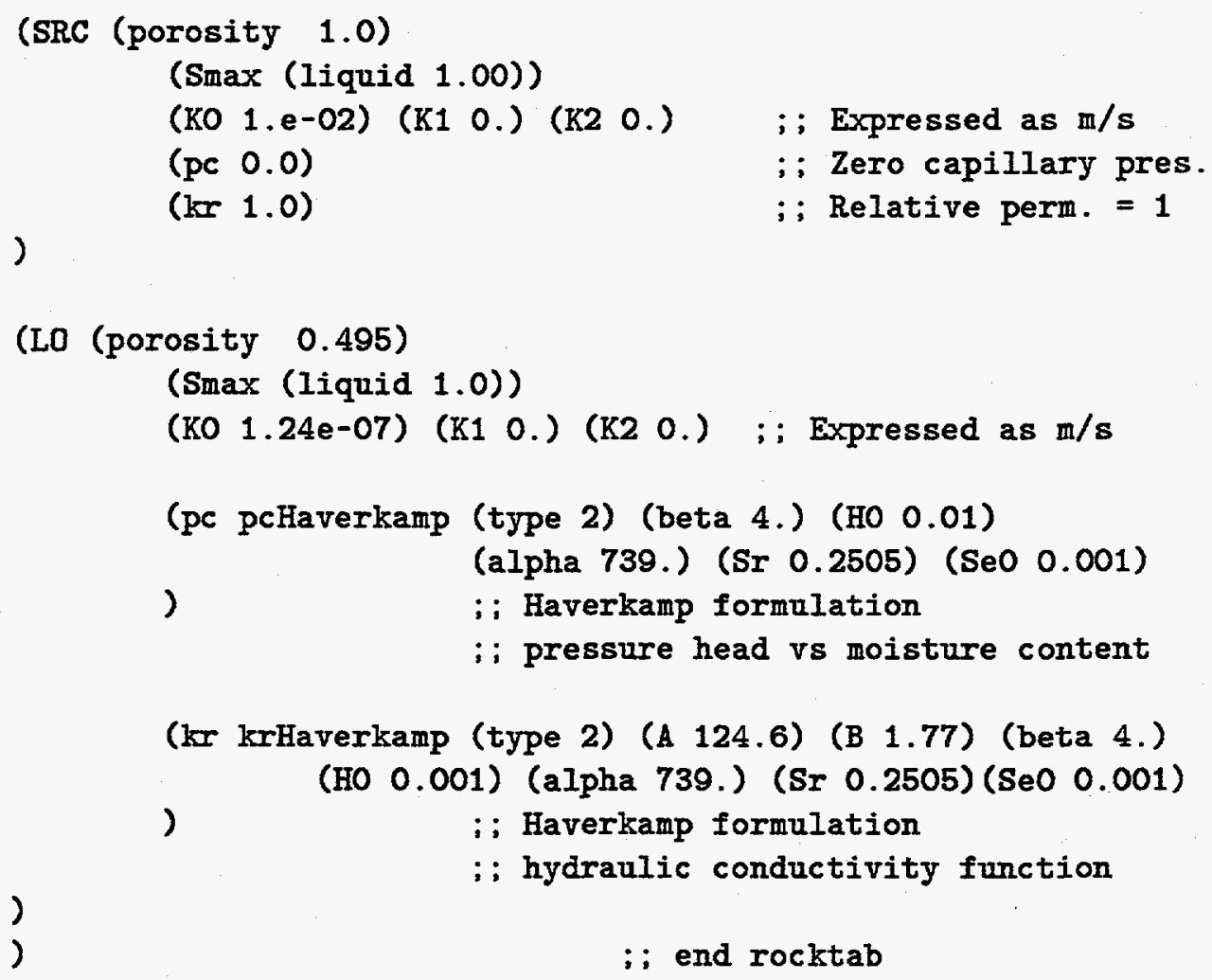


; $; * * * * * * * * * * * * * * * * * * * * * * * * * * * * * * * * * * * * * * * * * * * * * * * * * * * * * * * * * * * * * * * * *$

; ; set boundary conditions

(bctab ; ; maximum saturation in source element

(src

(range "S*")

i i source at saturation

(factor (water $0.0 \quad 1.0 \quad 4 h \quad 1.0)$ )

(tables

(s1 $0.1 .001 . e 301.00)$

(H $\quad 0.0 .00 \quad 1 . e 30 \quad 0.00)$

)

)

) ; ; end bctab

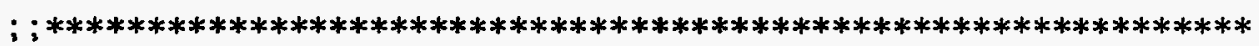

;; set initial conditions

(state

(S1 by-key ("S*" 1.00) ("L*" 0.4808))

(H by-key ("*" 0.00$)$ )

)

; ; end state

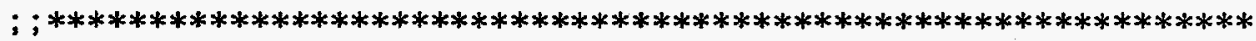
)

;: end of input

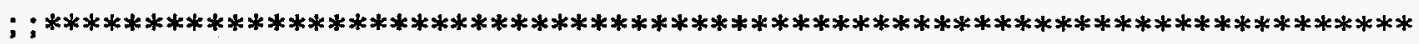

\subsection{Problem BI-1: Vertical Flow in a Laboratory Soil Column with Ponding.}

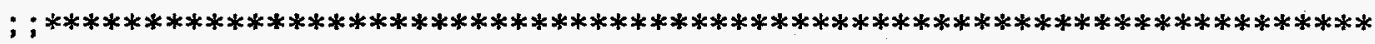

; ; Benchmark problem BI-1. VERTICAL FLOW IN LABORATORY SOIL COLUMN,

; ; WITH PONDING.

$; ; ;$ run $\operatorname{rn} 1 ; ; ;$

; ; file created $9-15-92$.

; ; modified 4-1-93. 


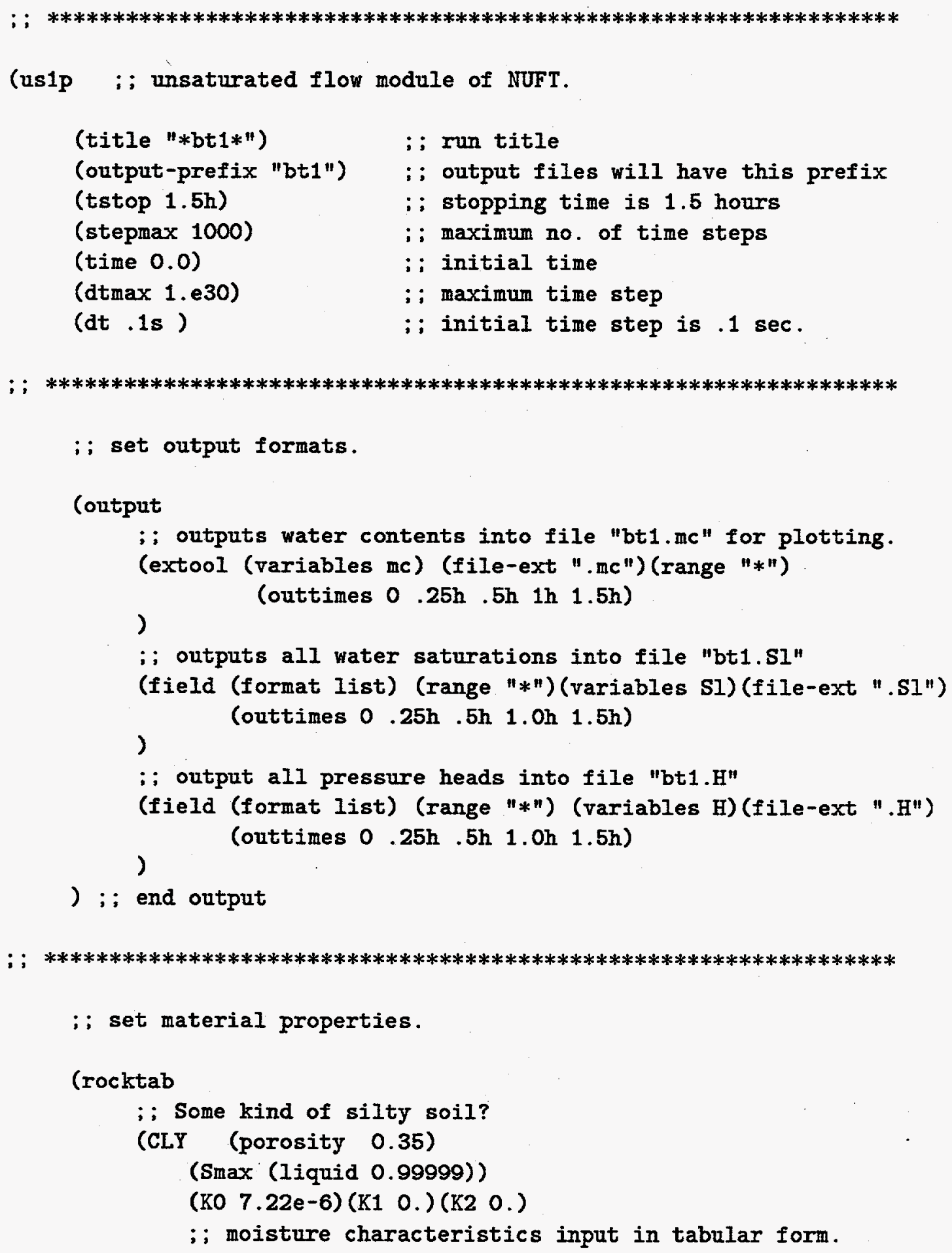


$\begin{array}{lllllllllllll}\text { (pe peTable (table } & .08 & 2.0 & .177 & 1.0 & .243 & .80 & .331 & .60 & .509\end{array}$ $\left.\begin{array}{lllllllll}.40 & .757 & .20 & .874 & .10 & 1.00 & 0.0 & 0\end{array}\right)$

;: relative hydraulic conductivity fen. in tabular form.

(kr krTable (table .08 $1.0 \mathrm{e}-6.177$ 1.0e-4 .286 $1.0 \mathrm{e}-3 \quad .429$

$\begin{array}{llllllllllll}1 . e-2 & .500 & .03 & .571 & .082 & .643 & .225 & .714 & .55 & .786 & .886 & .821\end{array}$

$\begin{array}{lllllllll}.963 & .857 & .992 & .874 & .997 & 1.00 & 1.00))\end{array}$

)

) ;: end rocktab

; ; set boundary conditions.

(bctab

(top

(range " $T *$ ")

;; set top element to constant pressure head of $.0075 \mathrm{~m}$.

(tables

(S1 $0 . .99999 \quad 1 . e 30.99999)$

(H $\quad 0 . \quad .0075 \quad 1 . e 30 \quad .0075)$

)

)

(bottom

(range "B*")

; ; set bottom element to constant sat. of $.129(\mathrm{mc}=.045)$. (tables

(SI $0 . .129 \quad 1 . e 30 \quad .129)$

(H $0.0 .1 . e 30$ 0.) ; ; dummy pressure heads.

)

) ;; end bctab.

$* * * * * * * * * * * * * * * * * * * * * * * * * * * * * * * * * * * * * * * * * * * * * * * * * * * * * * * * * * * * * * * * * * * * * * * * * * * * *$

; ; initial conditions.

(state

; ; top node saturated, all other nodes at $S=0.129$.

(S1 by-key ("T*" .99999) ("B*" 0.129) ("I*" .129)

)

(H by-key ("T*" 0.0075) ("B*" 0.$)(" I * " 0$.

) 


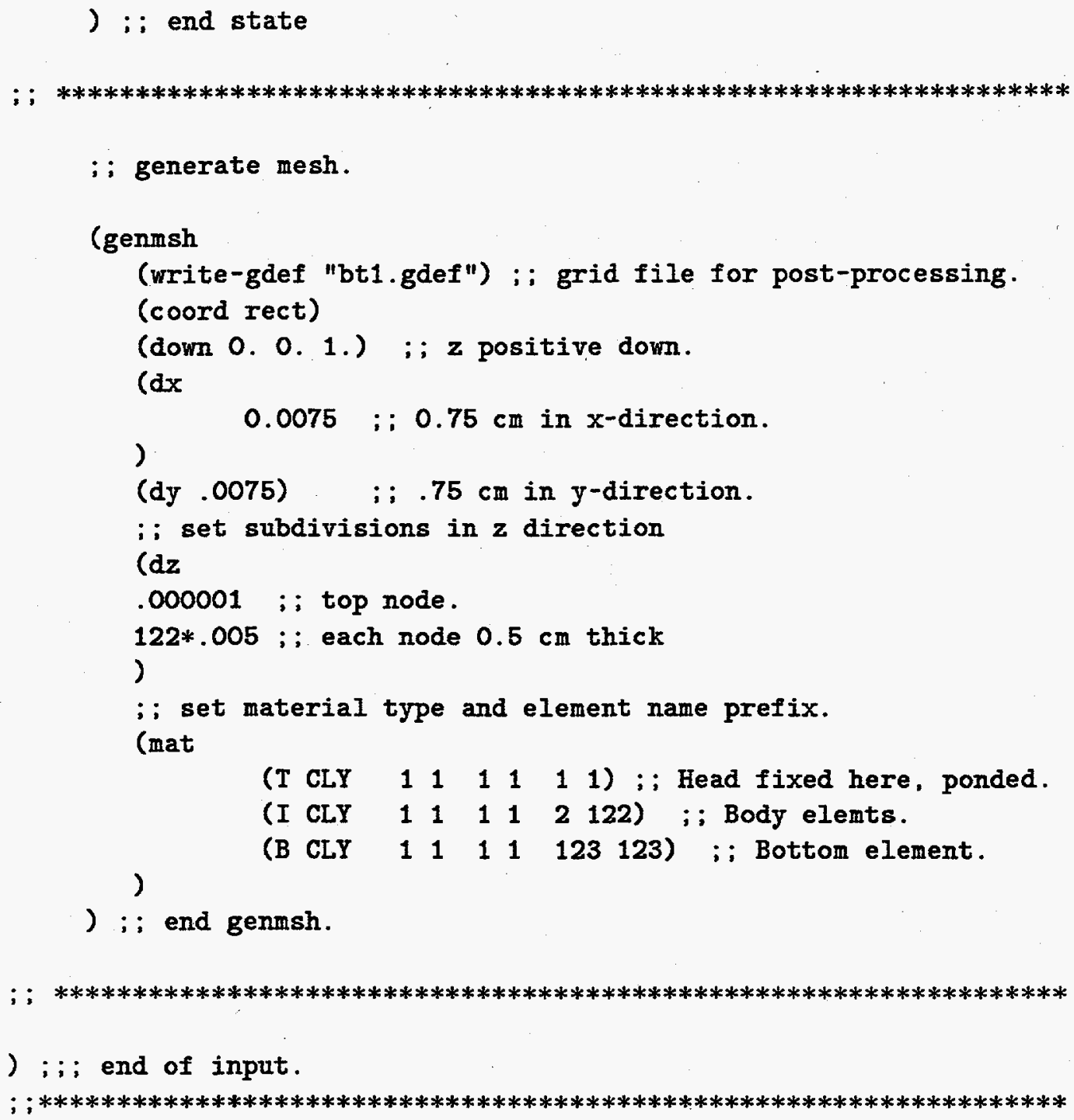

\subsection{Problem BI-2: Infiltration in a Stratified Vadose Zone.}

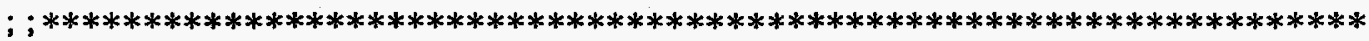

; ; file: bt2

;; PROBLEM BI-2: INFILTRATION IN A STRATIFIED VADOSE ZONE.

;; Reference: Huyakorn et al., 1984. WRR, Vol 20 No. 8, pp 1099-1115.

; : file created $11 / 2 / 92$.

i; modified 4-2-93. 
;: initial run to establish steady-state conditions.

; ; a restart run will generate transient.

; ; $* * * * * * * * * * * * * * * * * * * * * * * * * * * * * * * * * * * * * * * * * * * * * * * * * * * * * * * * * * * * * * * * * * * * * * * * *$

(us1p ;; unsaturated flow module of NUFT.

(title "*bt2*")

(output-prefix "bt2")

(tstop 2000y)

(stepmax 10000)

(time 0.0 )

(dtmax 1.e30)

(dt 1m)

(tolerdt $0.02 \quad .02$ )
;: run title

;; output file prefix

; ; stopping time is 2000 years

;; maximum number of time steps

;; start time

; ; maximum time step size

$\because$ initial time step $=1 \mathrm{~min}$

;; time step tolerance

$; \quad * * * * * * * * * * * * * * * * * * * * * * * * * * * * * * * * * * * * * * * * * * * * * * * * * * * * * * * * * * * * * * * * * * * * * * *$

;; set output formats.

Coutput

; ; outputs water contents and saturations for extool plotting.

(extool (variables mc Sl) (file-ext ".mcSl") (range "*")

)

(outtimes $010 \mathrm{y} 50 \mathrm{y} 100 \mathrm{y} 200 \mathrm{y} 500 \mathrm{y} 1000 \mathrm{y} 2000 \mathrm{y}$ )

;; output data for restart run, beginning at $2000 \mathrm{yr}$.

(restart

(file "bt2rst")

(outtimes 2000y)

)

) ; ; end output

; $; * * * * * * * * * * * * * * * * * * * * * * * * * * * * * * * * * * * * * * * * * * * * * * * * * * * * * * * * * * * * * * * * * * * * * * * * * * *$

; ; set material properties.

(rocktab

; ; sand properties. 


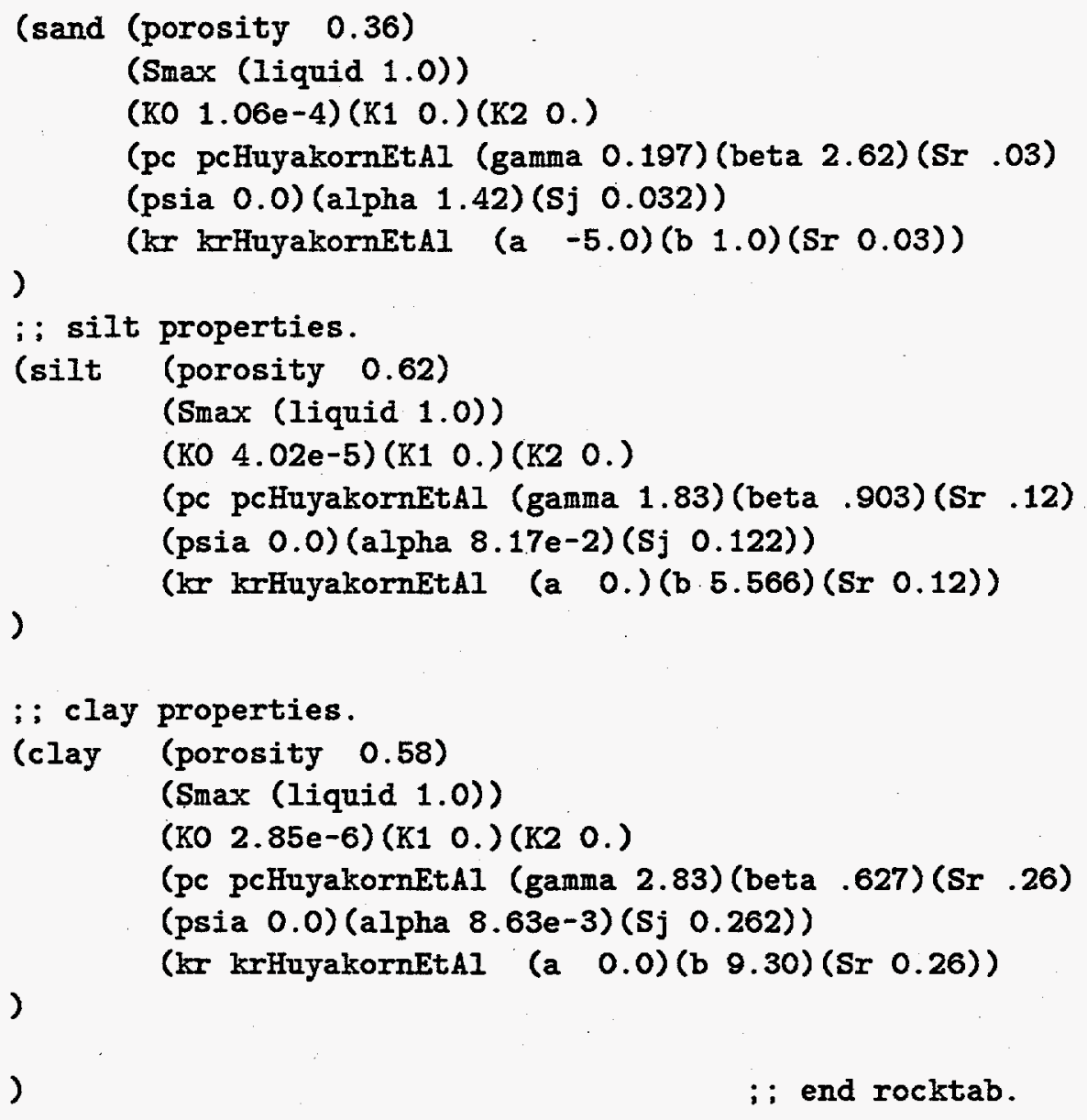

; $\quad * * * * * * * * * * * * * * * * * * * * * * * * * * * * * * * * * * * * * * * * * * * * * * * * * * * * * * * * * * * * * * * * * * * * * * * * * *$

;; generate mesh.

(genmsh

(write-gdef "bt2.gdef") ;; grid file for post-processing.

(coord rect)

(down 0.0.1.)

; ; rect coordinates.

(dx 1.0)

;; gravity on, $z$ positive down.

(dy 1.0)

$; ; d x$ and dy constant at $1.0 \mathrm{~m}$.

(dz

.00001

; ; upper boundary node.

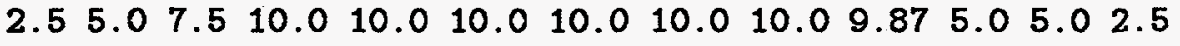
$\begin{array}{lllll}1.25 & .65 & .35 & .25\end{array}$ 
i; sand ends here, node no. 19

;; silt starts here, node no. 20

$\begin{array}{lllllllllllllll}.25 & .35 & .65 & 1.25 & 2.50 & 5.0 & 9.87 & 9.87 & 5.0 & 2.5 & 1.25 & .65 & .35 & .25\end{array}$

$.13 \quad ;$; silt ends here, node no. 35

.13

;; sand starts here, node no. 36

$\begin{array}{lllllllllllllll}.25 & 35 & 65 & 1.25 & 2.5 & 5.0 & 9.87 & 10.0 & 10.0 & 10.0 & 10.0 & 10.0 & 10.0\end{array}$

$10.010 .0 \quad 10.010 .010 .010 .010 .010 .0 \quad 10.0 \quad 10.0 \quad 10.010 .0$

$10.010 .010 .010 .010 .010 .010 .010 .0 \quad 9.87 \quad 5.0 \quad 2.5 \quad 1.25$

$\begin{array}{lll}0.65 & 0.35 & 0.25\end{array}$

.13

;; sand ends here, node no 77

.13

; ; clay starts here, node no. 78

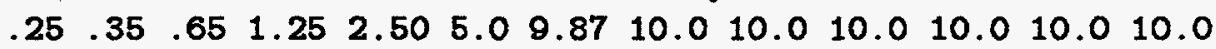

10.010 .010 .010 .010 .010 .010 .010 .010 .010 .010 .010 .0

$\begin{array}{llllllllllllll}10.0 & 10.0 & 10.0 & 10.0 & 5.0 & 5.0 & 2.5 & 2.0 & 1.5 & 1.0 & 0.5 & 0.5 & 0.5 & 0.5\end{array}$

$\begin{array}{llllll}.25 & .25 & .2 & .1 & .1\end{array}$

.1

;; clay ends here, node no. 123

.00001

;; bottom bdry node, no. 124

)

;; set material type and element name prefix

(mat

\begin{tabular}{|c|c|c|c|c|}
\hline ( $t$ sand & 11 & 11 & $11)$ & ; ; top most element \\
\hline (a sand & 11 & 11 & $219)$ & ; ; upper sand layer \\
\hline (b silt & 11 & 11 & $2035)$ & ;; silt layer \\
\hline (c sand & 11 & 11 & $3677)$ & ; ; lower sand layer \\
\hline (d clay & 11 & 11 & 78 123) & ; ; clay \\
\hline (1 clay & 11 & 11 & $124124)$ & ; ; bottom layer \\
\hline
\end{tabular}

; $\quad * * * * * * * * * * * * * * * * * * * * * * * * * * * * * * * * * * * * * * * * * * * * * * * * * * * * * * * * * * * * * * * * * * * * * * * * *$

;; specify source at upper boundary node.

(srctab

; ; input volumetric rate here $(\mathrm{m} * * 3 / \mathrm{sec})$.

(compflux water

(range " $t * "$ ) 


\section{(name t1)}

(table $0.0 \quad 5.073567 e-091.0 e 6 y \quad 5.073567 e-09$ )
)
)
; ; end srctab.

; ; $* * * * * * * * * * * * * * * * * * * * * * * * * * * * * * * * * * * * * * * * * * * * * * * * * * * * * * * * * * * * * * * * * *$

; ; specify boundary conditions.

(bctab

(bot

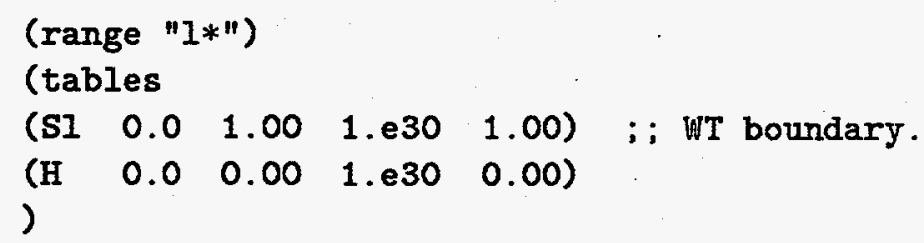

;: end bctab.

; ; $* * * * * * * * * * * * * * * * * * * * * * * * * * * * * * * * * * * * * * * * * * * * * * * * * * * * * * * * * * * * * * * * * * * * *$

;: set initial conditions.

(state

$$
\begin{aligned}
& \text { (Sl by-key ("t*" } 0.04)(" a * " 0.04)(" b * " 0.2) \\
& (" c * " 0.04)(" d * " .35)(" 1 * " 0.35)) \\
& (H \text { by-key }(" * " 0.00)) \quad \text {; ; end state }
\end{aligned}
$$$$
\text { ) }
$$

; ; $* * * * * * * * * * * * * * * * * * * * * * * * * * * * * * * * * * * * * * * * * * * * * * * * * * * * * * * * * * * * * * * * * * * * * * *$ 


\subsection{Problem BI-2: Infiltration in a Stratified Vadose Zone, Run 2.}

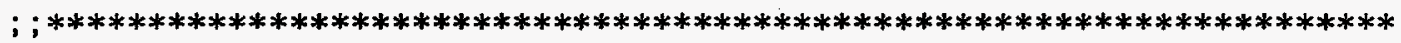
;; PROBLEM BI-2: INFILTRATION IN A STRATIFIED VADOSE ZONE.

;; Reference: Huyakorn et al., 1984. WRR, Vol 20 No. 8, pp 1099-1115.

; ; file created $11 / 2 / 92$.

; ; modified 4-2-93.

; : restart run to generate transient.

; ; $* * * * * * * * * * * * * * * * * * * * * * * * * * * * * * * * * * * * * * * * * * * * * * * * * * * * * * * * * * * * * * * * * * *$

(us1p ; ; unsaturated flow and transport module of NUFT.

(title "*bt21*")

(output-prefix "bt21")

(tstop 40y)

(stepmax 10000)

(time 0.0 )

(dtmax 1.e30)

(dt 1)

(tolerdt 0.01 .01)
;; run title

i; output file prefix

;: stopping time is 40 years

$; ;$ max number of time steps

;; start time

;; maximum time step size

;; initial time step $=1 \mathrm{sec}$

$;$; time step tolerances

; ; read restart data from earlier run that established

;: steady-state condition.

(read-restart (file "bt2rst")

(time 2000y))

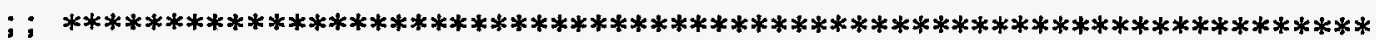

;: set output formats.

Coutput

i; output water contents and saturations for extool plotting.

(extool (variables mc SI) (file-ext ".SI")(range "*")

(outtimes $08 \mathrm{y} 40 \mathrm{y}$ )

)

)

; ; end output 


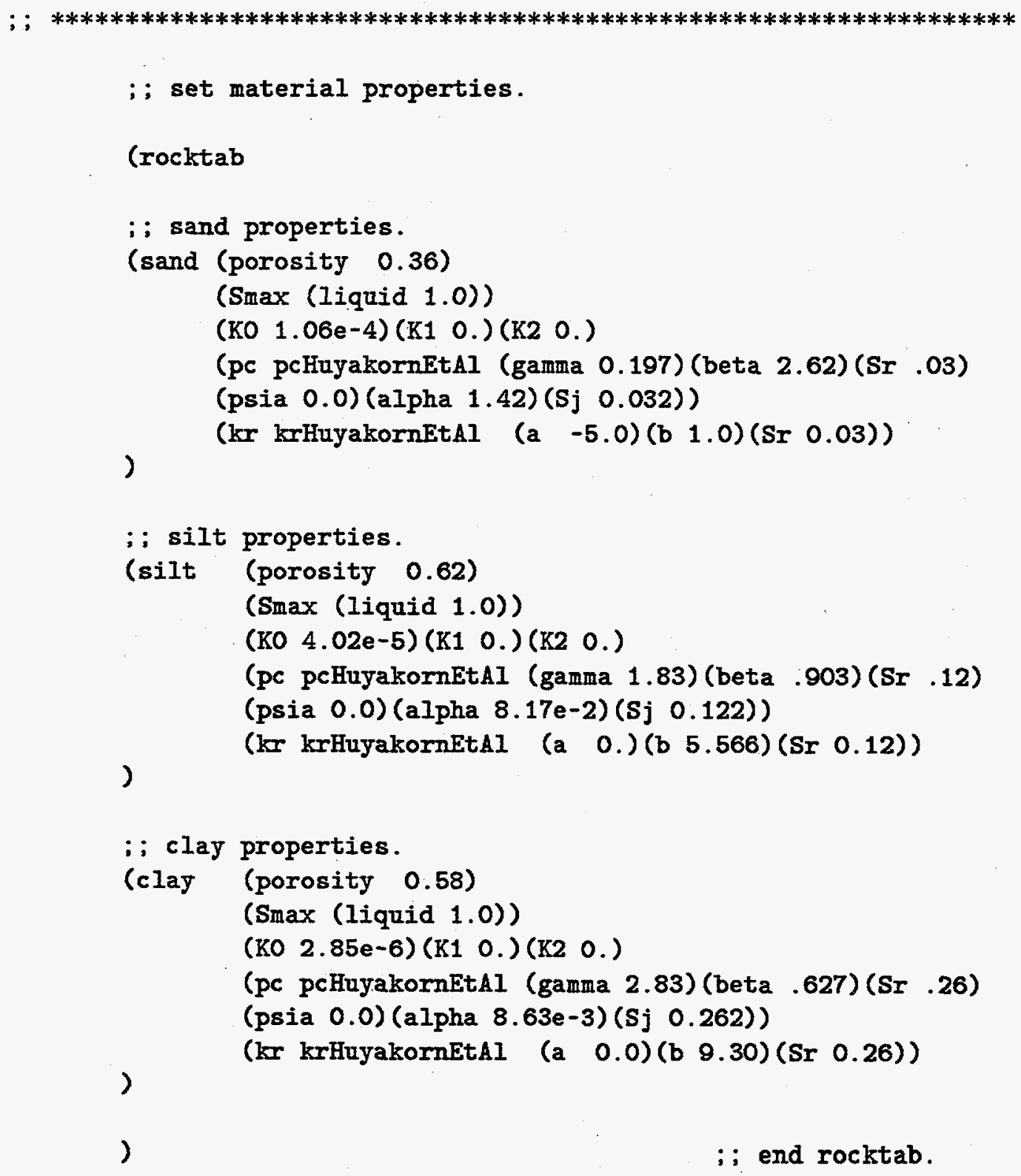


(down 0. 0. 1.)

$(\mathrm{dx} 1.0)$

(dy 1.0)

(dz

.00001

$2.5 \quad 5.07 .510 .010 .010 .010 .010 .010 .0 \quad 9.87 \quad 5.0 \quad 5.02 .5$

$\begin{array}{lllll}1.25 & .65 & .35 & .25\end{array}$

0.13

.13

$\begin{array}{lllll}.25 & .35 & .65 & 1.25\end{array}$

.13

.13

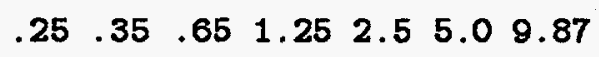

$10.0 \quad 10.0 \quad 10.010 .0 \quad 10.0 \quad 10.0 \quad 10.0 \quad 10.0 \quad 10.0 \quad 10.0 \quad 10.0 \quad 10.0$

$\begin{array}{llllllllllll}10.0 & 10.0 & 10.0 & 10.0 & 10.0 & 10.0 & 10.0 & 10.0 & 9.87 & 5.0 & 2.5 & 1.25\end{array}$

$\begin{array}{llll}0.65 & 0.35 & 0.25\end{array}$

.13

.13

;; sand ends here, node no 77

; ; clay starts here, node no. 78

$\begin{array}{llllllllllllll}.25 & 35 & 65 & 1.25 & 2.50 & 5.0 & 9.87 & 10.0 & 10.0 & 10.0 & 10.0 & 10.0 & 10.0\end{array}$

$10.010 .010 .010 .010 .0 \quad 10.010 .0 \quad 10.010 .0 \quad 10.0 \quad 10.010 .0$

$\begin{array}{llllllllllllll}10.0 & 10.0 & 10.0 & 10.0 & 5.0 & 5.0 & 2.5 & 2.0 & 1.5 & 1.0 & 0.5 & 0.5 & 0.5 & 0.5\end{array}$ $\begin{array}{lllllllll}.25 & .25 & .2 & .1 & .1\end{array}$

.1

.00001

;; clay ends here, node no. 123

;; bottom bdry node, no. 124

)

;: set material type and element name prefix (mat

\begin{tabular}{|c|c|c|c|c|c|}
\hline (t sand & 1 & 1 & 1 & 11) & ; ; top most element \\
\hline (a sand & 11 & 1 & 1 & (2 19) & ; ; upper sand layer \\
\hline (b silt & 11 & 1 & 1 & $2035)$ & ; ; silt layer \\
\hline (c sand & 11 & 1 & 1 & $3677)$ & ; ; lower sand layer \\
\hline (d clay & 11 & 1 & 1 & 78 123) & : : clay \\
\hline (1 clay & 11 & 1 & 1 & 124 124) & ; ; bottom layer \\
\hline
\end{tabular}




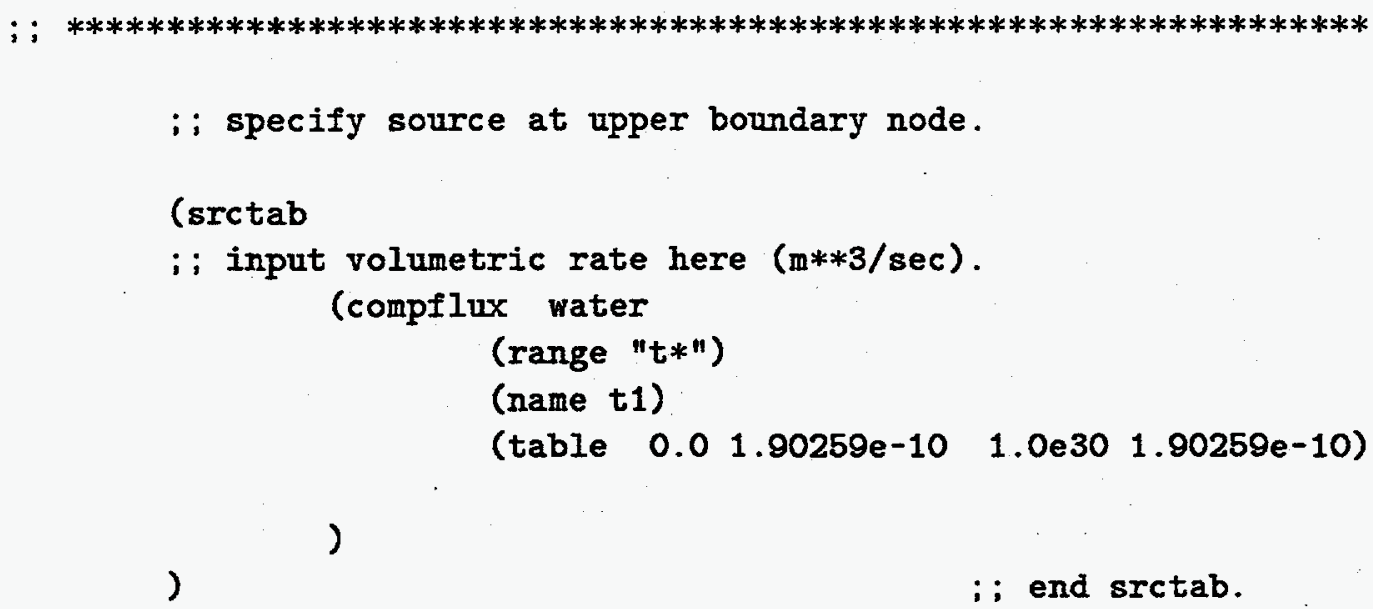

\subsection{Problem BI-3: Partially Saturated Flow in Basalt.}

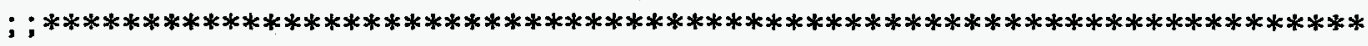

; ; problem BI-3: partially saturated flow in basalt.

; ; benchmarking problem BT-3 from Idaho National Eng. Lab. (INEL)

;: last modified Mar 23, 1993 


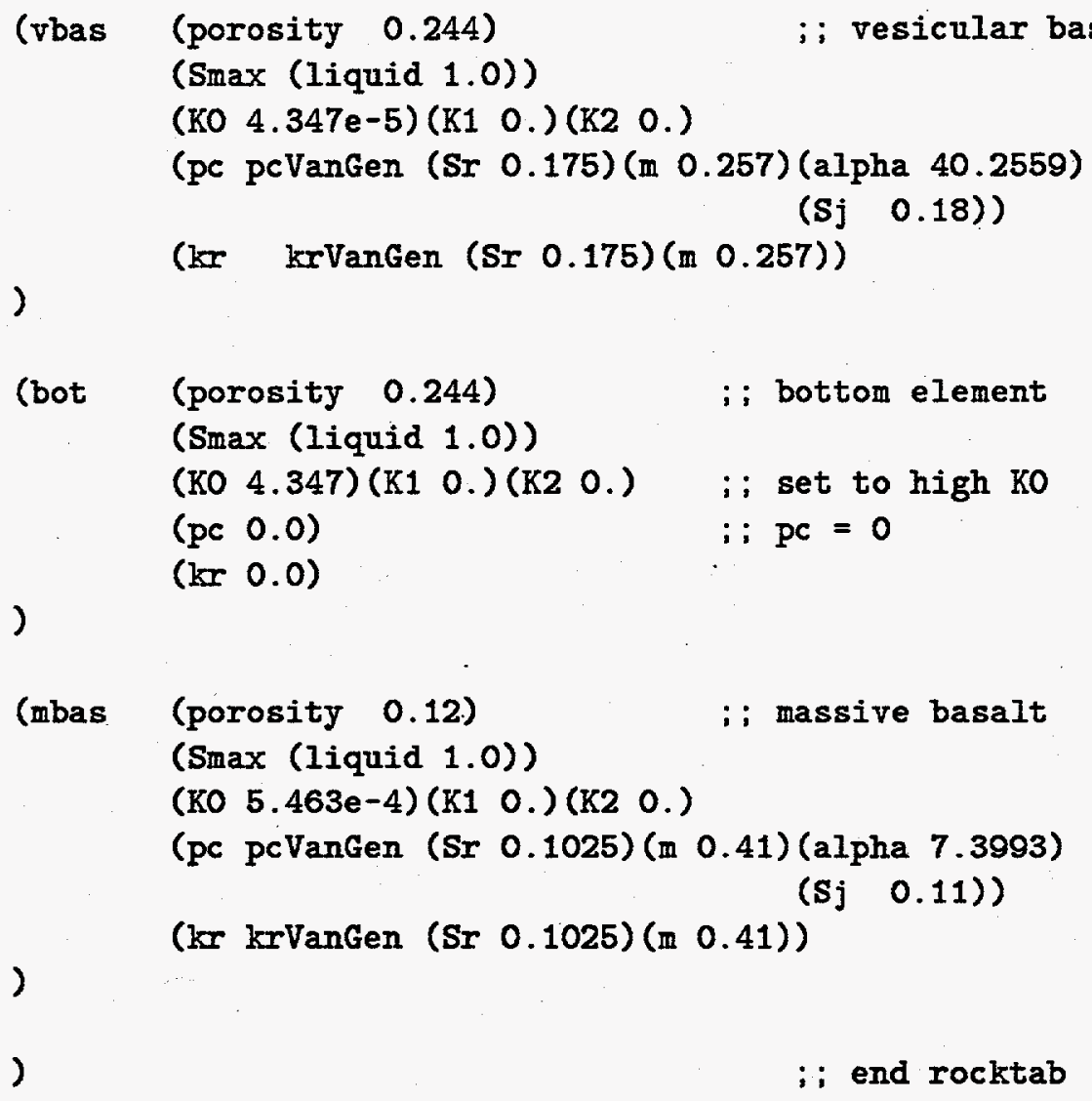

(genmsh

(write-gdef "bt3-uw1.0.gdef")

(coord cylind)

(down 0.0.1.)

(dx 1.0)

(dy 360.)

(dz
;; mesh generation routine

;; cylinder along $z$ coordinate

;; gravity on (z-dirn.)

;; column radius $1.0 \mathrm{~m}$

$: ;$ angle subdivision (degrees)

$\begin{array}{lllllllllll}0.01 & 0.015 & 0.025 & 0.025 & 0.025 & 0.05 & 0.05 & 0.1 & 0.2 & \text {; ; Wast } 1-18\end{array}$

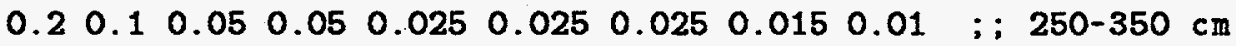

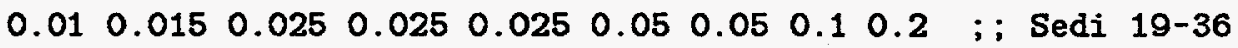

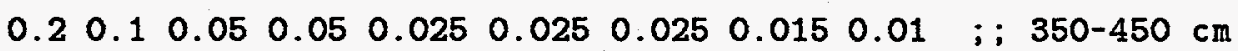




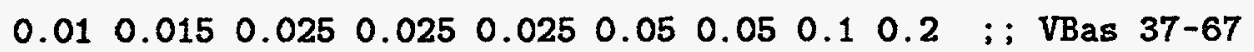

$0.250 .4 \quad 0.5 \quad 1.01 .5 \quad 1.5 \quad 1.5$

$\begin{array}{llllll}1.5 & 1.5 & 1.0 & 0.5 & 0.4 & 0.25\end{array}$

$\begin{array}{lllllllll}0.2 & 0.1 & 0.05 & 0.05 & 0.025 & 0.025 & 0.025 & 0.015 & 0.01\end{array} ;$ : $450-1730 \mathrm{~cm}$

$0.010 .0150 .0250 .0250 .0250 .050 .050 .1 \quad 0.20 ; ;$ MBas $68-91$

$\begin{array}{lll}0.4 & 0.5 & 0.95\end{array}$

$\begin{array}{lll}0.95 & 0.5 & 0.4\end{array}$

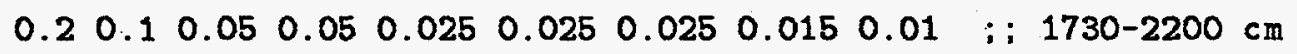

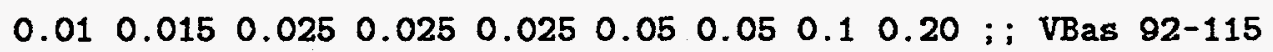

$\begin{array}{lll}0.4 & 0.5 & 0.75\end{array}$

$\begin{array}{lll}0.75 & 0.5 & 0.4\end{array}$

$\begin{array}{lllllllll}0.2 & 0.1 & 0.05 & 0.05 & 0.025 & 0.025 & 0.025 & 0.015 & 0.01\end{array} ; 2200-2630 \mathrm{~cm}$

$\begin{array}{lllllllll}0.01 & 0.015 & 0.025 & 0.025 & 0.025 & 0.05 & 0.05 & 0.1 & 0.20 ;\end{array}$ : MB $116-141$

$\begin{array}{llll}0.4 & 0.5 & 0.95 & 1.5\end{array}$

$\begin{array}{llll}1.5 & 0.95 & 0.5 & 0.4\end{array}$

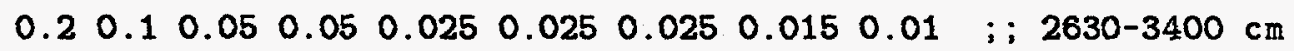

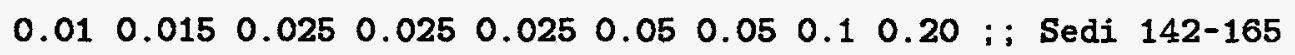

$\begin{array}{lll}0.25 & 0.5 & 0.75\end{array}$

$0.75 \quad 0.5 \quad 0.25$

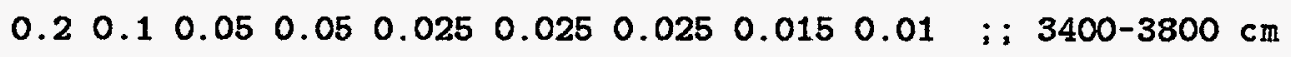

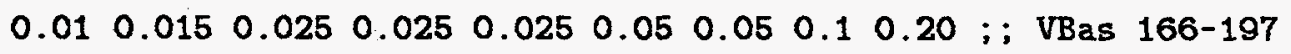

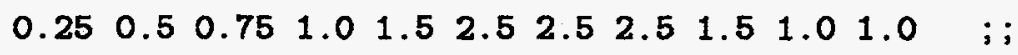

$0.5 \quad 0.25 \quad 0.25$

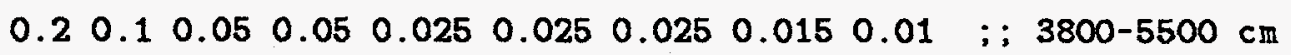
)

;: set material type and element name prefix

(mat

\begin{tabular}{|c|c|c|c|c|c|}
\hline (t top & 11 & 1 & 1 & 1) & ; ; top most element \\
\hline (w wast & 11 & 11 & 2 & 18) & ; ; waste \\
\hline (s sedi & 11 & 11 & 19 & 36) & ; ; sediments \\
\hline （v vbas & 11 & 11 & 37 & 67) & vesicular basalt \\
\hline (m mbas & 11 & 11 & 68 & 91) & massive basalt \\
\hline (v vbas & 11 & $1:$ & 92 & 115) & ;; vesicular basalt \\
\hline (m mbas & 11 & 1 & 116 & 141) & ; ; massive basalt \\
\hline (s sedi & 11 & 11 & 142 & 165) & ; ; sediments \\
\hline
\end{tabular}




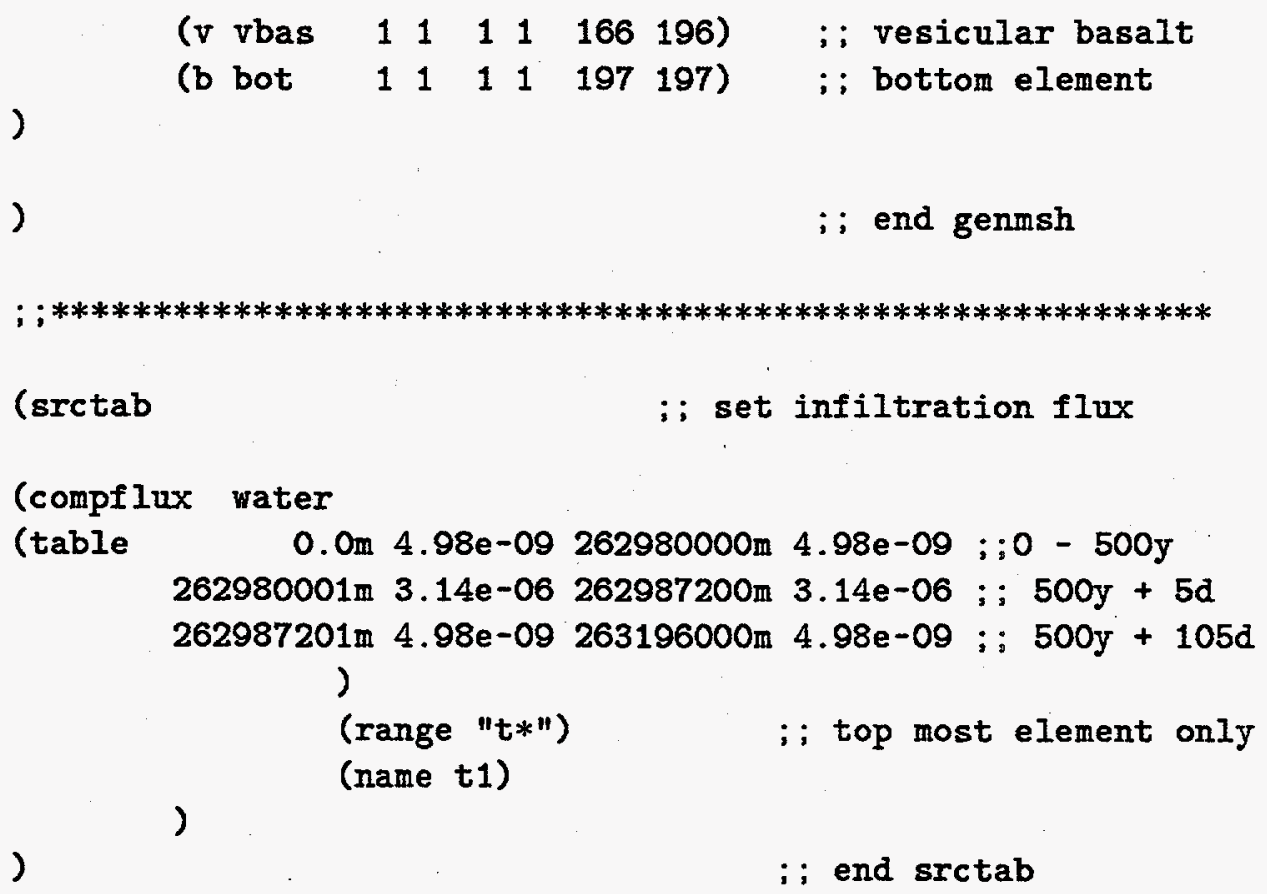

i; boundary conditions

;: free orainage at bottom

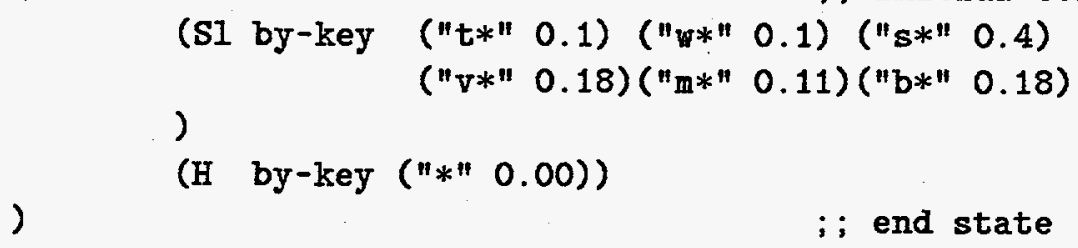




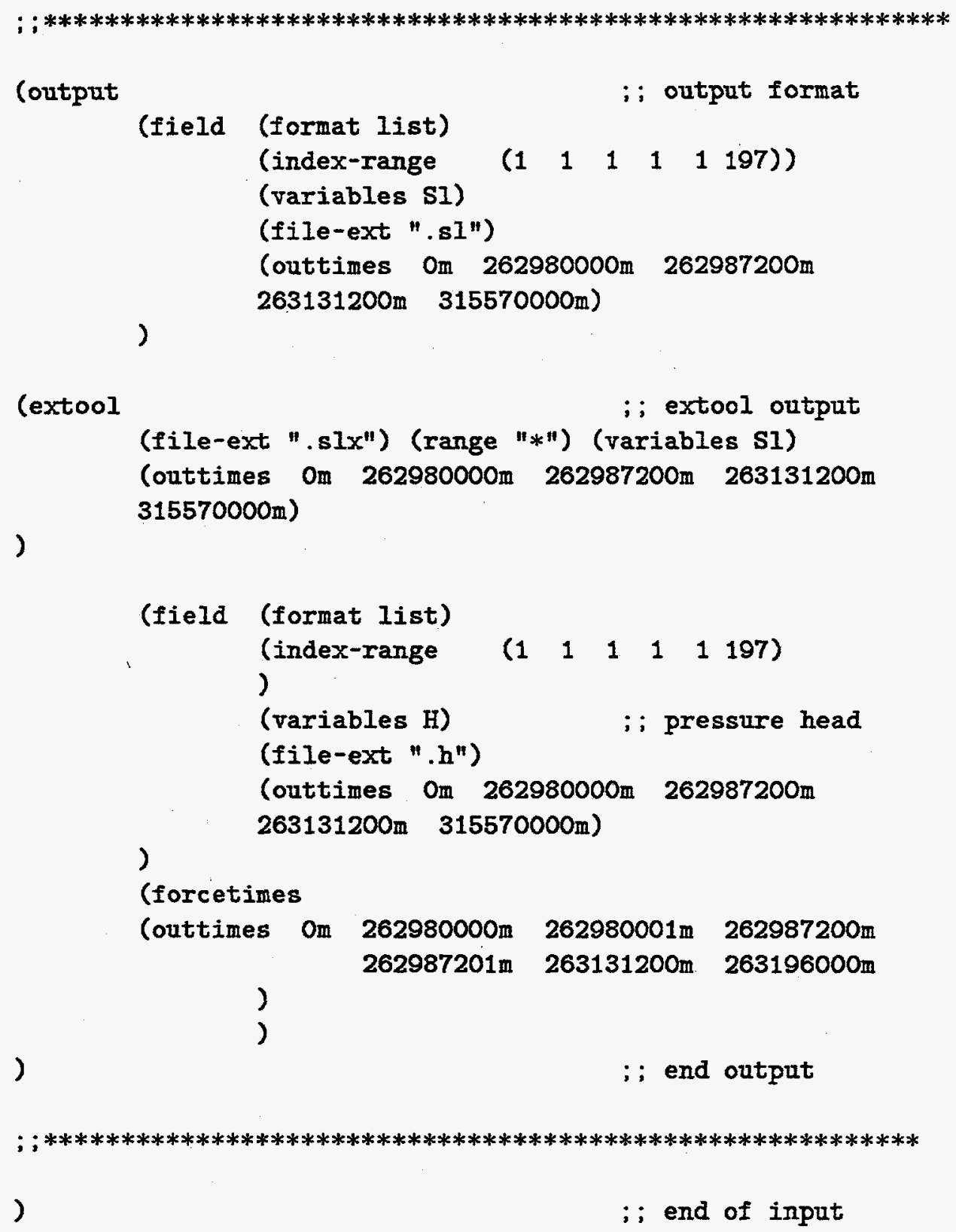

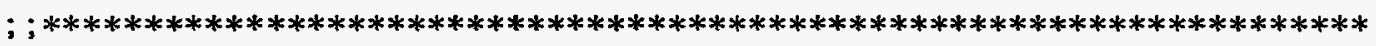




\subsection{Problem VT-1: Heat Conduction with Sinusoidal Boundary Condition.}

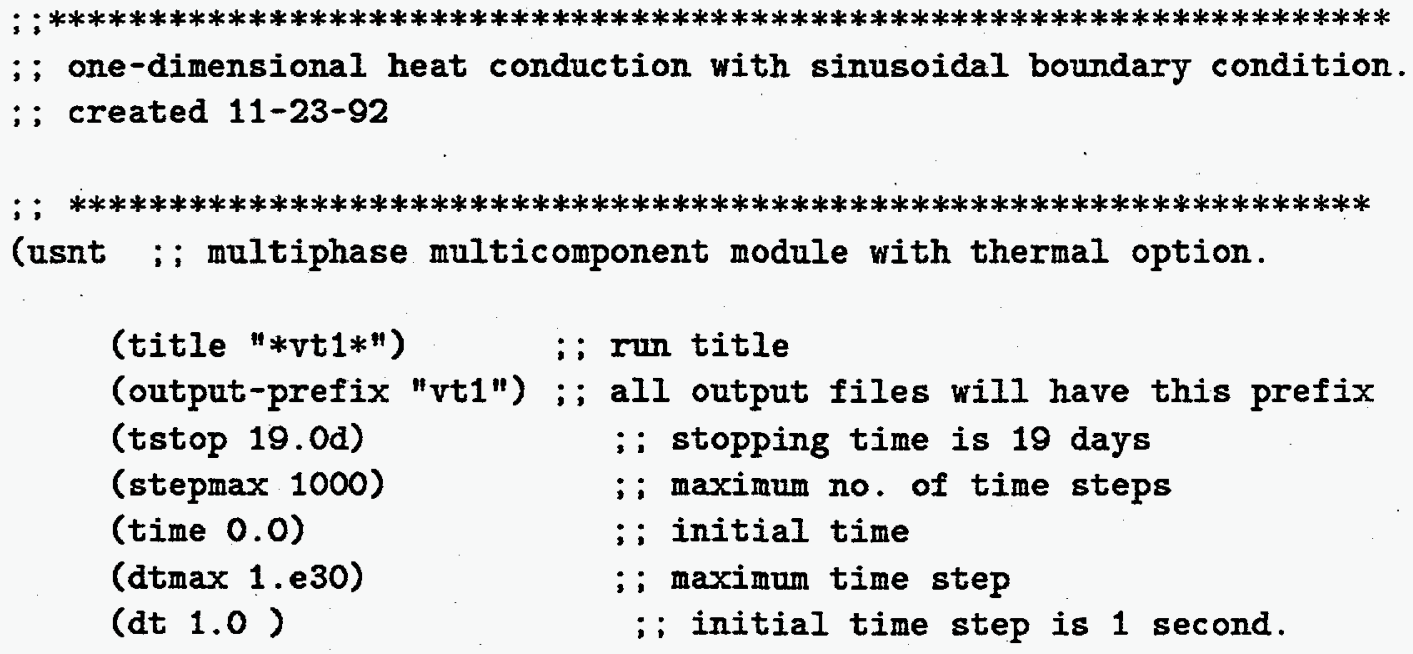




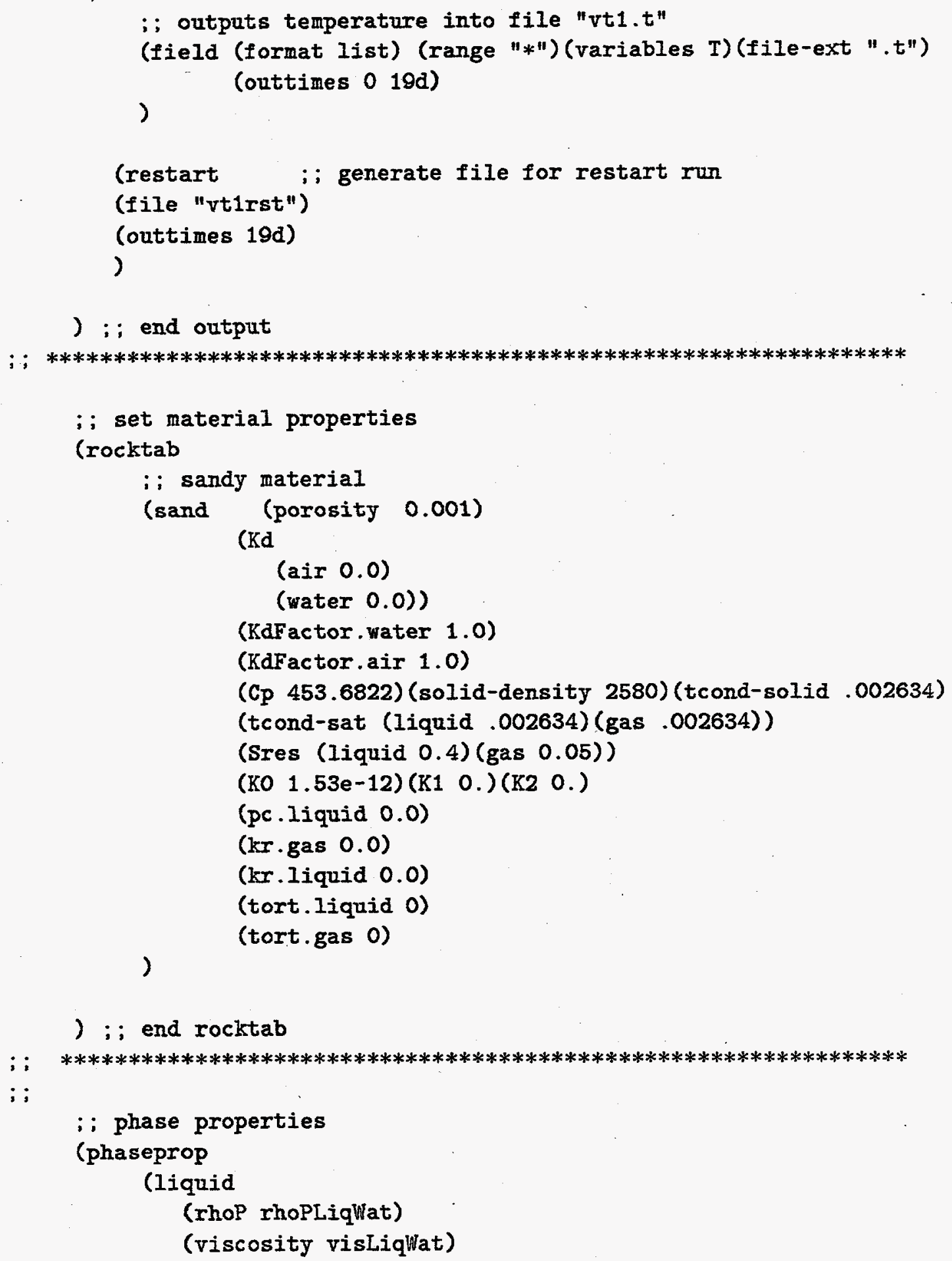


; ;

(tables

(s.liquid $0.25 \quad 1 . e 30 \quad .25)$

( $P \quad 0 . \quad 0.9 \mathrm{e} 51 . \mathrm{e} 30 \quad 0.9 \mathrm{e} 5)$

(C.air $0.1 . e-61 . e 301 . e-6$ )

(T

$0.00000 E+00$

11.952

$0.72000 \mathrm{E}+03$

11.916

$0.14400 \mathrm{E}+04$

11.887

$0.21600 E+04$

11.866

$0.28800 \mathrm{E}+04$

11.854

$0.36000 \mathrm{E}+04$

11.850

$0.43200 \mathrm{E}+04$

11.854

$0.50400 \mathrm{E}+04$

11.866

$0.57600 \mathrm{E}+04$

11.887

$0.64800 \mathrm{E}+04$

11.916

$0.17957 \mathrm{E}+07$

table truncated to save space

$0.17964 \mathrm{E}+07$

; ; must complete table to rerun.

$0.17972 \mathrm{E}+07$

14.998

14.841

14.684

$0.17979 E+07$

14.527

$0.17986 \mathrm{E}+07$

14.372

$0.17993 E+07$

14.217

)

)

; ; keep water table elements at saturated conditions (bot

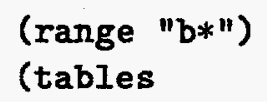

) ; ; end bctab

; ; $* * * * * * * * * * * * * * * * * * * * * * * * * * * * * * * * * * * * * * * * * * * * * * * * * * * * * * * * * * * * * * * * * * * * * *$ 


\section{; initial conditions}

(state

\section{(s. liquid}

)

$$
\text { by-key ("*". } 25)
$$

(c.air

$$
)
$$$$
\text { by-key ("*" 1.e-6) }
$$

(P by-key ("*" 1.e5)) ;; note that bctab will overwite $i ;$ these values by any set there

(T by-key ("*" 14.85))

) $;$; end state

; $* * * * * * * * * * * * * * * * * * * * * * * * * * * * * * * * * * * * * * * * * * * * * * * * * * * * * * * * * * * * * * * * * * * * * * * * * * *$

;: generate mesh

(genmsh

(write-gdef "vt1.gdef")

(coord rect)

; : note that increasing $\mathrm{z}$ coordinate will be downward

(down 0. 0.1.)

;; set subdivisions in radial $r$ direction

(dx .01)

(dy .01)

(dz

$.00001 \quad ;$; top node

$72 * .0025 ; ; .25 \mathrm{~cm}$ thick

) $.00001 ;$; bottom node

;: set material type and element name prefix

(mat

$$
\begin{aligned}
& \text { (t sand } \quad \begin{array}{llllll}
1 & 1 & 1 & 1 & 1 & 1 \text { ) }
\end{array} \text {; ; top boundary element } \\
& \text { (a sand } \begin{array}{llllll}
1 & 1 & 1 & 1 & 2 & 73 \text { ) ; ; body elements }
\end{array} \\
& \text { (b sand } \left.\quad \begin{array}{llllllll}
1 & 1 & 1 & 1 & 74 & 74
\end{array}\right) \text {; ; bottom boundary element } \\
& \text {;; end genmsh }
\end{aligned}
$$

)

$$
)
$$

; ; $\quad * * * * * * * * * * * * * * * * * * * * * * * * * * * * * * * * * * * * * * * * * * * * * * * * * * * * * * * * * * * * * * * * * * * * * * * * *$

) $; ; ;$ end of input

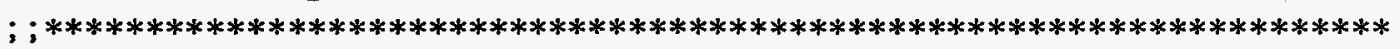


1.7. Problem VT-1: Heat Conduction with Sinusoidal Boundary Condition, Run 2.

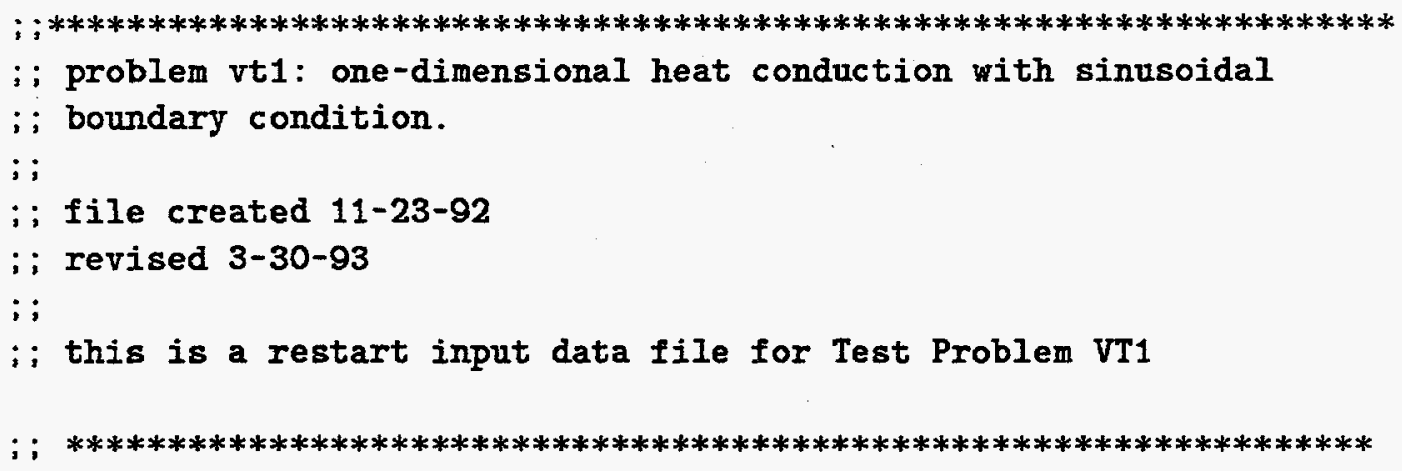

;: read restart data from earlier run that established initial cond.

$$
\begin{aligned}
\text { (read-restart } & (\text { file "vt1rst") } \\
& (\text { time 19d)) }
\end{aligned}
$$

; ; set tolerances.

; ; absolute time step tolerance (tolerdt $1 . e 4 \quad 0.1 \quad 0.1 \quad 0.050 .05 \quad .2$ )

; : relative time step tolerance

(reltolerdt $0.1 \quad 0.0 \quad 0.0 \quad 0.1 \quad 0.10 .02$ )

; ; absolute NR conv. tolerance

(tolerconv 100. 1.e-3 1.e-3 1.e-3 1.e-3 0.001)

; ; absolute $\mathrm{NR}$ conv. tolerance

(reltolerconv $1 . e-30.00 .01 . e-4 \quad 1 . e-4 \quad 1 . e-4)$ 


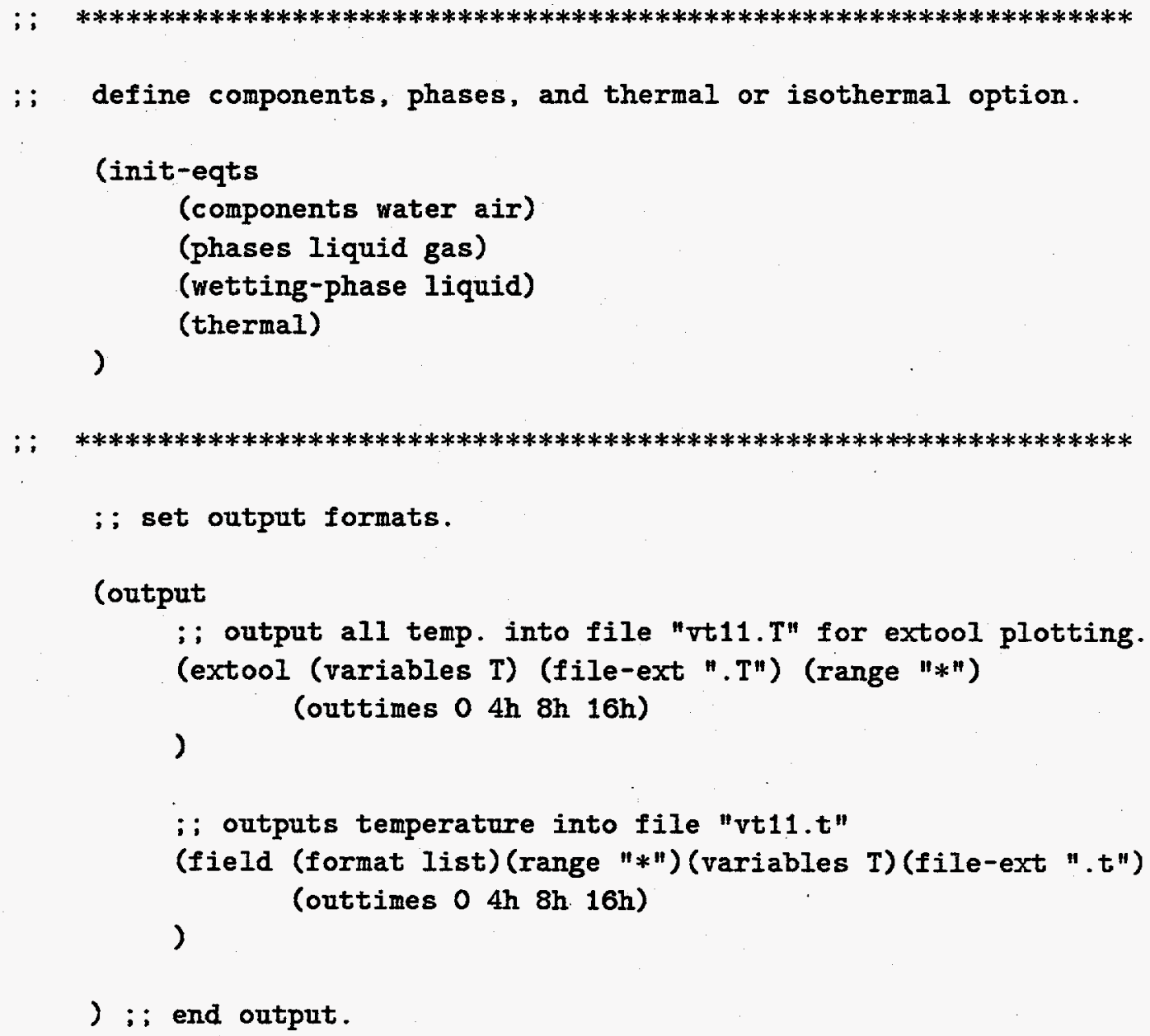

; ; $* * * * * * * * * * * * * * * * * * * * * * * * * * * * * * * * * * * * * * * * * * * * * * * * * * * * * * * * * * * * * * * * * * * * * * * * *$

; ; set material properties.

(rocktab

; ; sandy material

(sand (porosity 0.001) ;; very low porosity here.

(Kd

(air 0.0) ; ; no sorption of air on solid.

(water 0.0$)$ ) :; no water sorption on solid.

(KdFactor.water 1.0) ; ; no temp. modification of Kd.

(KdFactor.air 1.0) ; ; no temp. modification of $\mathrm{Kd}$.

(Cp 453.6822)(solid-density 2580)(tcond-solid .002634)

(tcond-sat (liquid .002634) (gas .002634)) 


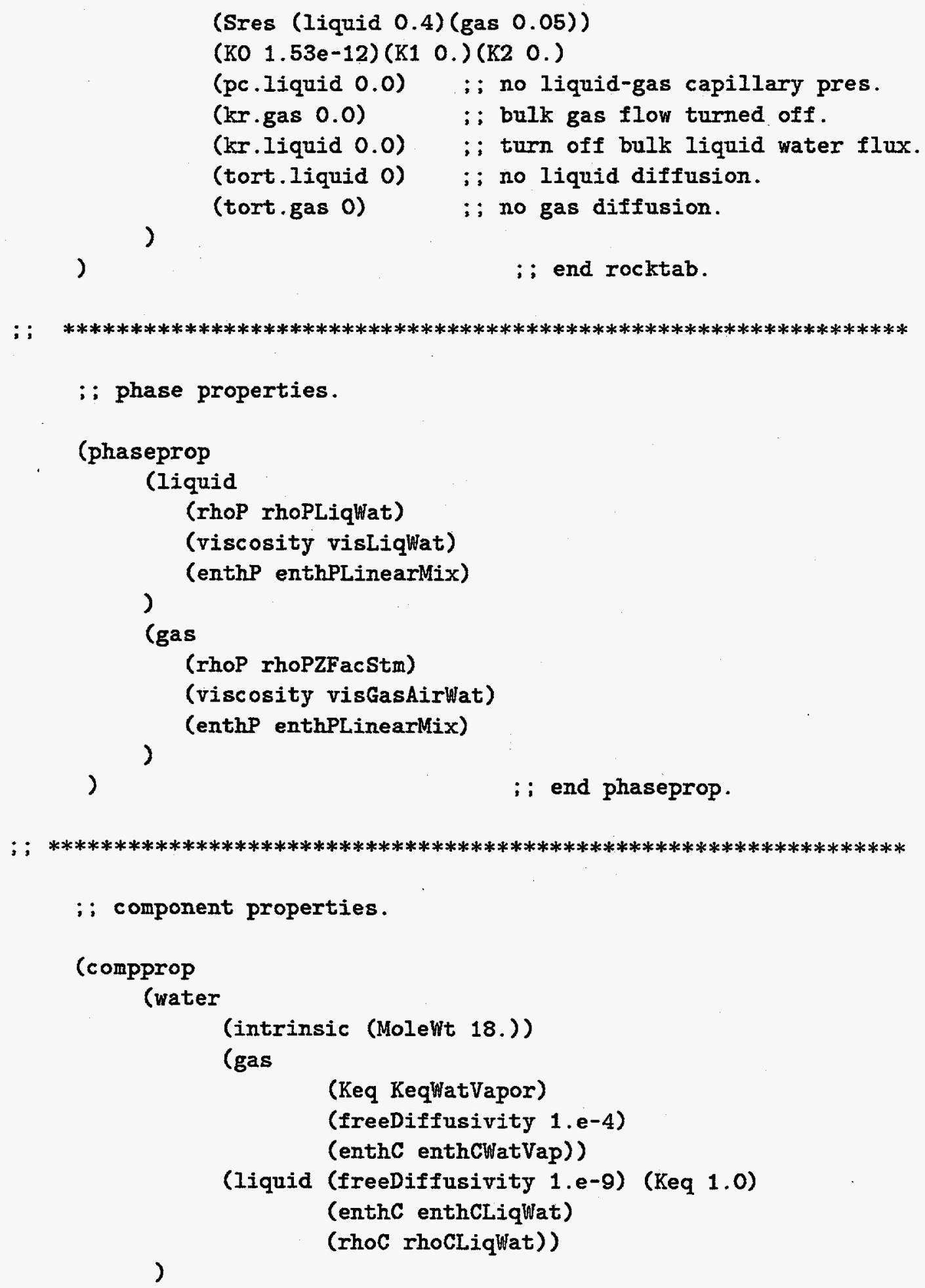




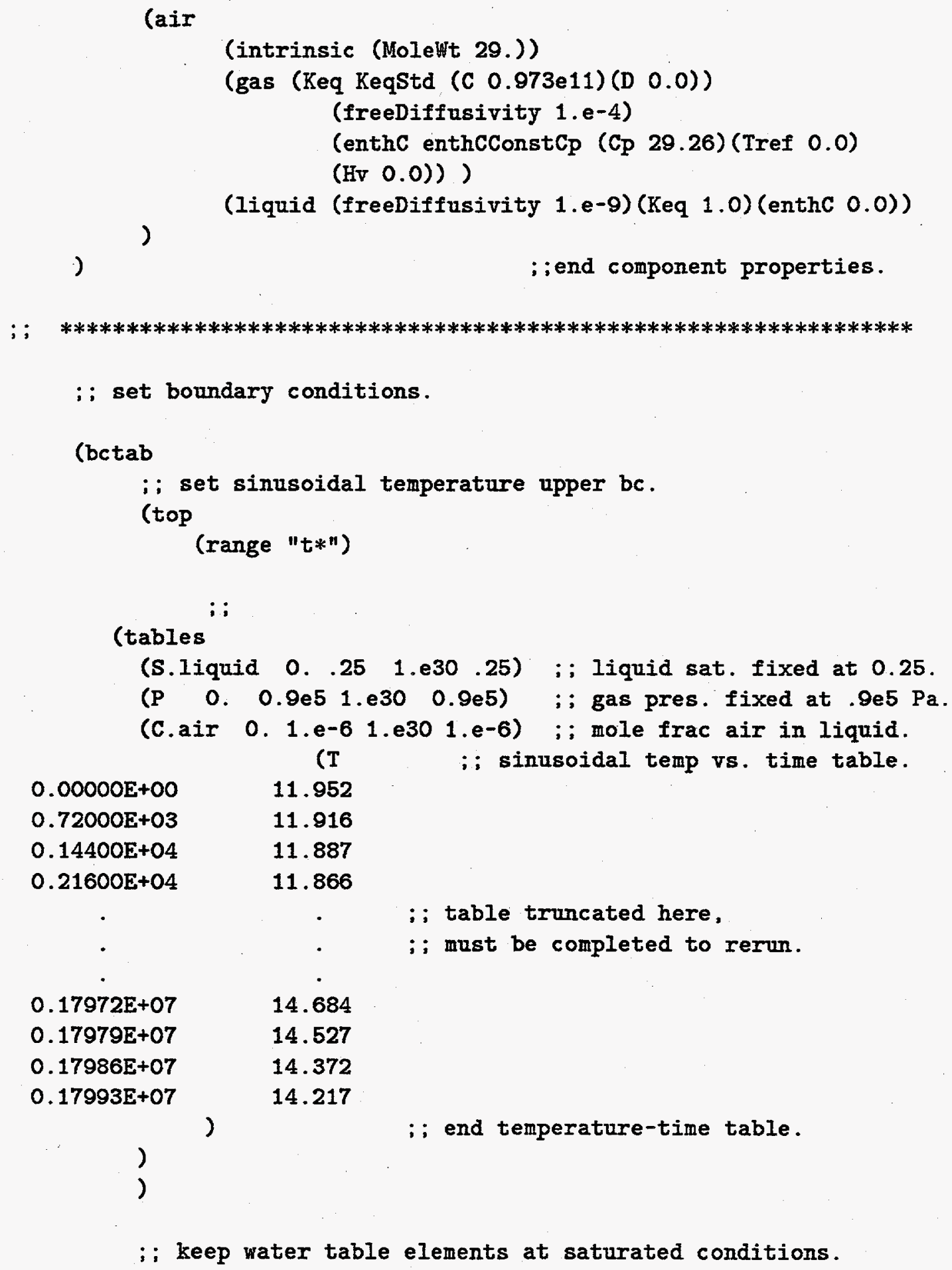


(bot

$$
\text { (range } " b * n \text { ) }
$$

(tables

$$
\begin{aligned}
& \text { (S.liquid } 0.1 .01 . e 301.0) \\
& (P \quad 0.1 . e 51 . e 301 . e 5) \\
& (C . a i r \quad 0.1 . e-61 . e 301 . e-6) \\
& \text { (T } 0.14 .851 . e 3014.85) ;: \text { lower bdry temp set at } \\
& \quad ; \text {; init value of } 14.85 \mathrm{C} . \\
& ; ; \text { end bctab. }
\end{aligned}
$$

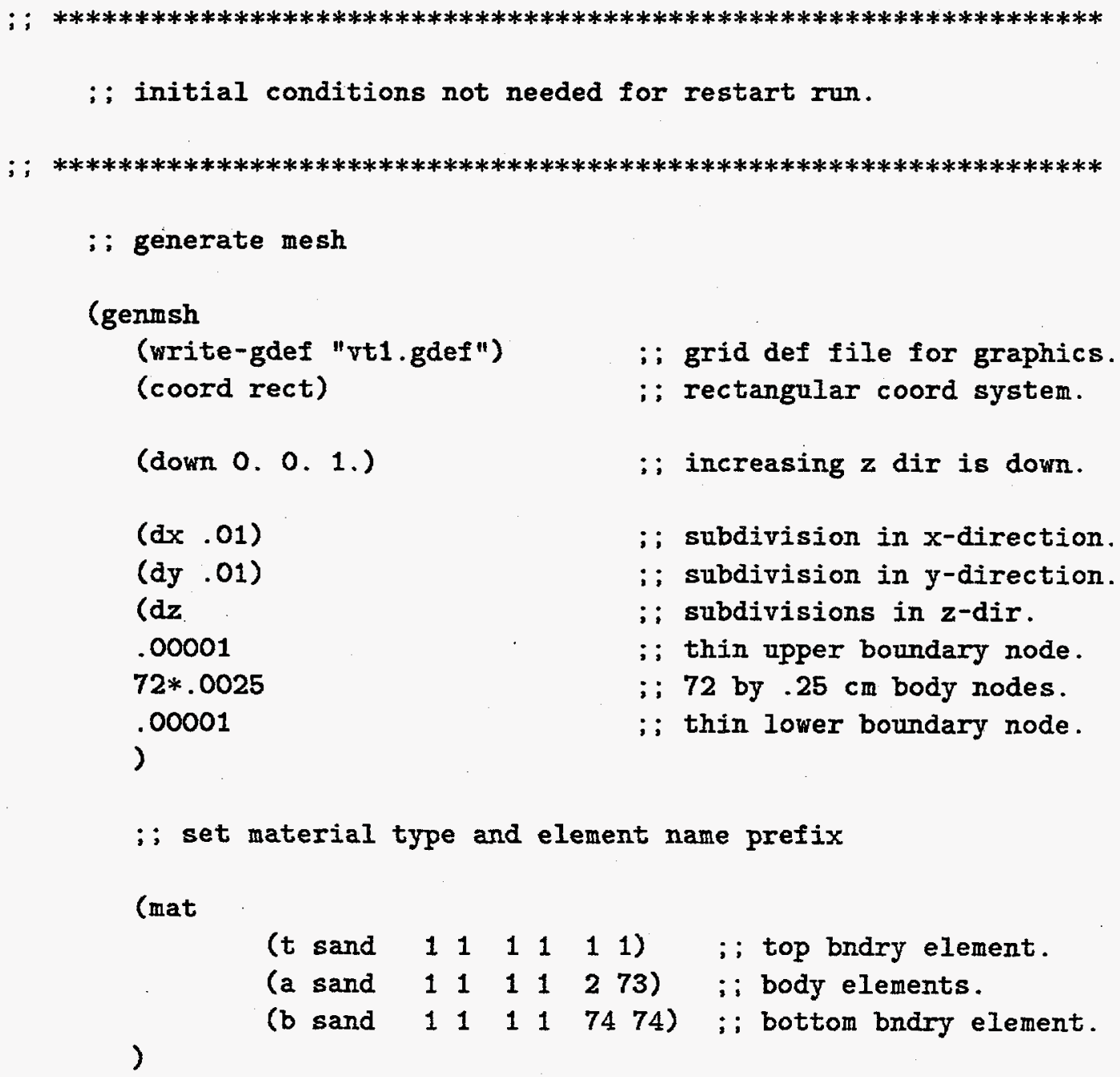




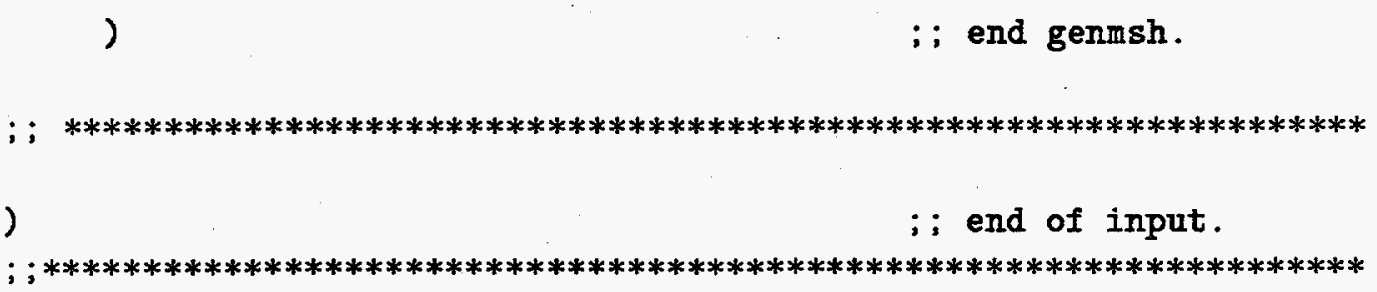

\subsection{Problem VT-2: Heat Conduction with Constant Heat Flux.}

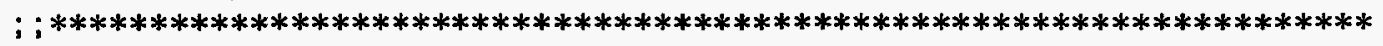

; ; NUFT Verification Problem Number VT-2.

; ; one-dimensional heat conduction with constant heat flux boundary.

; ; file created 11-30-92.

; ; revised $3-31-93$

; $* * * * * * * * * * * * * * * * * * * * * * * * * * * * * * * * * * * * * * * * * * * * * * * * * * * * * * * * * * * * * * * * * * * * * * * * * * *$

(usnt ; multiphase multicomponent module with thermal option.

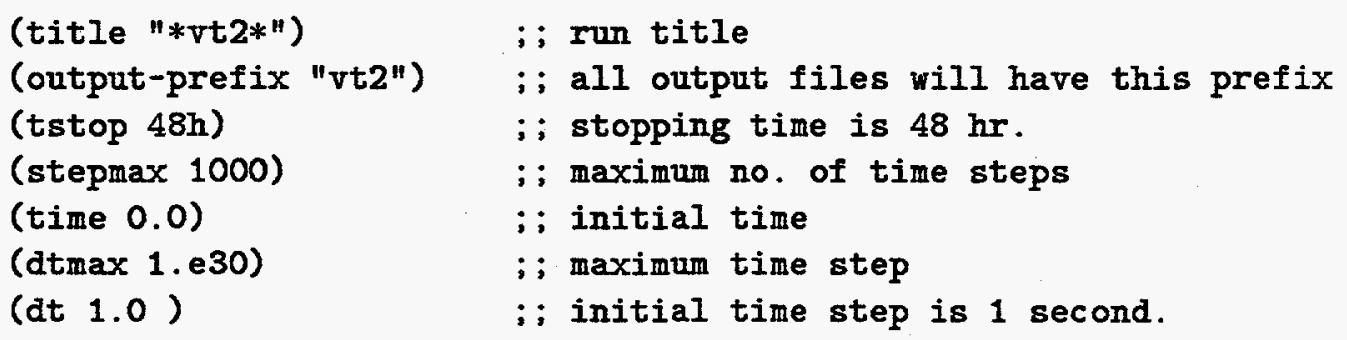

; ; set tolerances.

(tolerdt $1.04 \quad 0.1 \quad 0.1 \quad 0.050 .053$ )

$;$ abs. time step toler

(reltolerdt $0.10 .0 \quad 0.0 \quad 0.1 \quad 0.10 .02$ )

; rel. time step toler

(tolerconv 100.1.e-3 1.e-3 1.e-3 1.e-3 0.001); abs. NR conv. toler

(reltolerconv $1 . e-30.00 .01 . e-41 . e-41 . e-4) ;$ abs. NR conv. toler

; : define components, phases, and select thermal or isothermal option.

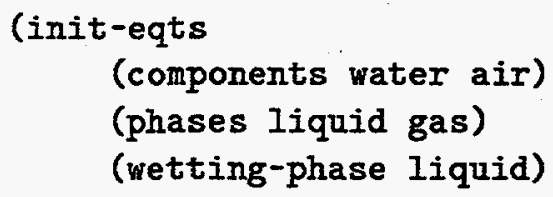




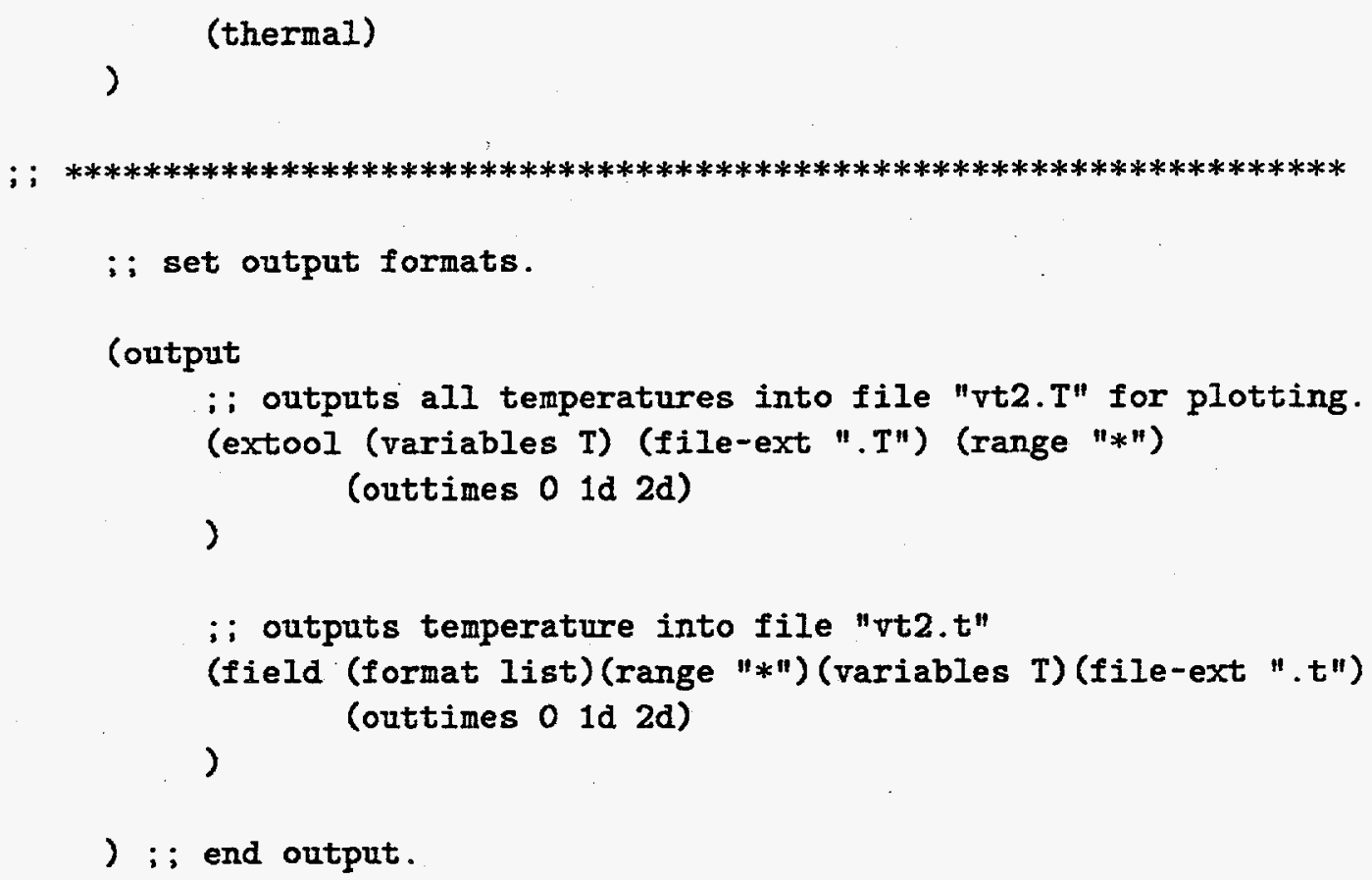


) ; ; end rocktab.

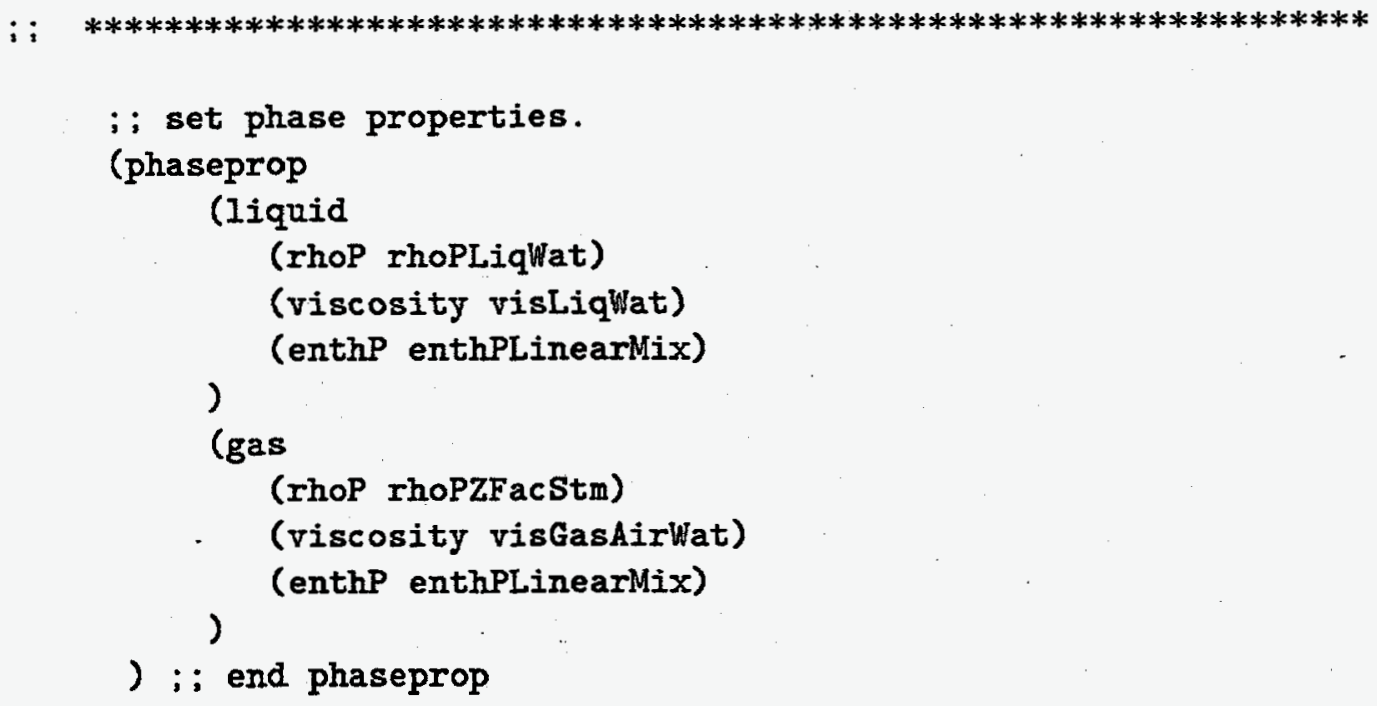




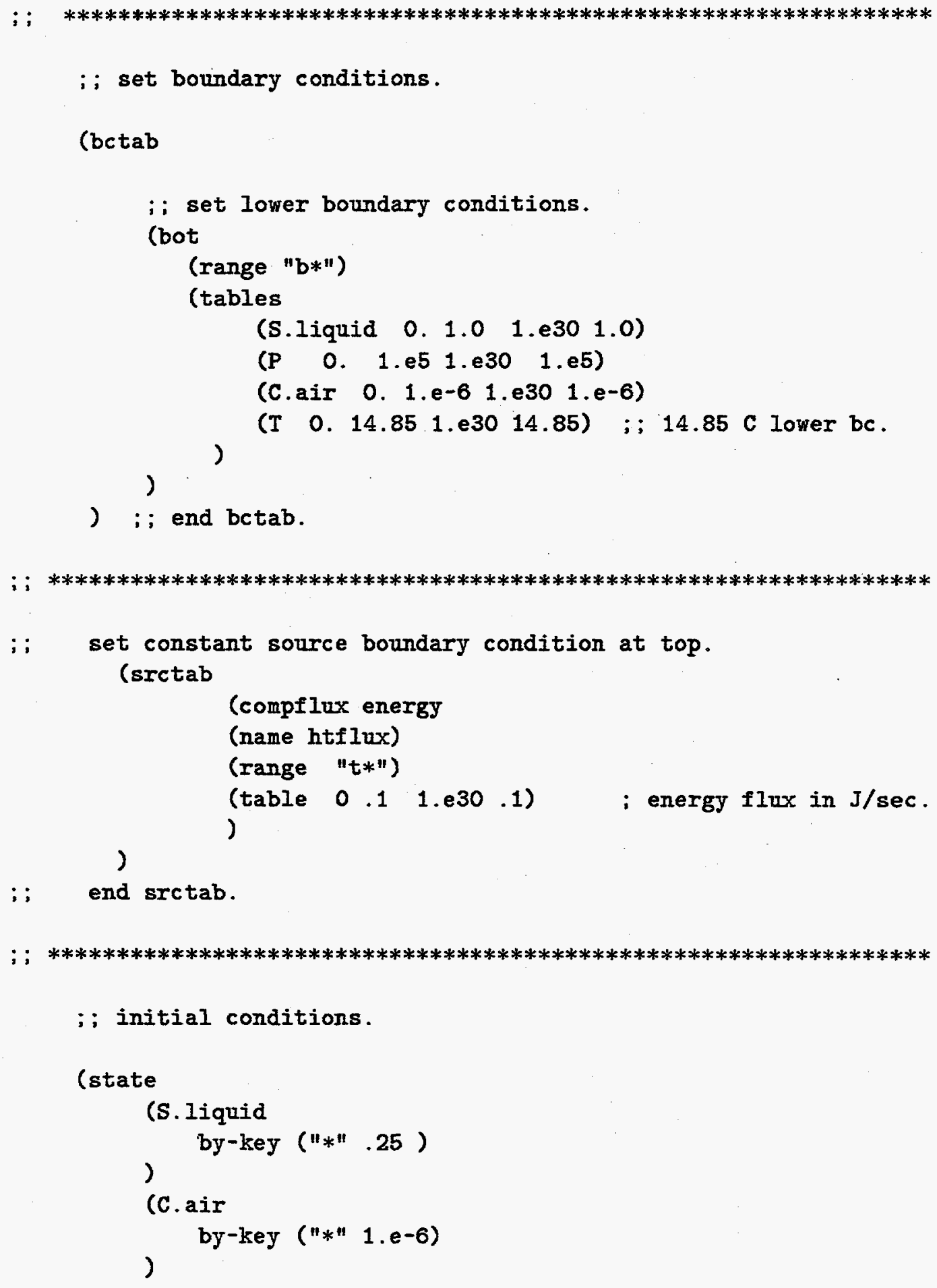




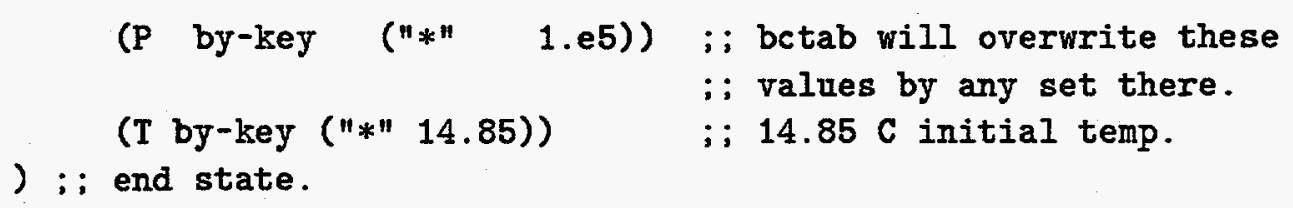

\section{(genmsh}

(write-gdef "vt2.gdef")

(coord rect)

;; note that increasing $\mathrm{z}$ coordinate will be downward

(down 0. 0.1.)

;; set subdivisions in $x y$ and $z$ directions.

$(\mathrm{dx} .01)$

(dy .01)

(dz

$.00001 \quad$;: upper boundary node.

$\begin{array}{llllllllll}.01 & .01 & .01 & .01 & .01 & .01 & .01 & .01 & .01 & .01\end{array}$

$\begin{array}{llllllllllll}.01 & .01 & .01 & .01 & .01 & .01 & .01 & .01 & .01 & .01\end{array}$

$\begin{array}{llllllllll}.01 & .01 & .01 & .01 & .01 & .01 & .01 & .01 & .01 & .01\end{array}$

$\begin{array}{llllllllll}.01 & .01 & .01 & .01 & .01 & .01 & .01 & .01 & .01 & .01\end{array}$

$\begin{array}{llllllllll}.01 & .01 & .01 & .01 & .01 & .01 & .01 & .01 & .01 & .01\end{array}$

$\begin{array}{lllllllllll}.01 & .01 & .01 & .01 & .01 & .01 & .01 & .01 & .01 & .01\end{array}$

$\begin{array}{llllllllll}.01 & .01 & .01 & .01 & .01 & .01 & .01 & .01 & .01 & .01\end{array}$

$\begin{array}{llllllllll}.01 & .01 & .01 & .01 & .01 & .01 & .01 & .01 & .01 & .01\end{array}$

$\begin{array}{llllllllll}.01 & .01 & .01 & .01 & .01 & .01 & .01 & .01 & .01 & .01\end{array}$

$\begin{array}{lllllllllll}.01 & .01 & .01 & .01 & .01 & .01 & .01 & .01 & .01 & .01\end{array}$

.00001

;; lower boundary node.

)

; ; set material type and element name prefix.

(mat

(t sand $\left.1 \begin{array}{llllll}1 & 1 & 1 & 1 & 1\end{array}\right) \quad$; ; top bndary source element.

(a sand $1 \begin{array}{llllll}1 & 1 & 1 & 2 & 101)\end{array}$; ; body elements.

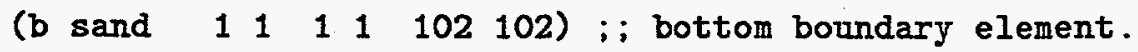
)

) ;; end genmsh. 
; ; $* * * * * * * * * * * * * * * * * * * * * * * * * * * * * * * * * * * * * * * * * * * * * * * * * * * * * * * * * * * * * * * * * * * * * * *$

) $; ; ;$ end of input.

; ; ****************************************************************************

\subsection{Problem BT-1: Thermal History of a Vadose Zone}

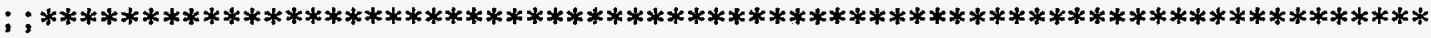

; ; benchmark problem BT-4 from Idaho National Eng. Lab. (INEL)

;; one-dimensional heat conduction only

(usnt ;: multiphase, multicomponent module with thermal option.

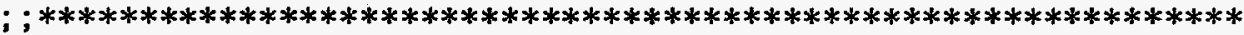

(title "*bt-4*")

(output-prefix "bt-4")

(time 0.0)

(tstop 1.0368e8)

(dt 1s)

(dtmax 1.e30)

(stepmax 1000)
;: run title

;; output file prefix

;; initial time

;: stopping time is $1200 \mathrm{~d}$

$:$ initial time step $=1 \mathrm{~s}$

;; maximum dt

; ; maximum number of time steps

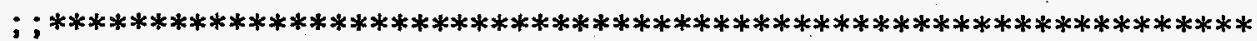

\section{(init-eqts}

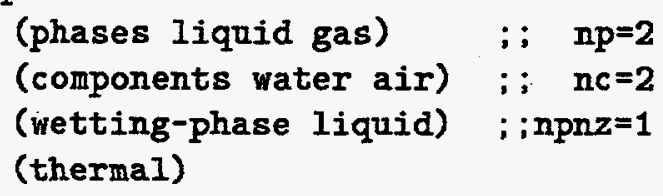

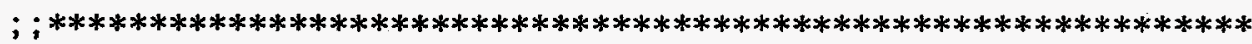




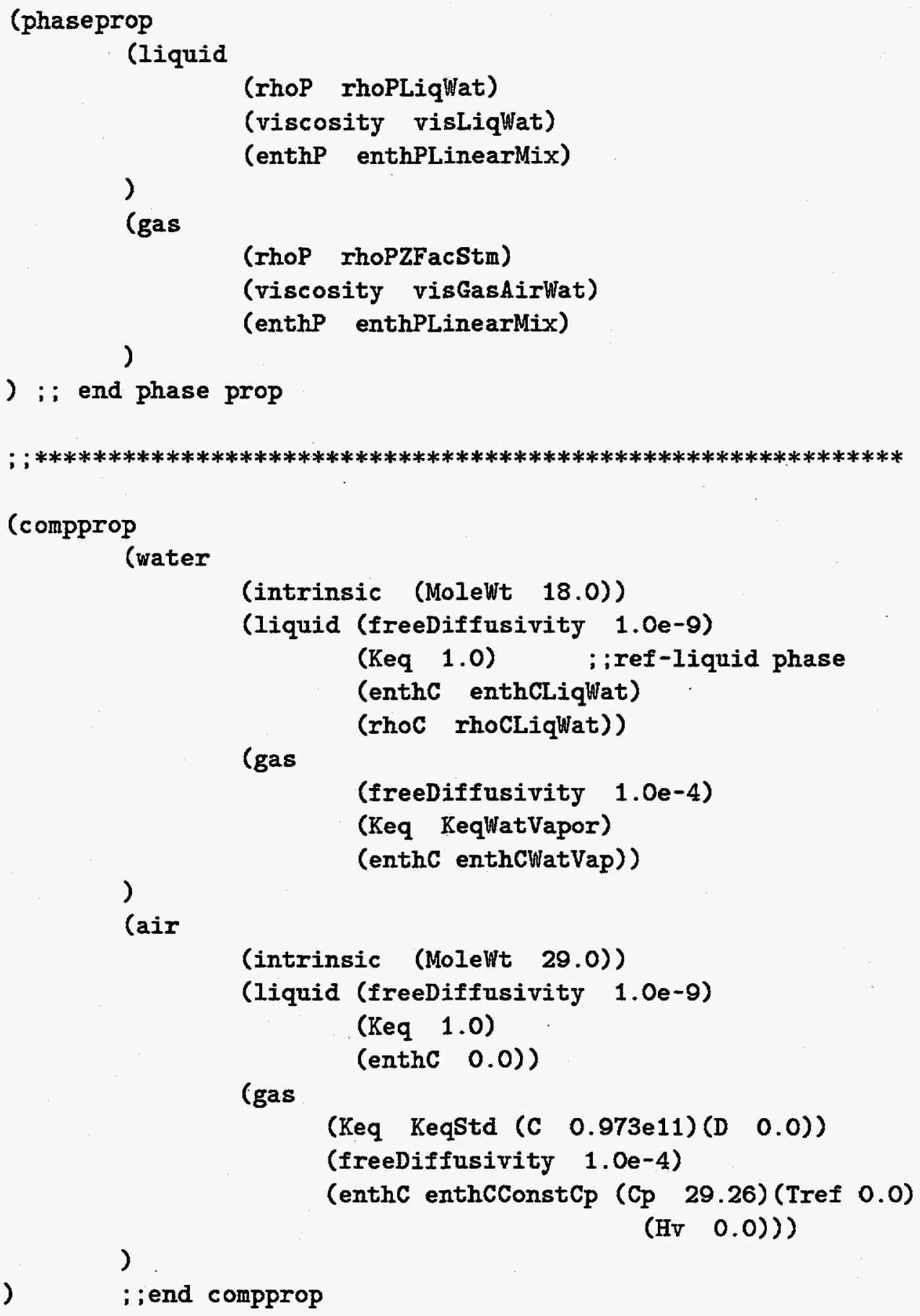

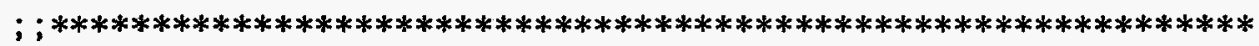




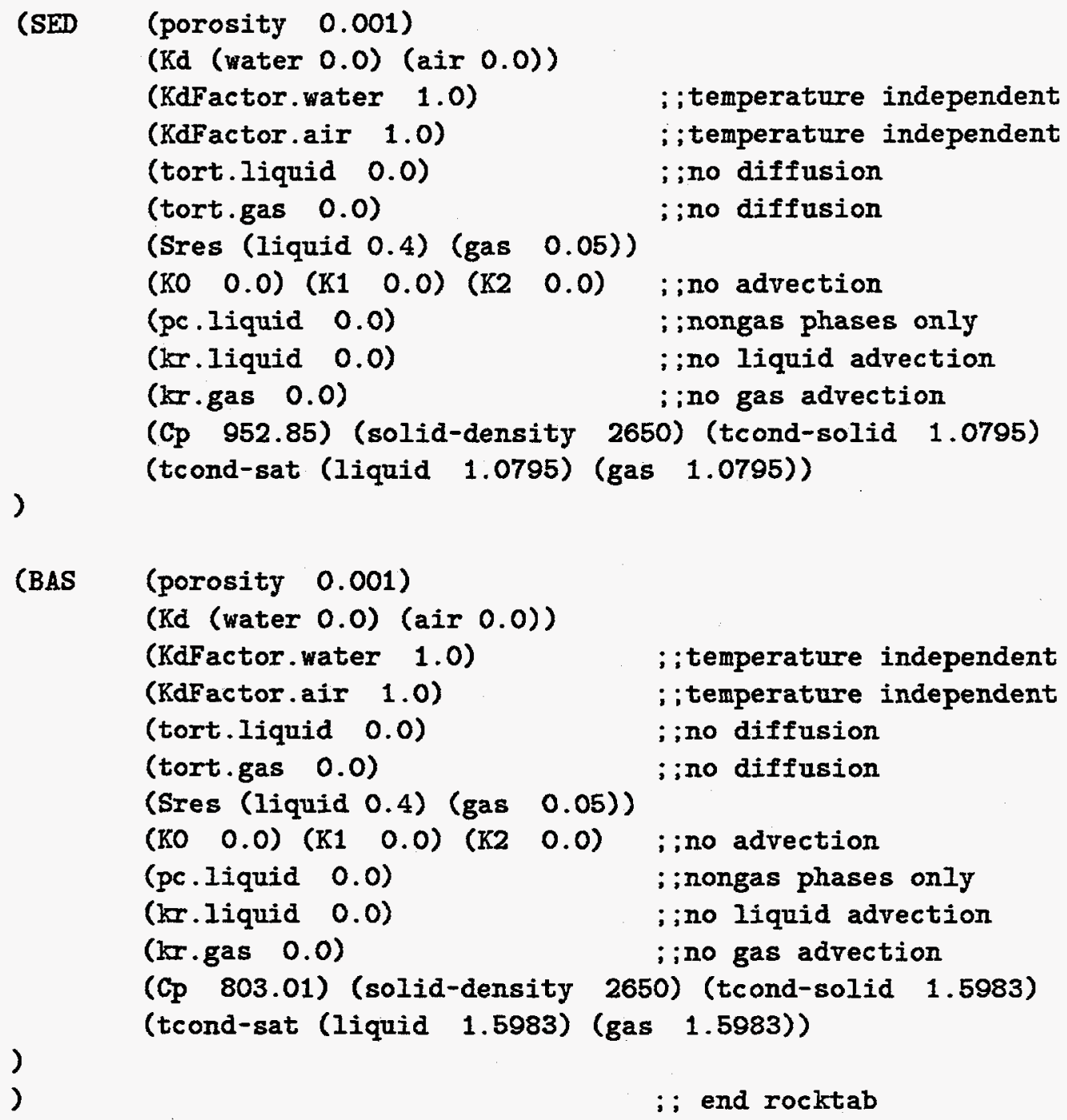




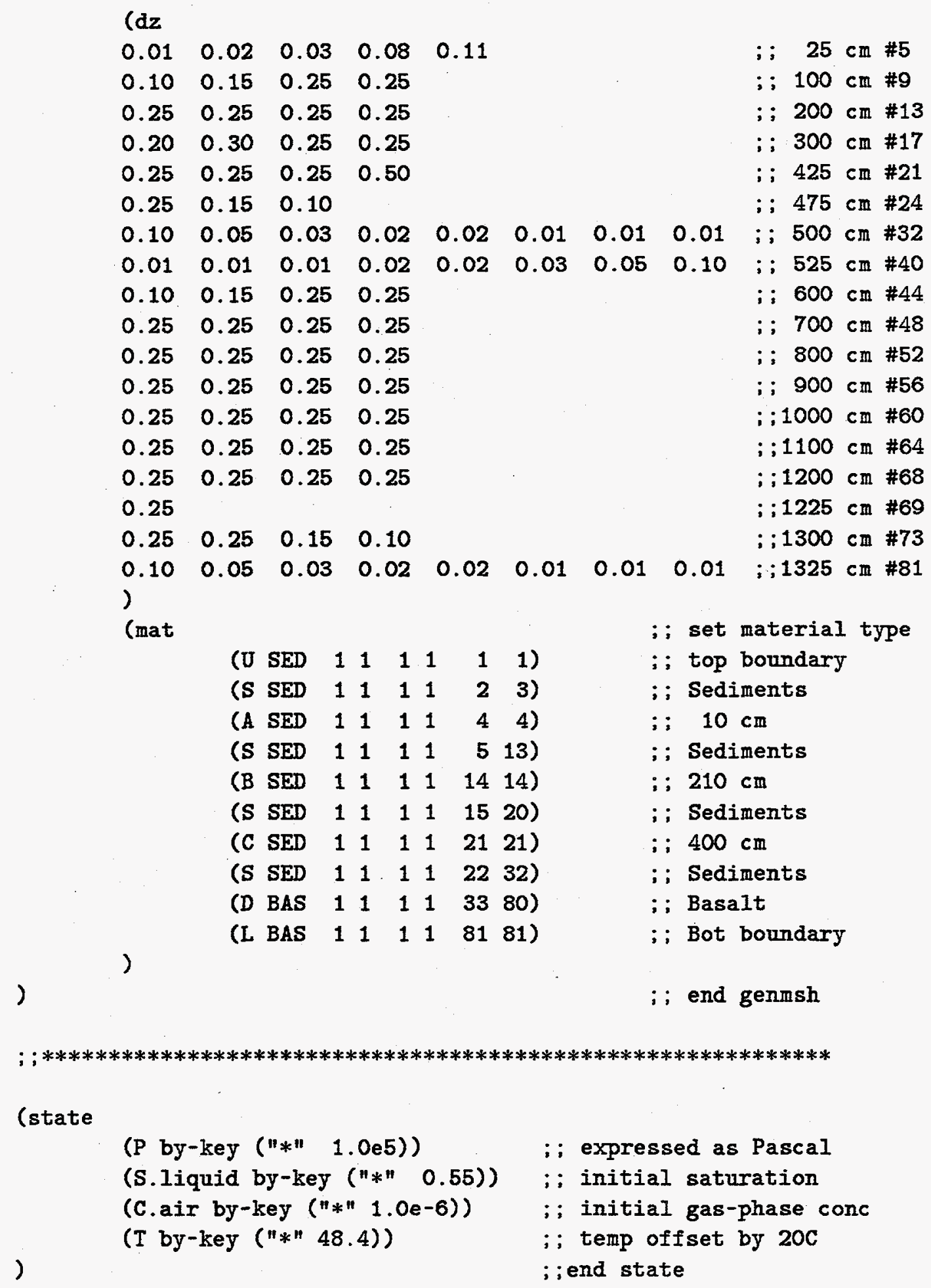




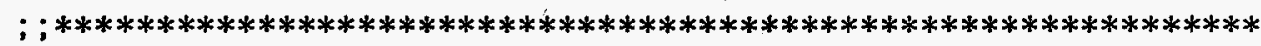

(bctab

(UBC

(range "U*")

;; upper boundary condition

(tables

(c.air $\quad 0.01 .0 e-6 \quad 1.0368 \mathrm{e} 81.0 \mathrm{e}-6)$

(S.Iiquid $0.0 \quad 0.95 \quad 1.0368 \mathrm{e} 8 \quad 0.95$ )

$\left.\begin{array}{lllll}(\mathrm{P} & 0.0 & 1.0 \mathrm{e} 5 & 1.0368 \mathrm{e} 8 & 1.0 \mathrm{e} 5\end{array}\right)$

(T

$0.000000 E+00 \quad 40.2598$

$8.640000 \mathrm{E}+04 \quad 40.1531$

$1.728000 \mathrm{E}+05 \quad 40.0504$

$2.592000 \mathrm{E}+05 \quad 39.9516$

- ;; table truncated here.

- ; : add missing data to rerun.

$1.033344 \mathrm{E}+08 \quad 40.8765$

$1.034208 \mathrm{E}+08 \quad 40.9607$

$1.035072 E+08 \quad 41.0469$

$1.035936 \mathrm{E}+08 \quad 41.1351$

$1.036800 \mathrm{E}+08 \quad 41.2254))$

)

(LBC

(range "L*")

(tables

(c.air $0.01 .0 e-6 \quad 1.0368 e 8 \quad 1.0 e-6)$

(S.Iiquid $0.0 \quad 0.55 \quad 1.0368 \mathrm{e} 80.95$ )

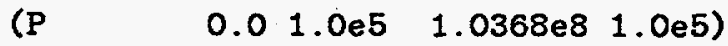

( (T $\quad 0.048 .4 \quad 1.0368 \mathrm{e} 848.4)$

)

;; lower boundary condition

)

) ; ; end betab

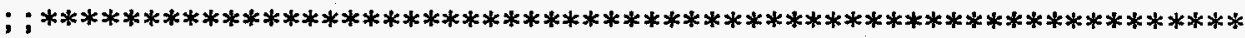

Coutput

(history 


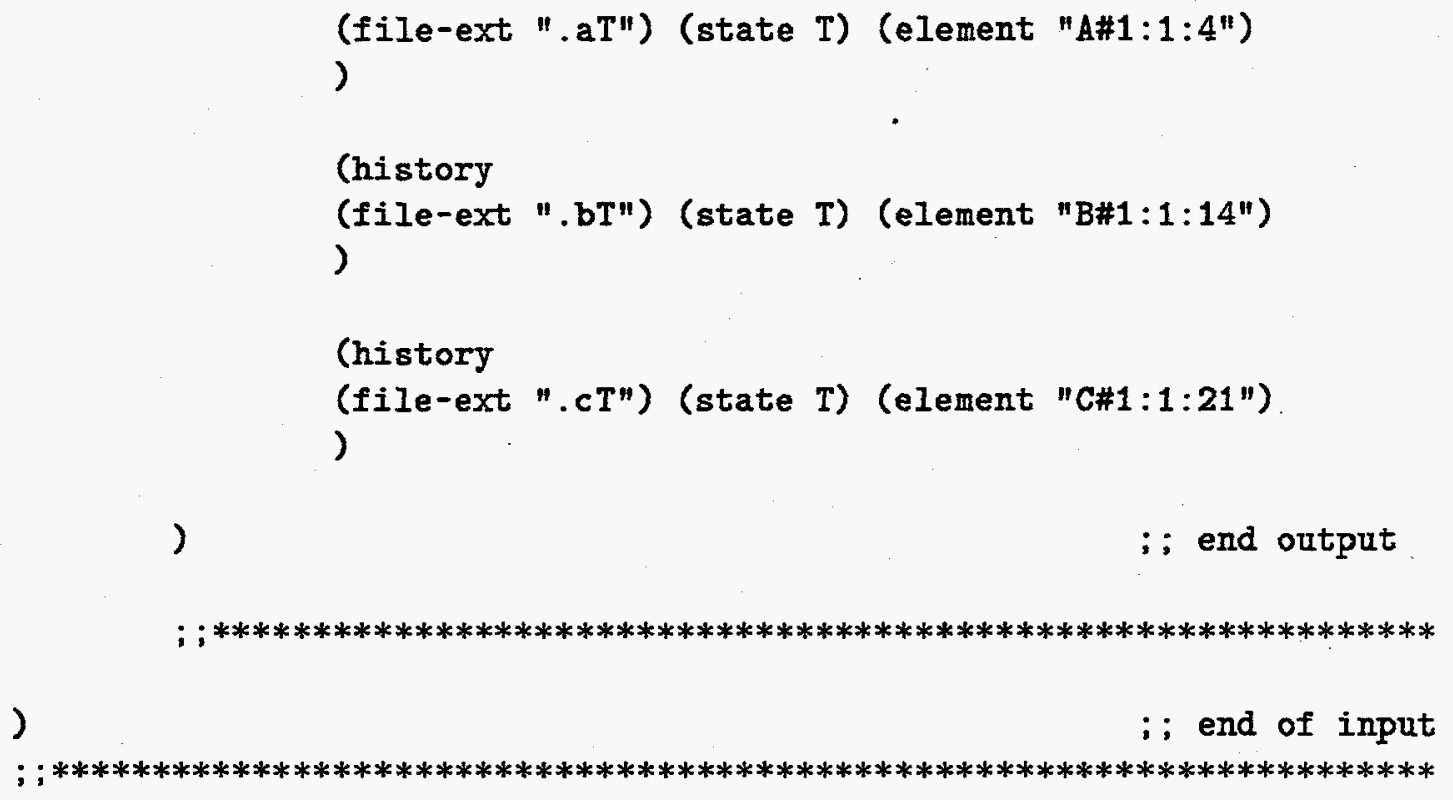

